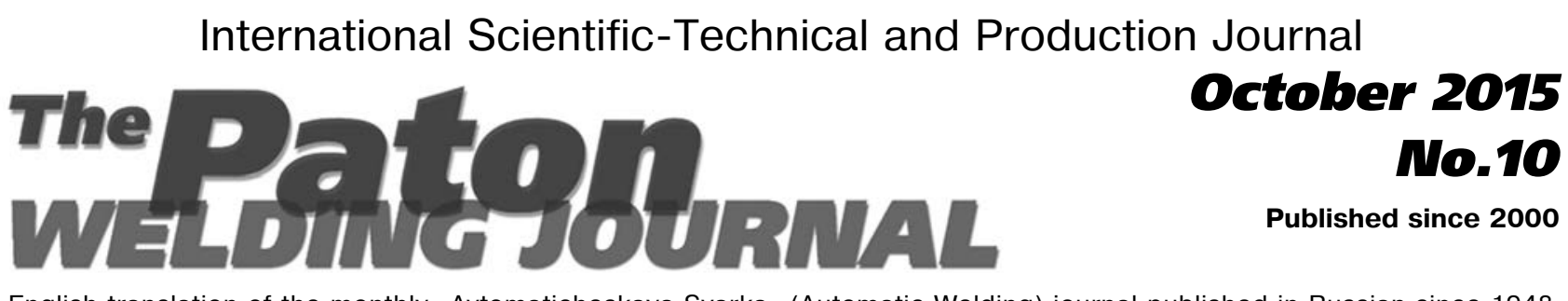

English translation of the monthly «Avtomaticheskaya Svarka» (Automatic Welding) journal published in Russian since 1948

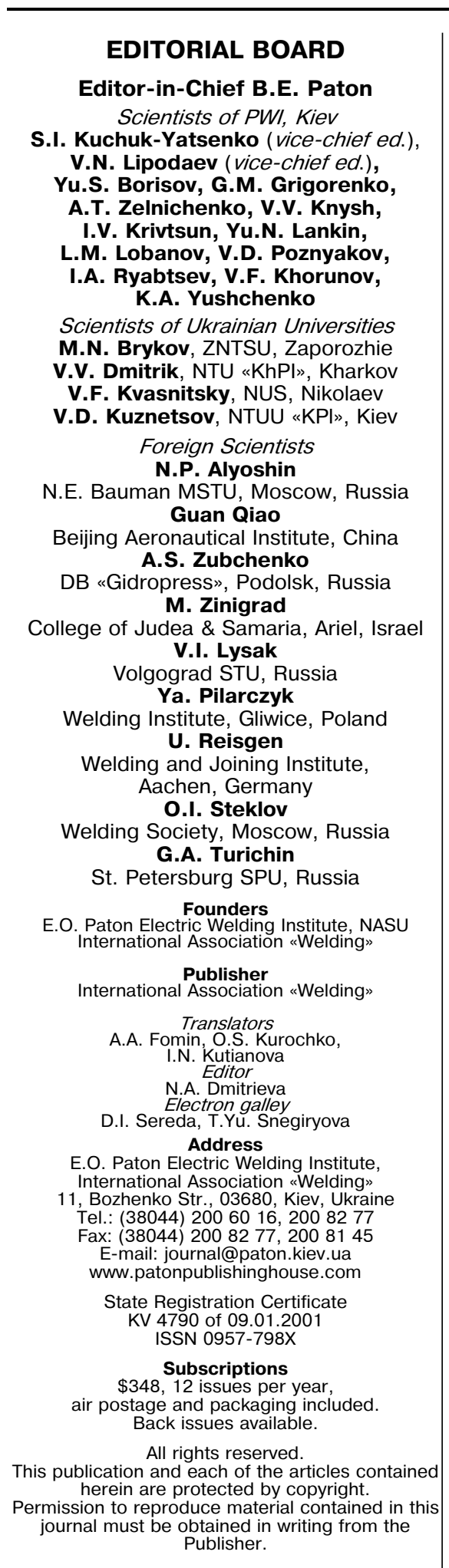

\title{
CONTENTS
}

\section{SCIENTIFIC AND TECHNICAL}

Kuchuk-Yatsenko S.I., Kazymov B.I., Zagadarchuk V.F. and Didkovsky A.V. Development of technology of combined joining of position butts of thick-walled pipes of high-strength steels

Kharlamov M.Yu., Krivtsun I.V., Korzhik V.N., Tkachuk V.I., Shevchenko V.E., Yulyugin V.K., Wu Boyi, Sitko A.I. and Yarosh V.E. Modelling the characteristics of constricted-arc plasma in straight and reverse polarity air-plasma cutting

Poznyakov V.D., Shelyagin V.D., Zhdanov S.L., Maksimenko A.A., Zavdoveev A.V. and Bernatsky A.V. Laser-arc welding of high-strength steels with yield strength of more than $700 \mathrm{MPa}$

Borisov Yu.S., Astakhov E.A., Murashov A.P., Grishchenko A.P., Vigilyanskaya N.V. and Kolomytsev M.V. Investigation of structure and properties of thermal coatings of WC-Co-Cr system produced by high-velocity methods of spraying

\section{INDUSTRIAL}

Makhlin N.M. Peculiarities of contactless ignitions of alternating current arc

Khomenko E.V., Grechanyuk N.I. and Zatovsky V.Z. Modern composite materials for switching and welding equipment. Information 1. Powdered composite materials

Peremitko V.V. and Kuznetsov V.D. Influence of abrasive mass fractional composition on deposited metal wear resistance

Babinets A.A. Method of evaluation of thermal resistance of multilayer deposited metal

Makovetskaya O.K. State-of-the-art and tendencies of development of world market of the main structural materials and welding equipment

\section{NEWS}

International Conference on Laser Technologies was held in Ukraine 


\title{
DEVELOPMENT OF TECHNOLOGY OF COMBINED JOINING OF POSITION BUTTS OF THICK-WALLED PIPES OF HIGH-STRENGTH STEELS
}

\author{
S.I. KUCHUK-YATSENKO, B.I. KAZYMOV, V.F. ZAGADARCHUK and A.V. DIDKOVSKY \\ E.O. Paton Electric Welding Institute, NASU \\ 11 Bozhenko Str., 03680, Kiev, Ukraine. E-mail: office@paton.kiev.ua
}

\begin{abstract}
The modern pipeline systems are designed for high operating pressures. During construction of such systems the pipes with wall thickness of up to $40 \mathrm{~mm}$ are applied. For joining of such pipes the new more effective methods are developed, including the combined ones. The combined technology envisages the welding of root and filling welds using different methods. To increase the rates of construction and quality of welding it is offered to weld the root using flash-butt welding (FBW), and the filling layers must be produced using automatic electric arc welding. The aim of this work is to study the features of formation of joints produced using FBW of root welds in pipes with thickness of more than $20 \mathrm{~mm}$ with different edge preparation and to investigate the quality of joints of root welds and combined joints. The influence of edge groove on the welding process and formation of joints under the conditions of increased heat removal from welding zone during flashing was investigated. The technology of FBW of root welds of the position butts of thick-walled pipes of high-strength steels, combined with electric arc welding, was developed. The optimum FBW parameters at different thickness of projections of root weld groove were determined. The level of influence of electric arc welding on the properties of root welds was established, including the improvement of ductile properties of welded joints. The comprehensive mechanical tests of joints of root welds produced using FBW and the combined arc-welded joints were carried out indicating their practical equal strength with the base metal. Such a combined process will allow a great simplification and acceleration of the process of assembly and welding of the root weld, which predetermines the productivity of the whole process of the position butt welding. This ensures the high reliability and quality of root welds of the joint. 14 Ref., 8 Figures.
\end{abstract}

Keywords: flash-butt welding, electric arc welding, thick-walled pipes, edge preparatinon, position butts, root weld, combined joint, technological gap, heat removal, welding parameters, temperature distribution, mechanical tests

In the modern power systems, including gas transporting ones, designed for high pressures, the pipelines are widely used, which are constructed of thick-walled pipes of high-strength steels [1, 2]. The joining of such pipes represents a labor-consuming and responsible operation, which is carried out in the field conditions, usually using electric arc welding (EAW) by highlyskilled specialists. For EAW technologies a special preparation of pipe ends before welding is required, i.e. preparation of edge groove, the geometric shape and sizes of which largely affect the quality and mechanical properties of the joints (Figure 1) [1, 3].

The most difficult and responsible technological operation in EAW of pipes is welding of a root weld. The experience of using position butt welding of different pipelines proves that the majority of defects, detected in them during non- destructive testing, occur in the root welds. Very promising for position butt welding of thickwalled pipes are the complexes of orbital EAW in the environment of shielding gas of the CRCEvans AW company. The distinguishing feature of this technology is the strict requirements to geometric parameters of groove and assembly of pipes before welding, providing the required size of gaps in welding. At the same time, the first technological operation, i.e. welding of root weld, is performed in a separate equipment using welding consumables, different from those used for filling the edge groove. The sizes of a root part of a groove are controlled by the reference and should be in the range of tenth fractions of a millimeter. At the same time, it is not always possible to achieve the same high standards by the level of assembly of heavy and large-sized pipes before welding with the absence of inadmissible gaps and displacements between them when assembling in the field conditions.

The many-year experience in application of flash-butt welding (FBW) of different pipelines 
of 114-1,420 $\mathrm{mm}$ diameter with wall thickness of $5-20 \mathrm{~mm}$ proves a high service reliability of welded joints of pipes produced by FBW in different climatic conditions, including those of the Far North regions, during the construction of different pipelines $[4,5]$. In the recent decades about $50,000 \mathrm{~km}$ of pipelines were welded using this method, which are successfully operating at the moment. The industry mastered the production of equipment for FBW of pipes, in particular, welding machines K584 for the pipes of 114$325 \mathrm{~mm}$ diameter with wall thickness of 5$14 \mathrm{~mm}$, as well as machines of K830 and K700 types for pipes of 1220 and $1420 \mathrm{~mm}$ diameter and wall thickness of $12.7-20 \mathrm{~mm}$.

For welding of pipes with a larger wall thickness (more than $20 \mathrm{~mm}$ ) a new generation of welding machines is required, which is first of all connected with increase in their set power capacity and upsetting force. The designs of such machines were developed at the E.O. Paton Electric Welding Institute. For their realization the appropriate orders and the potential volumes of production are required.

At the same time, considering the existing park of machines for FBW of pipes, it is advisable to use them for realization of the combined welding technology that combines two technological processes: welding of root weld by FBW and the further filling of the remaining edge groove by EAW [6]. This method allows a considerable simplification and acceleration of the process of assembly and welding of the root weld, which predetermines the productivity of welding works for position pipe butts. Moreover, the high reliability and quality of root welds and the whole combined joint is provided. To produce the root welds of thick-walled pipes the whole existing park of the machines for FBW can be used without their significant reconstruction.

For FBW of root weld it is necessary to prepare a special groove (see Figure 1, b) at the ends of pipes with the factory (standard) edge groove (Figure 1, a). The factory (standard) groove at the ends of pipes delivered to the route can be remade in the field conditions for different EAW methods [3] in order to save welding consumables. The parameters of edge groove depend on the wall thickness of pipes and welding method of both root, as well as filling layers of arc welds. When preparing the edge groove most specialists try to reduce the volume of removable metal of pipes. For comparison, Figure 1, $c$ shows a scheme for edge preparation of as-assembled pipes for welding by the CRC-Evans AW method.
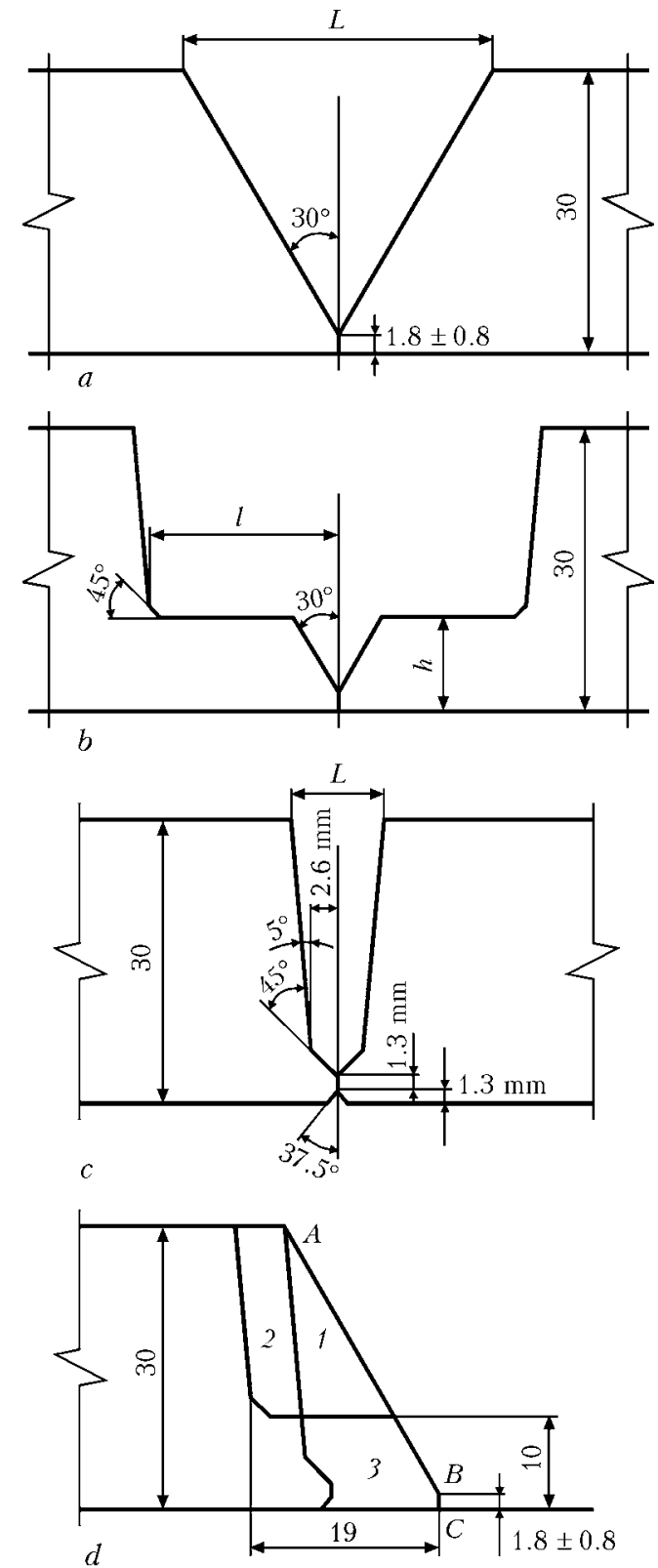

Figure 1. Schemes of edge preparation for manual EAW $(a)$, FBW $(b)$, CRC method $(c)$ and combined schemes $(d)$ (for designations see the text)

The parameters of edge groove for FBW of root welds of thick-walled pipes can vary within the wide ranges and significantly differ from the parameters of grooves of the known EAW methods. During welding of combined joints it allows minimizing the energy input during preparation and welding of pipes, improving the labor efficiency, reducing the consumption of welding consumables for EAW, the cost of which is $2-3$ times higher than that of pipe materials. The latter is particularly important in the construction of pipelines at the distant regions, where it is necessary to deliver a large volume of welding consumables for EAW.

The aim of this work is the development of technology for FBW of root welds during con- 
struction of pipelines with wall thickness of more than $20 \mathrm{~mm}$, as well as investigation of quality, determination of mechanical properties of root welds and combined joints.

The investigation of technology for welding of root welds was performed on the sectors of 100-200 mm width of pipes of $219 \times 20$ and $325 \times$ $\times 25 \mathrm{~mm}$ of carbon steel and thick-walled pipes of modern production of $1219 \times 27 \mathrm{~mm}$ of steel $10 \mathrm{G} 2 \mathrm{FB}$. For practicing the conditions for welding of root welds of 6-12 mm thickness the plates of carbon steel rolled metal of up to $30 \mathrm{~mm}$ thickness were used. Welding of sectors and plates was performed in the laboratory equipment with the program control of basic parameters of the condition [7]. For approbation of welding conditions the pipes of $219 \times 20 \mathrm{~mm}$ of steel $20 \mathrm{~T}$ were taken. The pipes were welded in machine K584 using the program, in which the basic parameters varied in the function of movement, that allowed performing the preset allowances for flashing and upsetting at the accuracy of $\pm 0.5 \mathrm{~mm}$.

The quality of the investigated butts was evaluated according to the results of mechanical tests conducted in accordance with the actual standards, as well as to the results of metallographic analysis of the joints and fractographic investigations of fractures of specimens specially fractured along the root weld.

For FBW of root weld the edge groove was carried out on pipe ends at the parameters of projections $h$ and $l$ as is shown in Figure 1,b. The groove was prepared by reducing the pipe wall thickness on the side of the pipe outer surface. For this purpose the standard equipment is applied, i.e. the mobile edge beveling machines. After welding of projections the root weld is formed. The scheme of the root weld produced by FBW is shown in Figure 2, $a$. After producing the joint the reinforcement of the root weld and overlaps of metal must be removed and the remaining part of the groove must be filled by EAW.

While determining the geometric sizes of edge groove for FBW of pipes it should be taken into account that with decrease in thickness of the projections the volume of mechanical treatment of edges increases, as well as the volume of groove for its filling by EAW.

In Figure $1, d$ the scheme for comparison of grooves for pipes with wall thickness of $30 \mathrm{~mm}$ for combined welding technologies is presented. As the analogue for comparison the following grooves were chosen: factory groove, marked by the contour $A-B-C$ (see Figure $1, d$ ) and groove, prepared according to the CRC technology (see
Figure 1,c). The parts of the edges, removable during different welding methods, are marked as 1,2 and 3. For FBW of root welds with $h=$ =6-7 $\mathrm{mm}$, region 1 is removed, and in welding at $h>7 \mathrm{~mm}$ region $1+2$ is removed. In CRC, respectively, region $1+3$ is removed. From the comparison of regions 2 and 3 it is seen that region 2 by its area is approximately equal to region 3. Therefore, the labor intensity of edge preparation in FBW does not exceed the volume of CRC works.

In the process of investigations the parameters of the groove were changed in the range of $h=$ $=6-12 \mathrm{~mm}$ and $l=10-22 \mathrm{~mm}$. Moreover, in all the cases the width of edge preparation $L$ (see Figure 2,a) along the outer surface of pipes remained equal to the specified size for producing the filling weld by EAW.

In FBW the projections of groove are shortened to the size of allowance for welding: $\Delta_{\mathrm{w}}=$ $=\Delta_{\mathrm{fl}}+\Delta_{\mathrm{ups}}\left(\Delta_{\mathrm{fl}}\right.$ and $\Delta_{\mathrm{ups}}-$ allowances for flashing and upsetting, respectively). Choosing the groove parameter value $l$ not only the allowance for welding should be taken into account, but also the features of FB-welded joint formation, when the reinforcement is formed between the edges of groove during upsetting on the root weld surface.

In Figure 2, $a$ the scheme of the joint is presented produced at the optimum correlation of the mentioned parameters considering the size of reinforcement. In case of violation of this requirement, the compression of reinforcement occurs with overlaps of the oxidized metal by edges of the groove. After removal of the upper part of reinforcement with overlaps of metal, especially during visual evaluation of cleaning of welded joint and the readiness of groove for filling by EAW, a false impression of complete removal of the reinforcement may appear. In fact, between the edges of groove and the remaining part of reinforcement the clamped interlayers of oxidized metal appear, which are difficult to remelt by EAW, when filling the groove.

The macrostructure of combined joint with the interlayers of oxidized metal at the root weld is presented in Figure 2, c. In order to guarantee the formation of a high-quality joint without such defect between the reinforcement and the edges of groove the technological gap $k$ should be provided (see Figure 2, $a$ ).

It was experimentally established that in welding of root welds with groove parameter $h=$ $=6-12 \mathrm{~mm}$ the technological gap $k$ should be 1.5-2 mm. Thus, parameter $l$ of groove before FBW of thick-walled pipes with wall thickness 

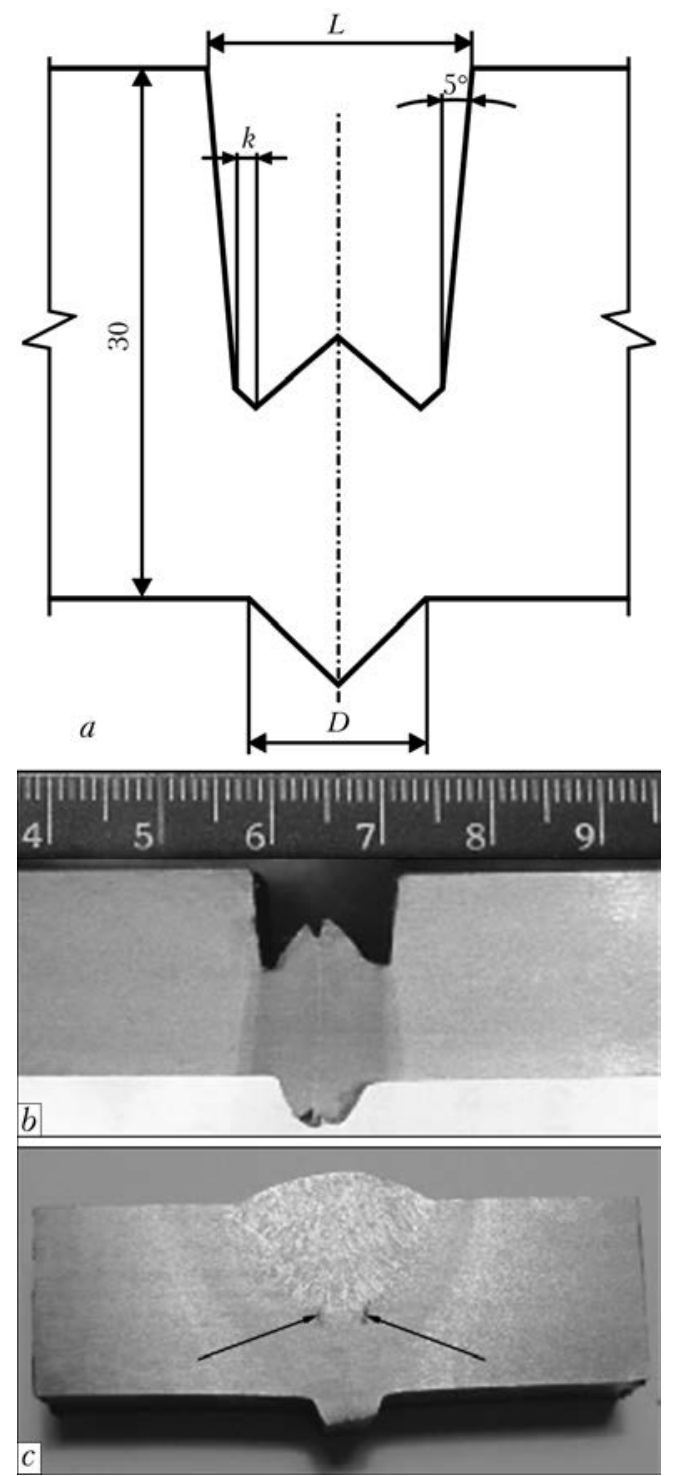

Figure 2. Scheme of root weld produced at optimal FBW conditions ( $a-$ for designations see the text), macrosection of root weld $(b)$, and macrosection of combined joint during violation of welding mode parameters $(c-$ arrows indicate lack-of-fusion of weld metal)

$\delta>20 \mathrm{~mm}$ is determined by the following dependence: $l=\Delta_{\mathrm{w}} / 2+D / 2+k$ (where $D$ is the width of root weld reinforcement). Since our investigations established that $D / 2+k \sim h / 2$, parameter of the groove projections is $l=\Delta_{\mathrm{w}} / 2+$ $+h / 2$ (where $h$ is the thickness of projection in the groove edges).

In determination of optimal conditions of FBW of pipes with different parameters of edge preparation it is necessary, first of all, to take into account the complex effect of thickness of projections $h$ on the basic values of flashing process. As is seen from the diagram of Figure 3, $a$, with the increase of $h$ parameter the duration of welding process and allowance for flashing are increased, and the specific power consumption is decreased. In welding of thick-walled pipes with
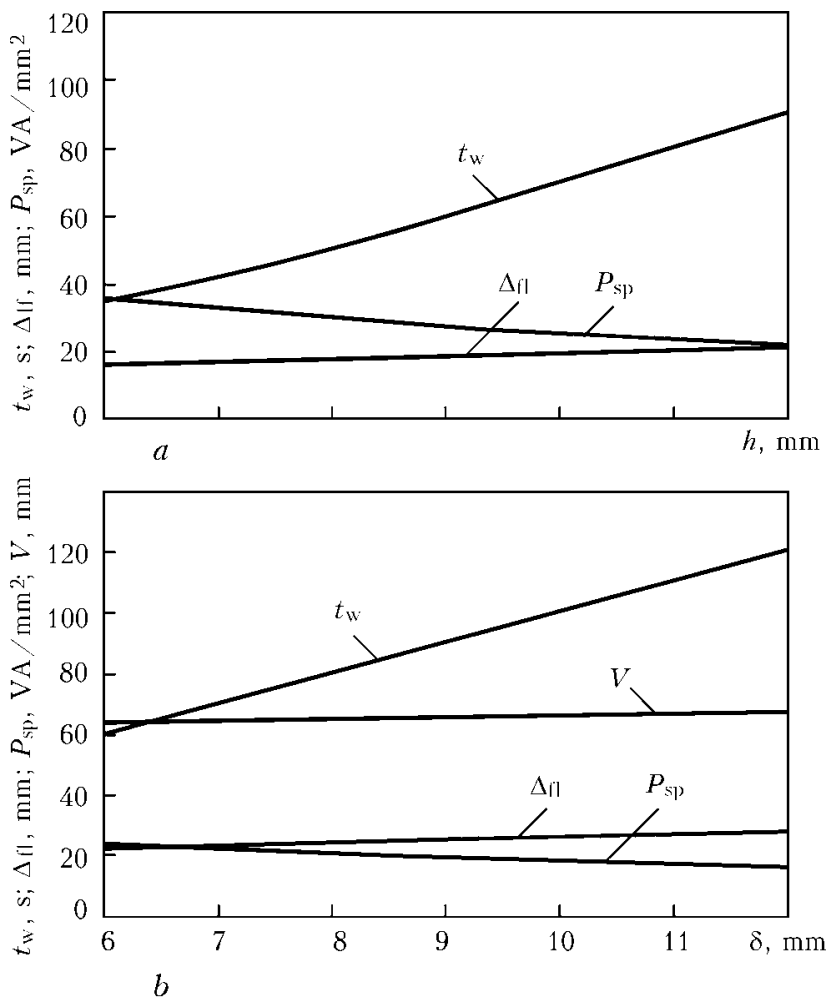

Figure 3. Dependence of duration of welding process, allowance for flashing, specific power in final period of flashing and value of extension from current-carrying clamps on thickness of projections $(a)$ and pipe wall thickness $(b)$

edge preparation at the identical conditions the formation of joint will occur under the conditions of more intensive heat removal from the welding zone to the body of thick-walled pipe. The configuration of pipe edges with the groove creates heating conditions, which occur during welding of pipes with reduced extensions. In the first case, heat is removed into the massive volumes of metal, and in the second case - into the current-carrying clamps.

Figure 4 shows the dependence of amount of heat accumulated in the heating zone on the value of extensions from the clamps of the welding machine during flashing of sectors of pipes with $\delta=10 \mathrm{~mm}$, obtained by the calorimetry of the flashed specimens. The 3.5 times shortening of the extensions of sectors in welding resulted in 45-50\% increase in energy losses. The presented data relate to the heating conditions in flashing of sectors, when heat removal into the clamps occurs on both sides. These losses are lower during one-sided heat removal in welding of pipes, but they can significantly influence the formation of joints at minimum distances from clamps to welding zone.

The data, given in Figure 3, $b$, corresponds to the conditions of FBW of pipes with $\delta=6-12 \mathrm{~mm}$ in machines K584. For example, during welding of $10 \mathrm{~mm}$ pipes without grooving, as is seen from 


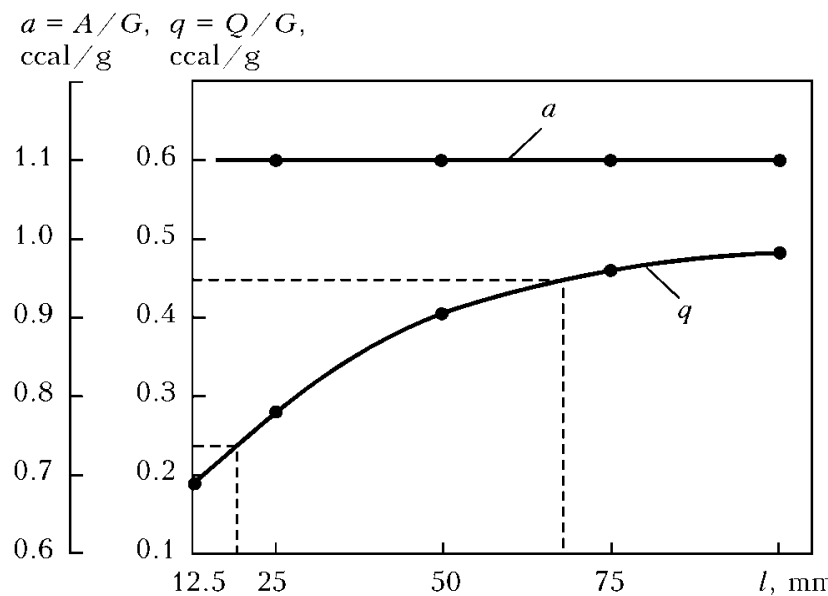

Figure 4. Dependence of specific volume of saved $q$ and consumed $a$ power on size of extensions in welding of sectors $10 \mathrm{~mm}$ thick

the diagram, the value of extensions from the clamps must be at least $68 \mathrm{~mm}$, which is 3.5 times larger than length $l$ of groove projections at $h=$ $=10 \mathrm{~mm}$.

Figure 5 (curve 1) shows distribution of temperature at the area of $12 \mathrm{~mm}$ length from the flashing surface during welding of pipes of $219 \mathrm{~mm}$ diameter with $\delta=10 \mathrm{~mm}$ at the standard conditions (distance between the current-carrying clamps is $68 \mathrm{~mm}, t_{\mathrm{w}}=95 \mathrm{~s}$ ), providing the quality welding.

Curve 2 in Figure 5 characterizes the distribution of temperature in the same HAZ area of specimens of thick-walled pipes with $\delta>20 \mathrm{~mm}$, $h=10 \mathrm{~mm}$ and $l=19 \mathrm{~mm}$. The temperature at the investigated area is lower than $100-150{ }^{\circ} \mathrm{C}$. At the bend tests of standard specimens of these joints the values were not stable. Some specimens encountered cracks along the joining zone.

The losses for heat removal can be compensated to some extent by increasing the intensity of heat source during flashing in its different periods envisaged by the program.

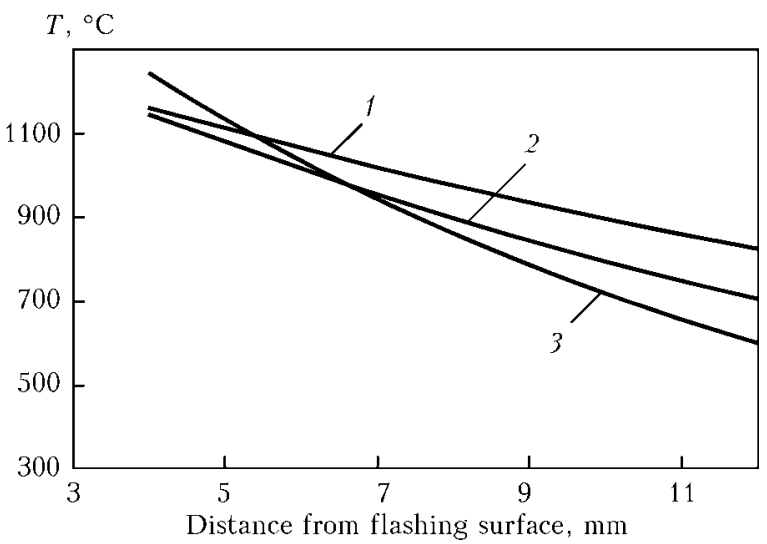

Figure 5. Linear distribution of temperature in welding of $219 \times 10 \mathrm{~mm}$ pipes at regulated conditions (1), of root weld with $h=10 \mathrm{~mm}$ of $219 \times 10 \mathrm{~mm}$ pipe at regulated (2) and optimal (3) condition
The more severe welding conditions for all the investigated thicknesses of the projections result also in increase of the specific pressures required for producing the quality joints. Therefore, when designing the specialized equipment for combined welding one can not expect a significant reduction in its power and weight, at least for the accepted correlation of sizes of the groove projections. With $l$ increase the conditions of welding of pipes will approach the accepted ones for the corresponding wall thicknesses without edge preparation, and the reduction in power values will be more noticeable.

It should be noted that at the optimization of the groove shape for combined welding the power values of the equipment are not dominant. The reduction of time for welding the root weld to 1-2 min regardless of diameter of the pipes allows improving the efficiency of general technological flow at the construction of pipelines.

In determination of the optimum $h$ value the tolerance of the accepted technology for the accuracy of pipes assembly before welding is a very important characteristic. With increase in thickness of groove projections the displacement of edges and the gap between them influence the quality of the joints to a lesser extent, and the admissible deviations may be wider. From this point of view the thicknesses of projections within the range of $8-12 \mathrm{~mm}$ appear to be the most acceptable.

As the result of carried out investigations the conditions of welding of thick-walled pipes of $219 \mathrm{~mm}$ diameter with $\delta=20 \mathrm{~mm}$ with edge preparation in machine K584 were developed. The thickness of groove projections varied in the range of $6-12 \mathrm{~mm}$, and the size $L$ of groove remained unchanged and equal to the preset value. The diagrams in Figure 3, $a$ show the optimal values of basic parameters at rigid conditions, providing the quality joints with different thickness of the projections. The optimal mode is characterized by an increased specific power (30 \%), shorter time of welding (by 20-40\%) and lower allowance for welding (by 20-30\%) than the recommended one for the pipes with the same wall thicknesses. Such joints are characterized by narrow HAZ, the size of which does not exceed parameter $l$. The macrosection of such joint with $h=10 \mathrm{~mm}$ is shown in Figure 2, b.

The temperature distribution in the heating zone during welding of root welds $10 \mathrm{~mm}$ thick at such conditions is shown in Figure 5 (curve 3 ). The comparison of curves 2 and 3 shows that increase in concentration of heating by increasing the power at all the welding stages allowed re- 
ceiving the temperature distribution in the contact areas required for formation of the quality joints.

The comprehensive mechanical tests of root welds of all the investigated thicknesses, carried out at optimal conditions, confirmed the high quality of joints.

The joints of root welds of low-alloy steel of strength group X70, produced at the optimum conditions, showed high and stable results. The specimens for rupture were fractured along the root, comprising in general the whole welding zone (Figure 6, $a$ ). Rupture stresses remained within the ranges of $\sigma_{\mathrm{r}}=640-657 \mathrm{MPa}$, which is higher than tensile strength of the metal of pipes $\left(\sigma_{t}^{p}=610 \mathrm{MPa}\right)$. This is explained by the fact that plastic deformation is concentrated in the narrow zone of root weld with small crosssection, which leads to mechanical hardening of metal of all the areas of the root.

After fracture the specimens had breaks, which are defined as tough ones, proving the ductility of the weld root. These data are confirmed by the bending tests of root welds. Due to the small extension of deformable area (of root weld), located in the edge grooves, high stresses occur in the metal. Despite such severe tests the specimens had bending angle of $180^{\circ}$ without cracks in welding zone (Figure $6, b$ ). Strength of root welds on pipes of steel 20 was $\sigma_{\mathrm{r}}=534-$ $559 \mathrm{MPa}$, and $\sigma_{\mathrm{t}}^{\mathrm{p}}=518 \mathrm{MPa}$.

The fracture surfaces of the root welds during the rupture tests had a developed homogeneous relief without defects of welding.

The next stage of the carried out investigations was the study of properties of the combined joints, produced by filling the groove formed as a result of manual EAW of root weld of the groove. Before deposition the reinforcement and metal overlaps of FB-welded joint were removed in the grooves.

Deposition was carried out using electrodes UONI-45/55 under the conditions recommended for welding of steel products. All the joints showed high properties that meet the requirements of standard documents [3, 8]. Figure 7 shows macrosection and specimens after rupture and bending tests. Strength and ductility of joints corresponds to the values of pipes metal. The rupture specimens were fractured beyond the welding zone along the pipes metal. The bent specimens at $180^{\circ}$ angles had no cracks.

During filling the grooves by EAW the root weld metal undergoes thermal effect, which by its nature is manifested itself as heat treatment. The measurements of metal temperature in con-

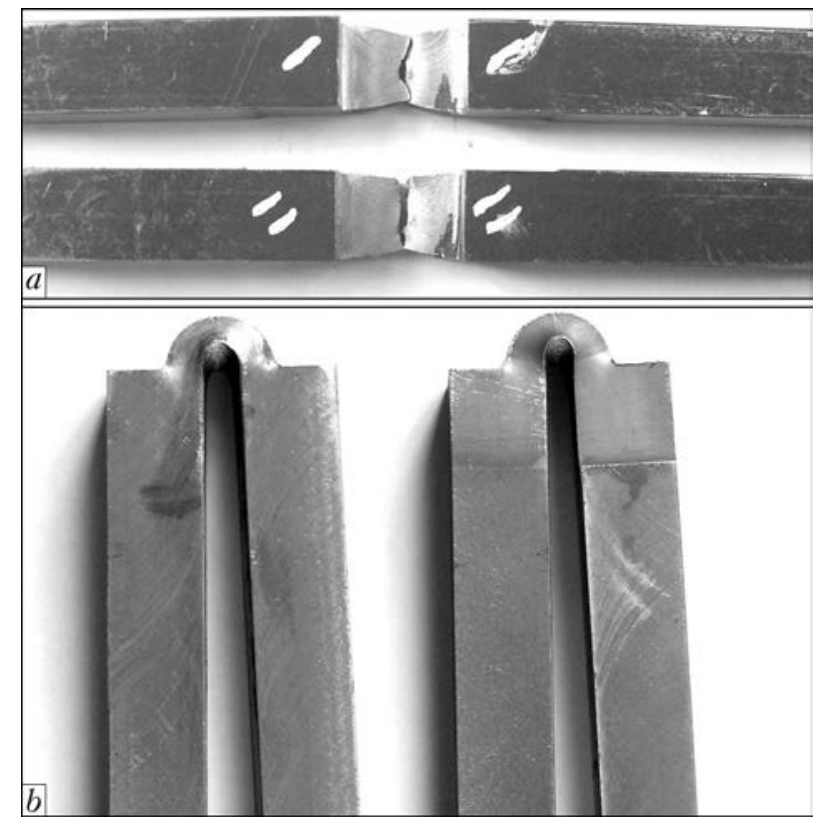

Figure 6. Specimens of steel 10G2FB joints with root weld after tensile $(a)$ and bend $(b)$ test

trol spots along the weld on the side of surface under the grooves showed that its values at the elementary area at different EAW conditions may vary within the range from 600 to $1150{ }^{\circ} \mathrm{C}$.

The efficiency of thermal effect of different EAW conditions on properties of the combined joints was evaluated according to the values of impact toughness. $K C V$ was determined on the standard specimens with a sharp notch, produced across the wall thickness. The proportion of FBwelded joints was 30-50\%. Such specimens determine to the greatest extent the ductile properties of joints with different state of the combined weld metal, one part of which was produced by FBW without ast metal, and another one - by EAW with cast metal.

The results of investigations showed a significant effect of EAW thermal cycle on the metal of root welds at the temperatures higher critical point $A_{c 3}$, i.e. at normalization temperatures. This method of heat treatment is recommended to improve the values of impact toughness of FB-welded joints [9, 10].

In deposition of $10 \mathrm{~mm}$ root weld the duration of staying the metal at $900-1150{ }^{\circ} \mathrm{C}$ at the certain areas of the weld regardless of its thickness was in the range of 20-30 s. As a result of this scattering of thermal effect parameters between the maximum and minimum values of impact toughness at the same weld a great difference is observed. Impact toughness of specimens of steel 20 joints was as follows, $\mathrm{J} / \mathrm{cm}^{2}$ : at $+20{ }^{\circ} \mathrm{C}-(62-$ 142) $/ 83$, at $-20{ }^{\circ} \mathrm{C}-(20-51) / 39$, for metal of pipes of steel 20 at $-20{ }^{\circ} \mathrm{C}$ it was $(23-49) / 40$. The joints of pipe steel 10G2FB showed impact 

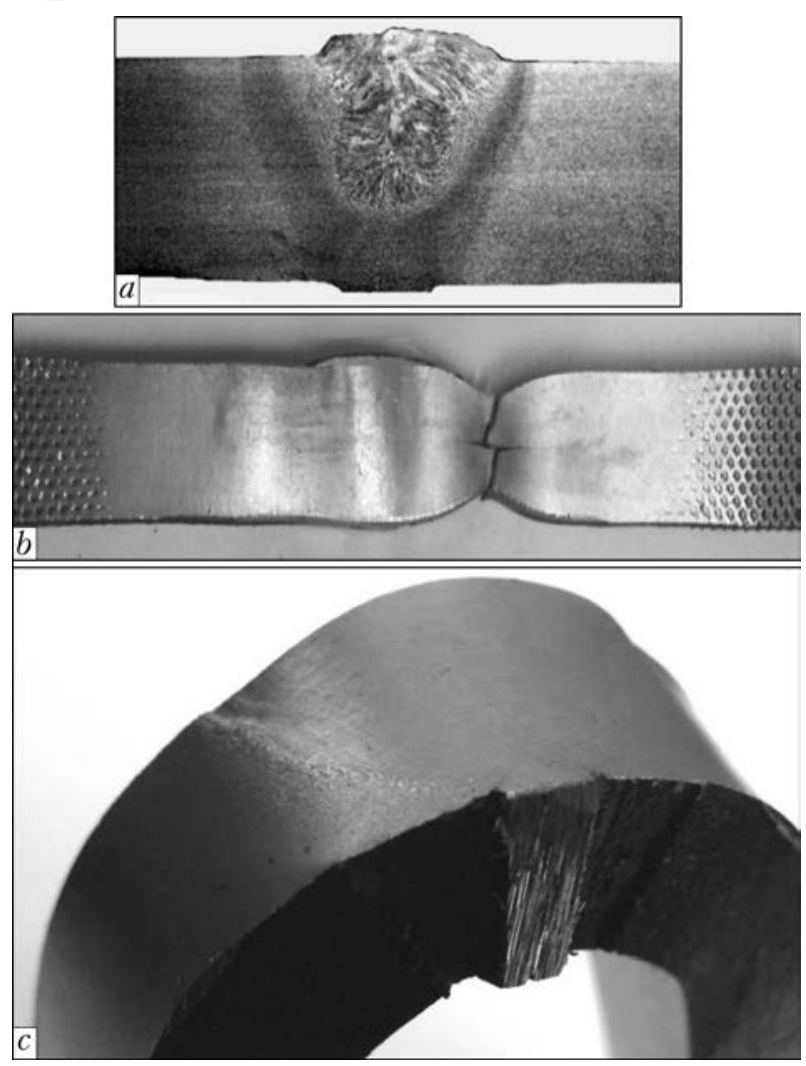

Figure 7. Macrosection ( $a$ ) of specimen of combined joint and its appearance after rupture $(b)$ and bend $(c)$ test

toughness at $+20{ }^{\circ} \mathrm{C}$ it was $(96-206) / 114$, and at $-20{ }^{\circ} \mathrm{C}(20-49) / 42 \mathrm{~J} / \mathrm{cm}^{2}$. At the negative temperature the individual specimens appear, which have the values lower than the minimum required ones. However, they do not negatively affect the operational properties of welded joints of pipes of the full cross-section. This is proved by the results of the presented studies [11, 12].

Thermal effect of EAW is increased with the increase in duration of staying the metal at the normalization temperatures by deposition of subsequent hot layers on the first deposited layer. In this case the root weld metal undergoes cyclic thermal effect (Figure 8). For example, in manual EAW the time of staying the elementary weld area at the normalization temperatures for the first cycle amounted to $20 \mathrm{~s}$. The total time of two cycles amounted to $45 \mathrm{~s}$, and at the account for the third cycle the time increased up to $80 \mathrm{~s}$. As a result, the average values of impact toughness increased by $8-14 \%$. At the same time, between the first-second and the second-third cycles there were technical breaks (for slag removal) of $90 \mathrm{~s}$ duration. The joints of steel X70 had 46$48 \mathrm{~J} / \mathrm{cm}^{2}$ impact toughness at $-20{ }^{\circ} \mathrm{C}$.

In the combined joints with root $12 \mathrm{~mm}$ thick the length of areas, not subjected to thermal effect, increases. As a result, the number of specimens with minimal values is increased.

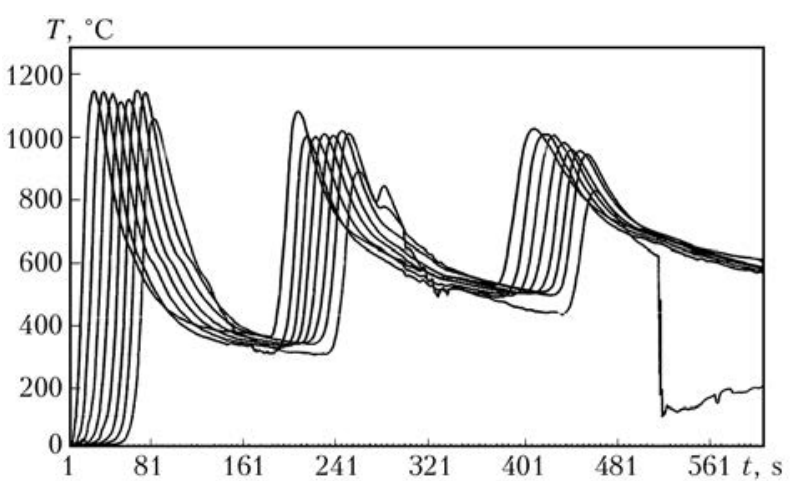

Figure 8. Temperature distribution in weld root during filling the groove by EAW

For manual EAW the non-uniformity of heat effect is characteristic. It can be judged by penetration depth of the root weld. At the area of $120 \mathrm{~mm}$ length at $10 \mathrm{~mm}$ root the penetration was in the range of $0.2-3.0 \mathrm{~mm}$.

It should be noted that a great difference between the minimum and maximum values of the individual specimens can be caused not only by the non-uniform heat effect on the root weld metal, but also by the objectively existing properties of impact tests of welded joints, regardless of their welding method, when in many cases the scattering of values occurs $[13,14]$.

The combination of flash-butt and electric-arc welds provides mutual positive effect on the properties of the joints. On the one hand, there is no cast metal in the flash-butt weld and, respectively, a number of defects peculiar to EAW is absent in it. At the same time, under the influence of EAW the root weld is subjected to heat treatment. Sometimes it turns to be insufficiently complete at the negative testing temperatures, but in any case it promotes the improvement of ductile properties of the welded joint metal.

\section{Conclusions}

The basic technology for FBW of thickened root welds of position butts of thick-walled pipes of 219-325 mm diameter with wall thickness of more than $20 \mathrm{~mm}$ of carbon and high-strength steels was developed, and the optimum geometric sizes of edge preparation and optimum parameters of FBW of root welds of thick-walled pipes were determined.

The comprehensive mechanical tests of root welds and combined joints were carried out proving their equal strength with the pipe metal.

The positive effect of heat input on ductile properties of the root weld metal, produced by FBW, during filling the groove of weld by EAW was established. 
The power characteristics of the equipment, required for FBW of root welds 6-12 mm thick, by using the existing park of machines for FBW of pipes were determined.

1. Vyshemirsky, E.M., Bespalov, V.I., Budrevich, D.G. et al. (2009) Definition of technical requirements to welded joints of gas pipelines from high-strength steels applicable to main Bovanenkovo-Ukhta pipeline. In: Proc. of 3rd Int. Sci.-Techn. Conf. on GasTransport Systems: Present and Future (27-28 Oct. 2009), 312-321.

2. Kozlov, V.V. (2010) Organizing and activities on quality assurance of welding operations in construction of main Sakhalin-Khabarovsk-Vladivostok pipeline. In: Proc. of branch meeting of OAO Gazprom (Moscow, 15-19 Nov., 2010), 108-112.

3. STO Gazprom: Instruction on welding of main pipelines with service pressure up to $9.8 \mathrm{MPa}$. Introd. 22.09.2007.

4. Paton, B.E., Lebedev, V.K., Kuchuk-Yatsenko, S.I (1979) Complex «Sever-1» for flash-butt welding of position joints of large diameter pipes. Avtomatich. Svarka, 11, 41-45.

5. Mazur, I.I., Serafin, O.M., Karpenko, M.P. (1989) Flash-butt welding of pipelines: Ways of improvement. Stroitelstvo Truboprovodov, 4, 8-11.

6. Khomenko, V.I., Kuchuk-Yatsenko, S.I., Kazymov, B.I. et al. Method of welding of pipes in construction of pipelines. Pat. 222998 RF. Publ. 27.02.2003.
7. Kuchuk-Yatsenko, S.I. (1992) Flash-butt welding. Kiev: Naukova Dumka.

8. API Standard 1104 (1999) Welding of pipelines and related facilities ASME boiler and pressure vessel. 19 ed.

9. Kuchuk-Yatsenko, S.I. Pismenny, A.S., Shinlov, M.E. et al. (2006) Accelerated induction heat treatment of pipe welds from controlled-rolled steels. The Paton Welding J., 3, 7-10.

10. Kuchuk-Yatsenko, S.I., Shvets, Yu.V., Zagadarchuk, V.F. et al. (2013) Technology of heat treatment of pipe joints from steel of K56 grade produced by flashbutt welding. Ibid., 2, 2-7.

11. Kuchuk-Yatsenko, S.I., Kirian, V.I., Kazymov, B.I. et al. (2008) Peculiarities of impact toughness tests of automatic flash butt welded joints on pipes. Ibid., 10, 5-10.

12. Kirian, V.I., Kuchuk-Yatsenko, S.I., Kazymov, B.I. (2015) Concerning requirements to impact toughness of joints of pipelines produced using flash butt welding. Ibid., 2, 2-6.

13. Kirian, V.I., Semenov, S.E. (1995) Evaluation of fitness for purpose of welded joints of main pipelines from microalloyed steels. Avtomatich. Svarka, 3, 4-9.

14. Kuchuk-Yatsenko, S.I., Kirian, V.I., Kazymov, B.I. et al. (2006) Methodology for control of fitness for purpose of flash butt welded joints in pipelines. The Paton Welding J., 10, 2-6.

Received 01.07.2015 


\title{
MODELLING THE CHARACTERISTICS OF CONSTRICTED-ARC PLASMA IN STRAIGHT AND REVERSE POLARITY AIR-PLASMA CUTTING*
}

\author{
M.Yu. KHARLAMOV ${ }^{2}$, I.V. KRIVTSUN ${ }^{1,2}$, V.N. KORZHIK ${ }^{1,2}$, V.I. TKACHUK ${ }^{2}$, V.E. SHEVCHENKO ${ }^{1,2}$, \\ V.K. YULYUGIN ${ }^{2}$, WU BOYI ${ }^{1}$, A.I. SITKO ${ }^{2}$ and V.E. YAROSH ${ }^{2}$ \\ ${ }^{1}$ Chinese-Ukrainian E.O. Paton Welding Institute (Guangdong General Research Institute of Industrial Technology \\ (Guangzhou Research Institute of Nonferrous Metals)) \\ 363 Changxing Road, Tianhe, 510650, Guangzhou, China. E-mail: vnkorzhyk@gmail.com \\ ${ }^{2}$ E.O. Paton Electric Welding Institute, NASU \\ 11 Bozhenko Str., 03680, Kiev, Ukraine. E-mail: office@paton.kiev.ua
}

\begin{abstract}
The paper deals with the issues of mathematical modelling of turbulent flow of electric arc plasma in straight and reverse polarity plasma cutting. It is noted that the main complexity of modelling reverse polarity cutting arises at description of plasma flow in near-electrode regions. In view of that, it is proposed to describe arc electromagnetic characteristics in the cut cavity proceeding from the known experimental data. Detailed comparative analysis of the influence of plasmatron operating modes and arc polarity on arc discharge electric characteristics, thermal and gas-dynamic characteristics of the plasma flow is performed on the base of numerical modelling. 17 Ref., 1 Table, 5 Figures.
\end{abstract}

Ke $\boldsymbol{y} \boldsymbol{w} \boldsymbol{o r d} \boldsymbol{s}:$ plasma cutting, straight and reverse polarity, electric arc plasma, turbulent flow, mathematical modelling, near-electrode regions, arc discharge electric characteristics

Plasma cutting is currently widely accepted in industry, primarily owing to high productivity and accuracy of the cutting process, as well as other factors, providing competitive advantages over other thermal cutting processes [1, 2]. So, for instance, laser cutting is inferior to plasma cutting, because of the high cost, as well as significant limitation on thickness of cut blanks (approximately $4 \mathrm{~mm}$ for metals), and oxygen cutting is inferior to plasma as to cut quality, cutting process effectiveness being largely determined by oxygen purity. Here, wider application of plasma cutting in practice is restrained by a number of limitations, inherent to this technology, among which we should, first of all, note the thickness of blanks being cut, limited by approximately $70 \mathrm{~mm}$ for steels [1]. Therefore, the priority tasks set for specialists involved in development of plasma cutting technologies, are increasing maximum cut thickness, alongside increase of cutting speed and blanks cutting-out accuracy, reduction of specific energy consumption, etc. These tasks can be solved by increasing the heat input in the cut zone, as well as providing more uniform heat distribution across the cut thickness, alongside creation of favorable gas-dynamic conditions for molten material blowing out.

Technological potential for equipment development for straight polarity (SP) plasma cutting, widely applied in practice, has practically been exhausted that is related to physics of the processes occurring here. In this connection, plasma cutting with application of reverse polarity (RP) arc, is an urgent direction of this technology development, fully meeting the modern industry requirements [1-3].

However, despite the fact that RP plasma cutting has been developed since 1970s, the process is still insufficiently studied, that does not allow designing reliable high-productivity cutting plasmatrons. Now, development of plasma cutting processes, alongside creation of the respective equipment (plasmatrons), is closely connected with deep and comprehensive study of physical processes running both in such plasmatrons, and in processed material. In particular, gas-dynamic, thermal and electric characteristics of arc plasma, generated by such plasmatrons, have a strong influence on productivity, stability, as well as resulting quality characteristics of plasma-arc processes of material processing. Here, in view of the complexity of these processes, mathemati-

\footnotetext{
* The work has been performed with financial support under Foreign Expert Program in PRC No.WQ20124400119, R\&D Project of Innovation Group of Guangdong Province No.201101C0104901263 and International Project of The Ministry of Science and Technology of PRC No.2013DFR70160. 
cal modelling methods are extremely important in performance of research aimed at improvement of plasmatron designs and selection of their optimum operation modes.

Development of mathematical model of arc plasma, generated by cutting plasmatrons in their operation both at straight and reverse polarity, as well as its application for conducting numerical experiments, were exactly the objective of this work.

There is a sufficient number of publications, devoted to theoretical studies of gas-dynamic, thermal and electromagnetic processes in plasma, generated by plasmatrons operating at straight polarity (see, for instance, [4-8]). Adequate mathematical models of plasmatrons with both transferred and non-transferred arc have been developed, allowing for a multitude of factors, including geometrical parameters of plasmatron working channel, turbulent nature of plasma flow, non-uniformity of electromagnetic field [9], etc.

These models are based on a system of NavierStokes magnetogasdynamic (MGD) equations [4-6], closed by additional equations, or relationships, describing the used turbulence model, magnetic component of pressure, etc.

A simplified system of MGD equations in boundary layer approximation can be used in most of the cases, which is derived from the condition of smallness of axial gradients of temperature and velocity of plasma, compared to radial ones [10]. A simplified model is used here to describe the arc electromagnetic characteristics, which is based on the assumption of smallness of radial component of electric current density, compared to axial component $\left(j_{r}<j_{z}\right)$. In the case of transferred-arc plasmatrons, in which part of the arc is running in open space, Maxwell equation [9] is applied for a more correct description of arc electromagnetic characteristics, for the solution of which boundary conditions are distributions of arc electromagnetic charac- teristics in near-electrode regions, which are assigned proceeding from experimental data. The best studied here are the processes on refractory (tungsten) cathode and in the near-cathode region of SP arc, running in different inert gases.

On the other hand, there are no models, describing the characteristics of electric arc plasma, generated by plasmatrons with RP arcs. In particular, during plasma cutting, RP electric arc continuously changes its length, while interacting with the gas flow, electromagnetic fields, walls of the electrode, nozzle channel and cut cavity, that makes the running processes complex for mathematical description. In this connection, at construction of mathematical model of cutting plasmatron, it appears rational to apply NavierStokes MGD equations together with the data of measurement of integral and distributed characteristics of arc plasma, generated by the plasmatrons operating at reverse polarity. Data of such measurements are given, for instance, in [2], and, in fact, allow selection of distributions of plasma parameters in near-electrode regions, required for further calculations. Application of these principles was exactly the basis for construction of a mathematical model of cutting plasmatrons with the arc of both straight and reverse polarity.

Problem definition. To construct a mathematical model of plasma arc at straight and reverse polarity air-plasma cutting, let us consider plasmatron schematic, given in Figure 1. Let us assume that constricted transferred arc runs between hollow electrode (anode or cathode, depending on arc polarity) and metal being cut, closing in the cut cavity. The arc runs both in the inner regions - plasmatron channel and cut cavity, and in the open section between plasmatron nozzle edge and surface of item being cut. Hollow electrode with inner radius $R_{p}$ is located at distance $Z_{1}$ from plasmatron outlet nozzle edge with the region of arc binding at $z=Z_{p}$. Plasma gas with flow rate $G$ is fed swirled through an-

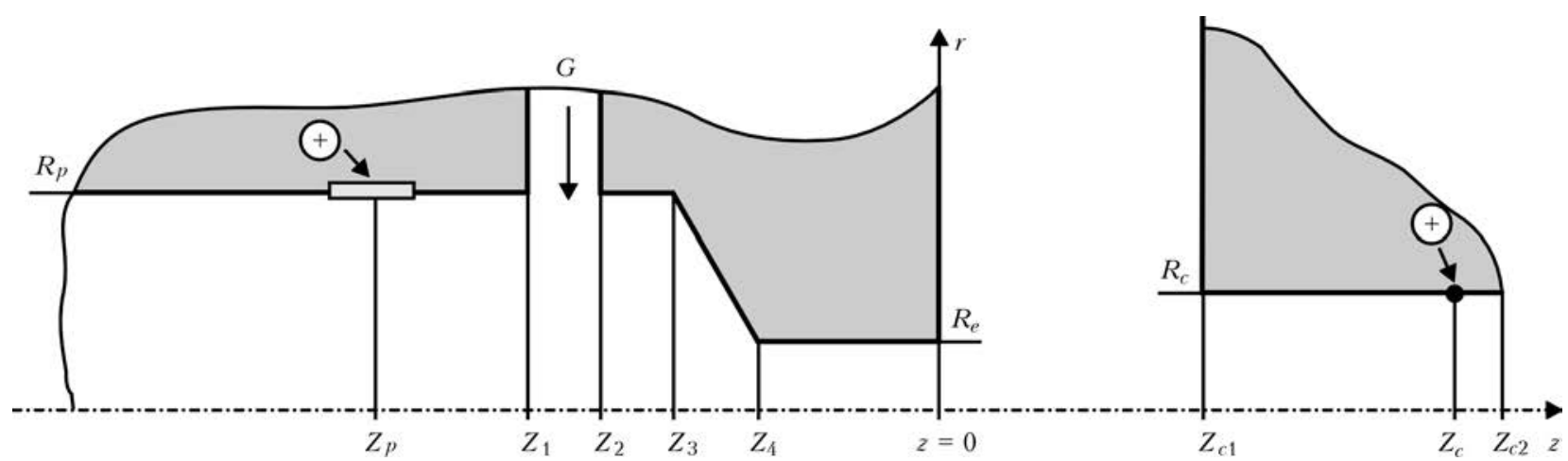

Figure 1. Calculation schematic of cutting plasmatrons and cut item in straight and reverse polarity cutting (for designations see the text) 
nular channel $Z_{1} \leq z \leq Z_{2}$ at $r=R_{p}$. Then plasma gas is heated and accelerated by the electric arc, and passing through convergent tube $\left(Z_{3} \leq \mathrm{z} \leq\right.$ $\leq Z_{4}$ ) and outlet nozzle of radius $r=R_{e}$ and length $Z_{4}$, it flows out into the environment. The arc expanding in the external area, then goes into the cut cavity, becoming constricted by its walls. Location of the arc basic spot in cut cavity $(z=$ $=Z_{c}$ ) can change within the thickness of item being cut, i.e. in region $Z_{c 1} \leq z \leq Z_{c 2}$.

We will consider the simplest variant of a stationary discharge in axially symmetric plasmatrons, operating in plasma gas turbulent flow mode, when the influence of electromagnetic factors on the nature of turbulence can be ignored, i.e. it can be considered purely gas-dynamic. The latter means that pulsations of current density, magnetic field intensity, as well as electric conductivity coefficient can be neglected, considering these values as averaged.

We will take the following assumptions for mathematical description of arc plasma flow in cutting plasmatron:

- considered plasma system has cylindrical symmetry, and the processes running in it are assumed to be stationary;

- disturbances, introduced into the flow, when bypassing the ledges in channel expansion planes, do not have any essential influence on the jet thermal and gas-dynamic characteristics;

- plasma is in the state of local thermodynamic equilibrium, plasma natural radiation is volumetric;

- main mechanism of plasma heating is Joulean heat evolution (work of pressure forces and viscous dissipation can be neglected), and energy transfer in the plasma flow occurs due to heat conduction and convection (natural convection is disregarded);

- plasma flow is viscous, subsonic, flow mode is turbulent;

- external magnetic fields are absent.

Tangential feeding of plasma gas into the plasmatron working channel and its relatively high flow rate should be also taken into account.

Basic equations. Allowing for the assumptions made, gas dynamic and thermal characteristics of plasma flow generated by cutting plasmatron can be described by the following system of MGD equations (with gas swirling) in the approximation of turbulent boundary layer for time-averaged values of plasma temperature and velocity $[5,6,10]$ :

$$
\frac{\partial}{\partial z}(\rho u)+\frac{1}{r} \frac{\partial}{\partial r}(r \rho \bar{v})=0 ;
$$

$$
\begin{gathered}
\rho\left(u \frac{\partial u}{\partial z}+\bar{v} \frac{\partial u}{\partial r}\right)=\frac{1}{r} \frac{\partial}{\partial r}\left(r \bar{\eta} \frac{\partial u}{\partial r}\right)-\frac{\partial}{\partial z}\left(p+\mu_{0} \frac{H_{\varphi}^{2}}{2}\right) ; \\
\rho\left(u \frac{\partial w r}{\partial z}+\bar{v} \frac{\partial w r}{\partial r}\right)=\frac{1}{r} \frac{\partial}{\partial r}\left(r \bar{\eta}\left(\frac{\partial r}{\partial r}-2 w\right)\right) ; \\
\rho C_{p}\left(u \frac{\partial T}{\partial z}+\bar{v} \frac{\partial T}{\partial r}\right)=\frac{1}{r} \frac{\partial}{\partial r}\left(r \bar{\chi} \frac{\partial T}{\partial r}\right)+\frac{j^{2}}{\sigma}-\psi .
\end{gathered}
$$

Here, $T$ is the averaged plasma temperature; $\bar{v}=$ $=\left(\rho v+\rho^{\prime} v^{\prime}\right) / \rho$, where $v$ is the averaged radial velocity; $\rho$ is the averaged plasma density; $\rho^{\prime}$ and $v^{\prime}$ are the pulsations of density and radial velocity; $u$ is the averaged axial plasma velocity; $w$ is the averaged azimuthal rotational speed; $p$ is the pressure; $C_{p}$ is the specific heat capacity of plasma at constant pressure; $\sigma$ is the plasma electric conductivity; $j$ is the vector of electric current density; $\psi$ is the volume density of natural radiation power; $\bar{\eta}$ and $\bar{\chi}$ are the total coefficients of dynamic viscosity and heat conductivity of plasma, which are a sum of molecular and turbulent viscosity and heat conductivity, respectively; $\mu_{0}$ is the universal magnetic constant;

$$
H_{\varphi}=\frac{1}{r} E_{z} \int_{0}^{r} \sigma r d r
$$

is the azimuthal component of arc current magnetic field, where $E_{z}$ is the axial component of electric field intensity.

Within the used boundary layer approximation, description of distributed electromagnetic characteristics of the arc is performed under the condition that $j_{r}<<j_{z}$. In this case, addendum $j^{2} / \sigma$ in equation (4), describing energy evolution in the plasma due to electric current flowing, becomes $j_{z}^{2} / \sigma$. Here, the axial component of arc electric field intensity is practically constant across channel cross-section [6], and is found from the condition of total current preservation:

$$
I=2 \pi E_{z} \int_{0}^{R_{\sigma}(z)} \sigma r d r,
$$

where $R_{\sigma}(z)$ is the radius of current-conducting region.

Considering that plasma conductivity is practically zero outside this region, calculated region radius can be used as upper limit of integration in formula $(6)$, i.e. in the channel $(z<0)$ it can be assumed equal to channel radius $R_{\sigma}(z)=$ $=R_{p}(z)$, where $R_{p}(z)=R_{p}$ at $z<Z_{2}, R_{p}(z)=$ $=R_{e}$ at $Z_{4} \leq z<0$, and $R_{p}(z)=R_{e}+((z-$ $\left.\left.Z_{4}\right) /\left(Z_{3}-Z_{4}\right)\right)\left(R_{p}-R_{e}\right)$ at $Z_{3} \leq z<Z_{4}$; in open 
region $\left(0 \leq z \leq Z_{c 1}\right) R_{\sigma}(z)-R_{\delta}(z)=\mathrm{R}$, and in cut cavity $\left(Z_{c 1}<z \leq Z_{c 2}\right)-R_{\sigma}(z)=R_{c}$ (see Figure 1).

Pressure distribution within the plasma-forming channel $(z \leq 0)$ is determined allowing for magnetic component of pressure and gas swirling:

$$
\begin{aligned}
p=p_{\text {ext }}-\int_{z}^{0} \frac{d p_{c}}{d z} d z+\mu_{0} E_{z} \int_{r}^{R_{p}(z)} \sigma H_{\varphi} d r- \\
\quad-\int_{r}^{R_{p}(z)} \frac{w^{2}}{r} d r,
\end{aligned}
$$

where $p_{\text {ext }}$ is the ambient pressure.

Gas-static pressure gradient $d p_{c} / d_{z}$ in boundary layer approximation is also constant across the channel section [10] and is determined from the conditions of preservation of total mass flow of plasma gas:

$$
\rho_{0} G=2 \pi \int_{0}^{R_{p}(z)} \rho u r d r
$$

where $\rho_{0}$ is the gas mass density under normal conditions; $G$ is the volume flow rate of gas. In the open discharge region, as well as in the cut cavity $(z>0)$ pressure is given by the following expression:

$$
p=p_{\text {ext }}+\mu_{0} E_{z} \int_{r}^{R_{c}(z)} \sigma H_{\varphi} d r-\int_{r}^{R_{c}(z)} \rho \frac{w^{2}}{r} d r .
$$

System of equations (1)-(9) is complemented by the following relationships:

$$
\begin{gathered}
\rho=\rho(T, p) ; \quad C_{p}=C_{p}(T, p) ; \quad \chi=\chi(T, p) ; \\
\eta=\eta(T, p) ; \quad \sigma=\sigma(T, p) ; \quad \psi=\psi(T, p),
\end{gathered}
$$

determining the dependencies of thermodynamic characteristics, molecular transfer coefficients and optical properties of plasma on temperature and pressure. Detailed tables of the above values for the used plasma gases are given, for instance, in $[6,11]$.

In the section of currentless (inertia) plasma flow, which under the described conditions can occur in the cut cavity beyond the arc binding region $\left(z>Z_{c}\right)$, the same system of gas-dynamic equations can be used, assuming $E_{z}=H_{\varphi}=0$.

Turbulence modelling. Coefficients of dynamic viscosity and heat conductivity of plasma used in the above equations have the following form:

$$
\bar{\eta}=\eta+\eta_{t} ; \quad \bar{\chi}=\chi+\chi_{t},
$$

where $\eta, \chi$ are the coefficients of molecular viscosity, determined according to $(9) ; \eta_{t}, \chi_{t}$ are the coefficients of turbulent viscosity and heat conductivity.

Turbulent transfer coefficients were determined using $k-\varepsilon$ model [12], in which coefficients of turbulent viscosity and heat conductivity are given by the following expressions:

$$
\begin{gathered}
\eta_{t}=\frac{C_{\mu} \rho(\bar{k})^{2}}{\varepsilon} ; \\
\chi_{t}=\eta_{t} \frac{C_{p}}{\operatorname{Pr}_{t}}
\end{gathered}
$$

where $\bar{k}$ is the kinetic turbulence energy; $\varepsilon$ is the turbulence dissipation rate; $C_{\mu}=0.09$ is the empirical constant; $\operatorname{Pr}_{t}$ is the turbulent Prandtl number, which is selected according to recommendations of [13], or is taken equal to a unity [6]. Equation of turbulent viscosity is closed by equations of transfer for kinetic energy of turbulence and dissipation rate:

$$
\begin{gathered}
\rho\left(u \frac{\partial \bar{k}}{\partial z}+\bar{v} \frac{\partial \bar{k}}{\partial r}\right)= \\
=\frac{1}{r} \frac{\partial}{\partial r}\left[r\left(\eta+\frac{\eta_{t}}{\operatorname{Pr}_{k}}\right) \frac{\partial \bar{k}}{\partial r}\right]+G-\rho \varepsilon \\
\rho\left(u \frac{\partial \bar{\varepsilon}}{\partial z}+\bar{v} \frac{\partial \bar{\varepsilon}}{\partial r}\right)= \\
=\frac{1}{r} \frac{\partial}{\partial r}\left[r\left(\eta+\frac{\eta_{t}}{\operatorname{Pr}_{\varepsilon}}\right) \frac{\partial \bar{\varepsilon}}{\partial r}\right]+C_{1} G \frac{\varepsilon}{\bar{k}}-C_{2} \rho \frac{\varepsilon^{2}}{\bar{k}} .
\end{gathered}
$$

Here, $G=\eta_{t}\left(\frac{\partial u}{\partial r}\right)^{2}$ is the source term, and $C_{1}$, $C_{2}, \operatorname{Pr}_{k} \operatorname{Pr}_{\varepsilon}$ are the constants of $k-\varepsilon$ model of turbulence, equal to $1.44,1.92,1.3$ and 1.0 , respectively.

Boundary conditions. To close the described system of equations, it is necessary to assign the boundary and initial (input) conditions, corresponding to the considered conditions of plasma cutting (see Figure 1).

The following conditions were assumed to be valid on the system axis of symmetry $(r=0)$ :

$$
\frac{\partial T}{\partial r}=0 ; \frac{\partial u}{\partial r}=0 ; \bar{v}=0 ; \frac{\partial \bar{k}}{\partial r}=0 ; \frac{\partial \varepsilon}{\partial r}=0 .
$$

On plasmatron walls, i.e. at $z \leq 0$ and $r=$ $=R_{p}(z)$, «sticking» condition is set and cooled wall temperature $T_{w}$ is assigned, i.e.

$$
u=\bar{v}=w=0 ; \quad T=T_{w} .
$$

To assign $\bar{k}$ and $\varepsilon$ values near the channel wall, it is necessary to apply the near-wall function $[12,14]$, determining the above values as follows: 


$$
\bar{k}=\frac{u_{*}^{2}}{\sqrt{C_{\mu}}}, \quad \varepsilon=\frac{u_{*}^{3}}{k_{0}\left(R_{c}-r\right)},
$$

where $k_{0}=0.41$, and $u_{*}$ is the solution of transcendental equation (logarithmic wall law):

$$
\frac{u}{u_{*}}=\frac{1}{k_{0}} \ln \left[\frac{\Lambda \rho u_{*}\left(R_{c}-r\right)}{\eta}\right] \text {, }
$$

where $\Lambda=9.0$ is the wall roughness parameter.

Expressions (17), (18) are used for correct allowance for viscous underlayer at determination of $k$ and $\varepsilon$ in near-wall region, i.e. at $y^{+}=$ $=\rho\left(R_{c}-r\right) u_{*} / \eta<f^{+}$, where $f^{+}$is selected in the range of 20-100 [14]. Equations (13), (14) of fully developed turbulent flow are used to describe the flow inner region $\left(y^{+} \geq f^{+}\right)$.

Conditions of smooth coupling with the environment are selected on the external boundary of calculated region (open section):

$$
T=T_{\text {ext }} ; \quad u=\bar{v}=w=0 .
$$

Considering the complexity of mathematical description of the region of plasma flow near the arc basic region in plasmatron discharge chamber, initial conditions were set in $z_{0}=Z_{1}$ section:

$$
\begin{gathered}
\bar{v}\left(r, z_{0}\right)=0 ; \quad u\left(r, z_{0}\right)=u_{0}(r) ; \\
w\left(r, z_{0}\right)=w_{0}(r) ; \quad T\left(r, z_{0}\right)=T_{0}(r) .
\end{gathered}
$$

Used as initial conditions $u_{0}(r), w_{0}(r), T_{0}(r)$ was the solution for arc in plasmatron channel in one-dimensional approximation (at $\bar{v}=0$ and $\left|\frac{\partial \psi}{\partial z}\right|=0$, where $\left.\psi=\{T, u, \bar{v}, r w\}\right)$ :

$$
\begin{gathered}
\frac{1}{r} \frac{\partial}{\partial r}\left(\bar{\eta} \frac{\partial u}{\partial r}\right)-\frac{\partial p}{\partial z}=0 \\
\frac{1}{r} \frac{\partial}{\partial r}\left(r \bar{\gamma} \frac{\partial T}{\partial r}\right)-\frac{j^{2}}{\sigma}-\psi=0
\end{gathered}
$$

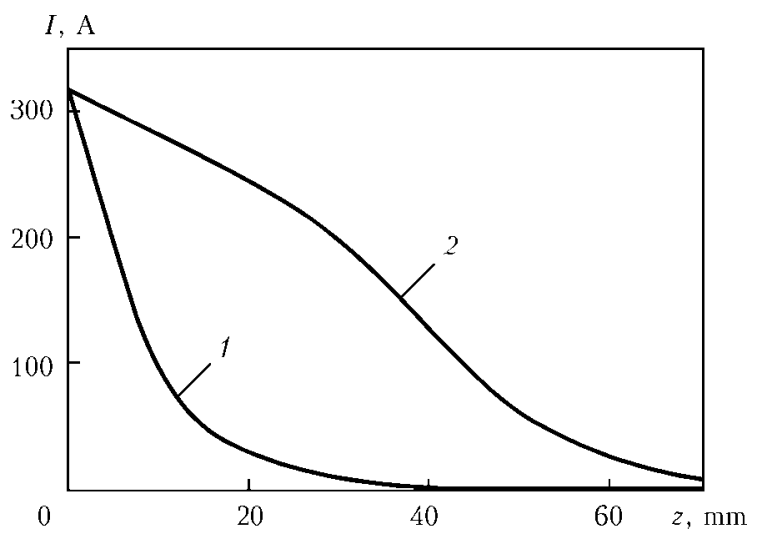

Figure 2. Change of total current of plasma arc along the cut cavity at straight (1) and reverse (2) polarity cutting at $I=315 \mathrm{~A}, G=3.4 \mathrm{~m}^{3} / \mathrm{h}, Z_{c 2}-Z_{c 1}=70 \mathrm{~mm}, R_{c}=$ $=5.5 \mathrm{~mm}$ complemented by empirical distribution of azimuthal rotational speed [6]

$$
w(r)=A\left(1-e^{-k r^{2}}\right) / r,
$$

where $A$ and $k$ constants are related to maximum speed and its coordinate $r_{m}$ :

$$
A=1.4 r_{m} \omega_{m} ; \quad k=1.25 / r_{m}^{2} ; \quad r_{m}=R / \sqrt{3} .
$$

Equations (21)-(23) were closed by expressions for arc current (6), plasma gas flow rate (8), as well as boundary conditions on the axis of symmetry (15) and walls of plasmatron channel (16). Solution of equation (21)-(23) was determined for assigned arc current $I$ and plasma gas flow rate $G_{0}=\varepsilon G$, where $\varepsilon$ was taken equal to 0.05 .

Volumetric flow rate of plasma gas through plasmatron working channel was determined allowing for vortex feeding of plasma gas via annular channel $Z_{1} \leq z \leq Z_{2}$ :

$$
G=\left\{\begin{array}{l}
0, z<Z_{1}, \\
\frac{z-Z_{1}}{Z_{2}-Z_{1}} G_{1}, Z_{1}<z<Z_{2} \\
G_{1}, Z_{2}<z<0,
\end{array}\right\}
$$

where $G_{1}$ is the volume fraction of plasma gas fed into plasmatron working channel.

And, finally, in cut cavity $\left(Z_{c 1} \leq z \leq Z_{c 2}\right)$ conditions (15), (16) were set, and arc current distribution along the cut cavity was assigned:

$$
I_{c}=I_{c}(z),
$$

which was determined proceeding from experimental data.

Current distribution along the cut cavity. To assign distribution of arc current of straight and reverse polarity along the cut cavity during plasmatron operation, experimental data [2] were used, which were the basis for construction of interpolation polynomial. Here, considering that the results of [2] were obtained for working current of $90 \mathrm{~A}$, current values in the cut cavity were determined in proportion to cutting plasmatron working current $I$, used in calculations. Figure 2 gives current distributions in the cut cavity, plotted for arc current of $315 \mathrm{~A}$.

Computer modelling results. Defined problem was solved numerically, by the method of finite differences $[15,16]$. Main difference scheme for integration of systems of equations of the type of boundary layer equation was used [17]. Second-order differential equations (2), (3), (13), (14) were approximated by implicit two-layer six-point difference scheme, and firstorder equation (1) - by explicit four-point 

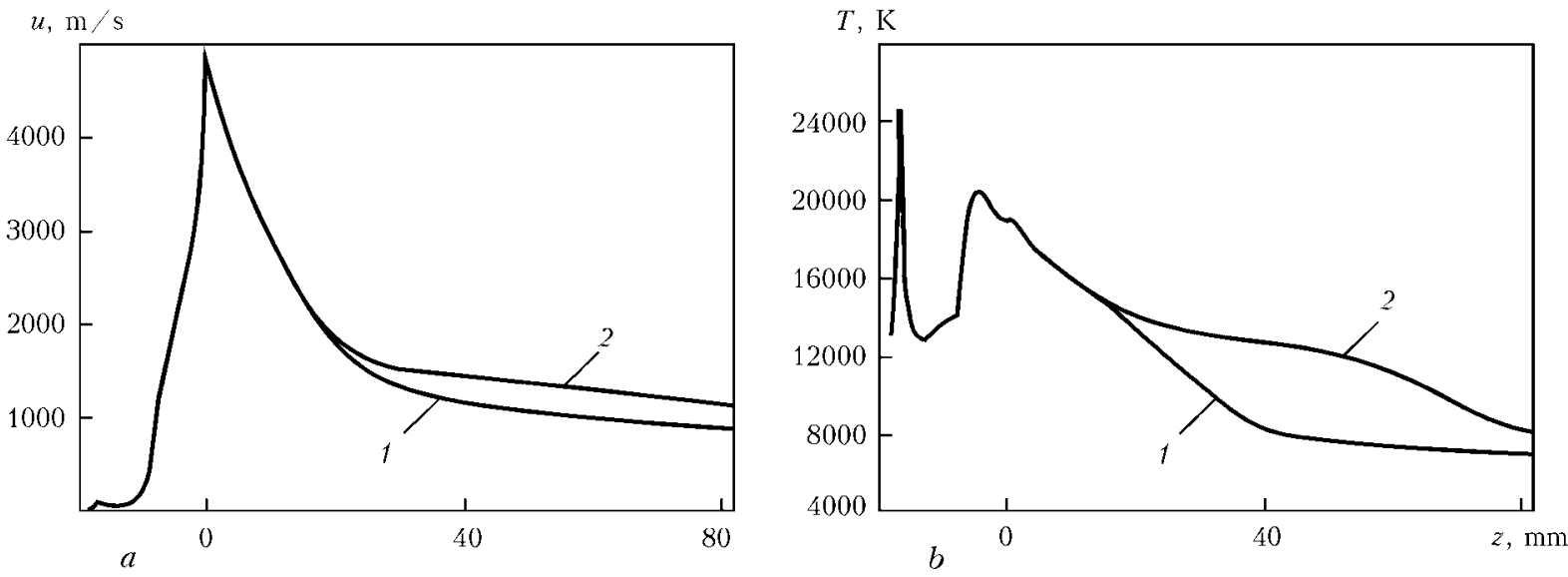

Figure 3. Distribution of axial values of plasma velocity $(a)$ and temperature $(b)$ along the axis of constricted arc generated by cutting plasmatron at its operation at straight (1) and reverse (2) polarity

scheme. Derived algebraic system of difference equations was solved by sweep method using layered iterations over $z$, with which global iterations over pressure were used to obtain a solution in cutting plasmatron channel.

Proceeding from the developed physicomathematical model, corresponding to computational scheme and software for is computer realization, numerical analysis has been performed of the characteristics of turbulent flow of arc plasma generated by the cutting plasmatron at different modes of its operation, both at straight and at reverse polarity.

During calculations, geometrical parameters of cutting plasmatron (internal dimensions of hollow anode, swirler, outlet nozzle) were assigned as follows (see Figure 1): $R_{e}=2 \mathrm{~mm}$, $Z_{4}=-8 \mathrm{~mm}, Z_{3}=-13 \mathrm{~mm}, Z_{2}=-17 \mathrm{~mm}, Z_{1}=$ $=-18.5 \mathrm{~mm}, Z_{p}=-58.5 \mathrm{~mm}, R_{p}=7 \mathrm{~mm}$. Distance to item being cut $Z_{c 1}$ was assumed to be equal to $12 \mathrm{~mm}$, thickness of cut item $Z_{c 2}-Z_{c 1}=$ $=70 \mathrm{~mm}$, cut cavity diameter $-11 \mathrm{~mm}$. The following parameters were used as the main parameters of cutting plasmatron operation: arc current $I=315$ A, plasma gas (air) flow rate $G=$ $=3.4 \mathrm{~m}^{3} / \mathrm{h}$. Ambient pressure was atmospheric.

Let us, first of all, consider the results of calculation of distributed characteristics of plasma flow, generated by cutting plasmatron at its operation at straight and reverse polarity. Calculated distributions of the values of plasma temperature and velocity along the plasma jet are given in Figure 3.

Proceeding from the presented results, plasma behaviour in the considered plasmatron, as well as in the open region and in cut cavity, can be presented as follows. Cold plasma gas entering the plasmatron via annular channel $Z_{2} \leq z \leq Z_{3}$ is gradually drawn into the flow. On the other hand, plasma flow core starts forming gradually in this flow section. However, annular near-wall flow of cold gas prevents expansion of heated plasma regions, resulting in formation of quite narrow current-conducting region, in which plasma temperature reaches the values of 15$24 \mathrm{kK}$ at quite low flow velocities.

Further plasma flow in plasmatron working channel is associated with expansion of flow core in the region $Z_{2} \leq z \leq Z_{3}$ and plasma temperature drop on the axis. Then, passing into the convergent tube $Z_{3} \leq z \leq Z_{4}$, the plasma flow is compressed, plasma velocity and temperature rising significantly. By the moment of entering plasmatron outlet nozzle $Z_{4} \leq z \leq 0$, the plasma flow practically completely fills the channel section. Being squeezed by relatively narrow walls of plasmatron outlet nozzle, the flow is intensively accelerated and heated by the electric arc, reaching the values of plasma velocity and temperature of the order of $5000 \mathrm{~m} / \mathrm{s}$ and $20 \mathrm{kK}$, respectively, on plasmatron nozzle edge.

Then plasma arc flows into open region $0 \leq$ $\leq \mathrm{z} \leq Z_{c 1}$, in which the plasma flow is somewhat expanded, that leads to lowering of the values of plasma velocity and temperature in the open region. Here, plasma in the flow is still exposed to electromagnetic forces, being in the region of electric arc impact. Then, penetrating into the cut area, the plasma arc is squeezed by its walls.

Differences in plasma flow parameters at straight and reverse polarity cutting are observed, primarily, in the cut cavity, that is associated with the nature of current distribution along the cut length in different arcing modes.

At SP cutting, plasma velocity and temperature decrease quite intensively, when going deeper into the cut cavity. In this case, the largest heat flow will come to subsurface regions of the item being cut. Now, at RP cutting distribution of plasma velocity and temperature along the cut cavity is of a more uniform nature; therefore intensive heat evolution in the arc occurs over the 
SCIENTIFIC AND TECHNICAL

Arc voltage in plasma cutting at straight and reverse polarity

\begin{tabular}{|c|c|c|c|c|c|c|}
\hline \multirow{2}{*}{ Polarity } & \multirow{2}{*}{$U_{\mathrm{a}}, \mathrm{V}$ (experiment) } & \multirow{2}{*}{$U_{\mathrm{a}}, \mathrm{V}$ (calculation) } & \multicolumn{4}{|c|}{$U, \mathrm{~V}$, at } \\
\hline & & & $Z_{p}<z<Z_{1}$ & $Z_{1}-0$ & $0-Z_{c 1}$ & $Z_{c 1}-Z_{c 2}$ \\
\hline Straight & 320 & 318 & 33 & \multirow[t]{2}{*}{173} & \multirow[t]{2}{*}{56} & 46 \\
\hline Reverse & 340 & 375 & 8 & & & 127 \\
\hline
\end{tabular}
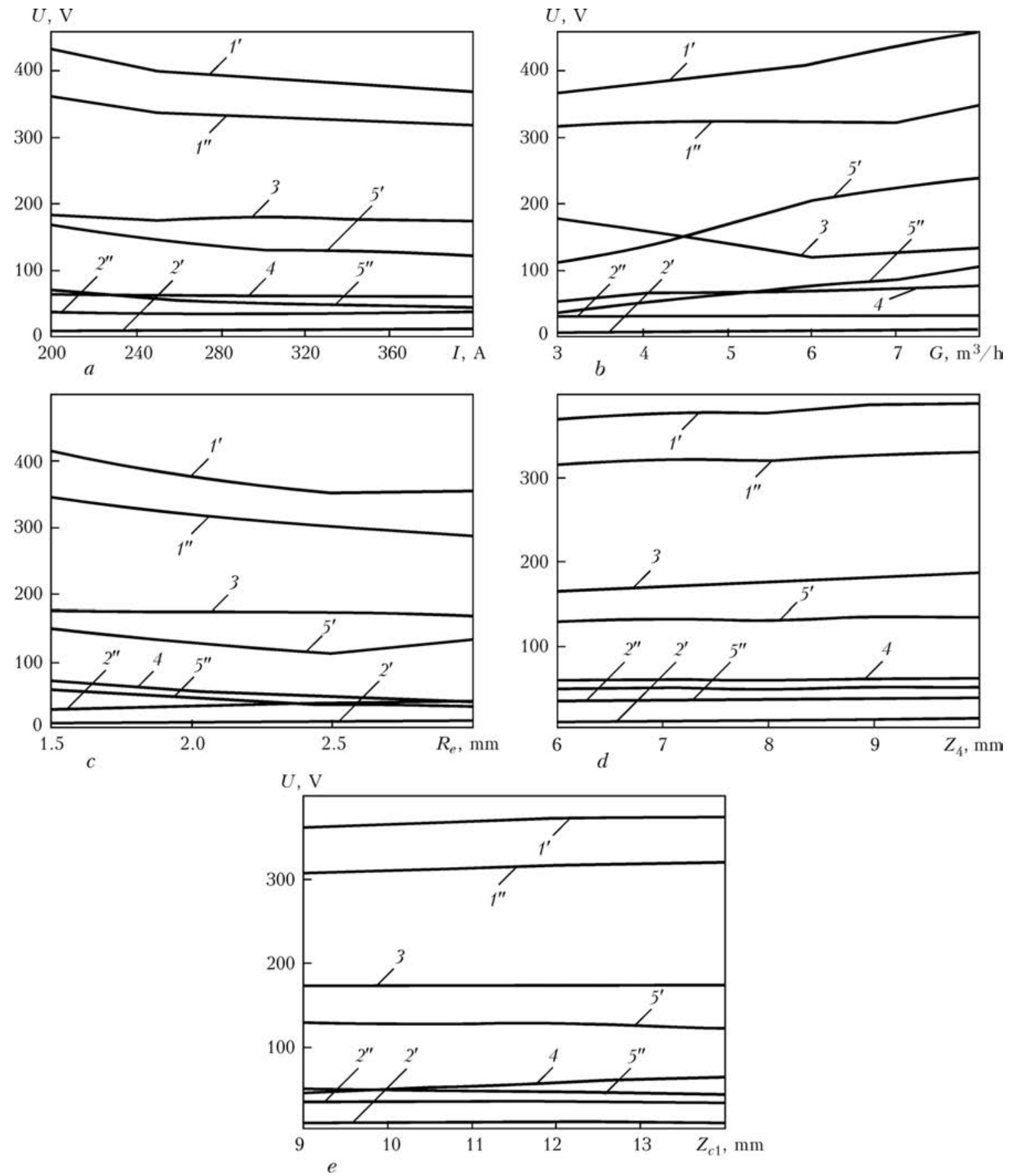

Figure 4. Dependencies of voltage drop across different parts of constricted arc column on current $(a)$, plasma gas flow rate $(b)$, radius $(c)$, length $(d)$ of plasmatron outlet nozzle and distance to cut item $(e): 1$ - total arc voltage drop; 2 - voltage drop inside hollow electrode; 3 - in plasma-forming channel; 4 - in arc open section; 5 - in cut cavity at plasmatron operation at reverse $\left(1^{\prime}, 5^{\prime}\right)$ and straight $\left(1^{\prime \prime}, 5^{\prime \prime}\right)$ polarity 

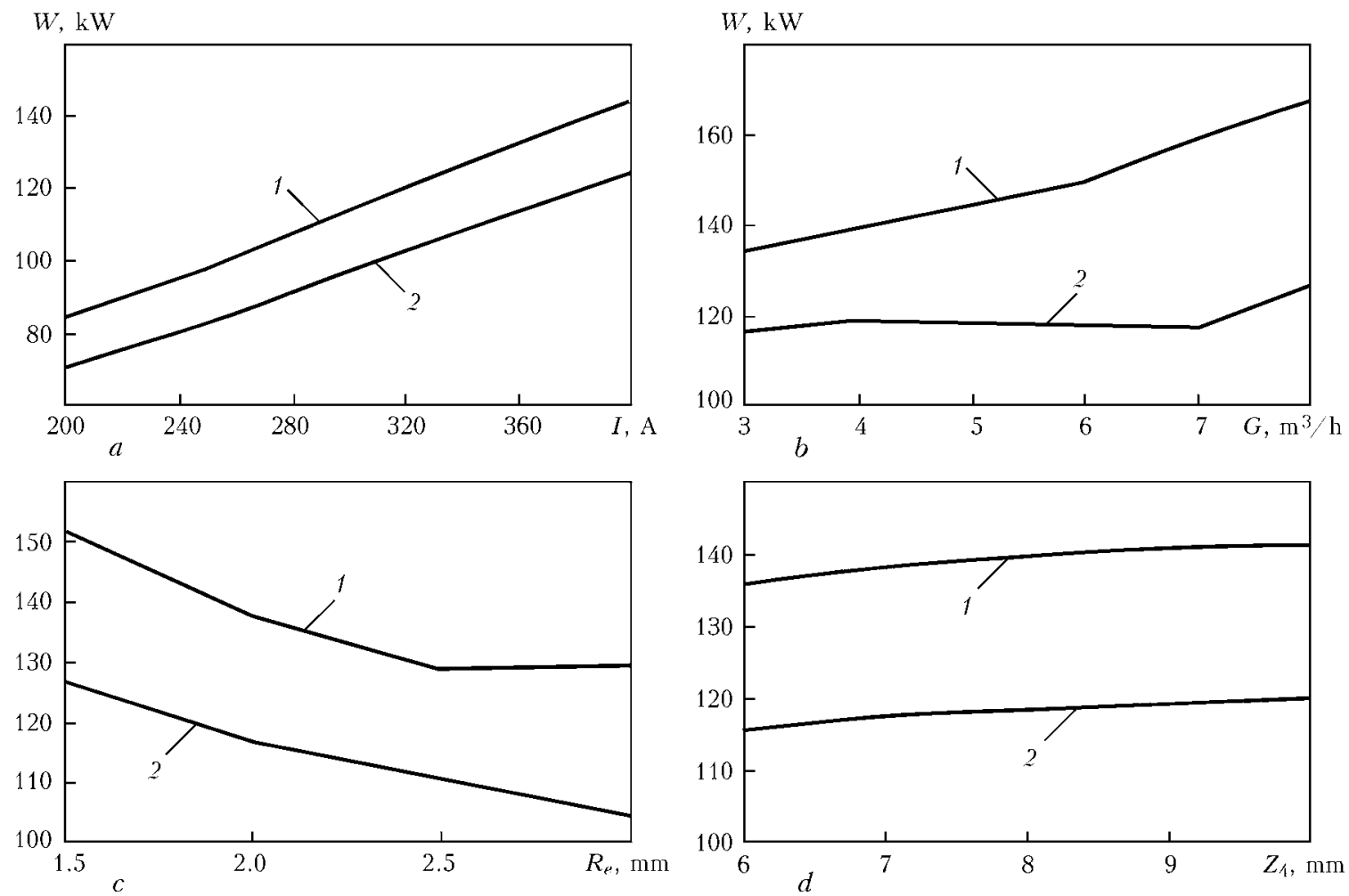

Figure 5. Dependencies of plasmatron total electric power on arc current $(a)$, plasma gas flow rate $(b)$, radius $(c)$ and length $(d)$ of plasmatron outlet nozzle at operation at reverse (1) and straight (2) polarity

entire depth of cut cavity that promotes increase of cutting process effectiveness.

Calculated total arc voltage, as well as voltage in arc individual regions, compared to experimentally measured voltage at cutting of $70 \mathrm{~mm}$ thick steel sheet in the considered plasmatron operation mode, are given in the Table.

Estimation of the value of total voltage drop across the cutting arc was performed under the following conditions: it was assumed that voltage drop near the regions of arc cathode and anode binding was equal to $10 \mathrm{~V}$ in sum; voltage drop in hollow electrode $\left(Z_{p}<z<Z_{1}\right)$ was evaluated using experimental findings, in keeping with which at SP cutting the arc binding is performed near the hollow electrode farther wall $\left(Z_{p}-Z_{1} \sim\right.$ $\sim 40 \mathrm{~mm}$ ), and at RP cutting - near the channel of plasma gas feeding $\left(Z_{p}-Z_{1} \sim 10 \mathrm{~mm}\right)$.

Let us now consider the results of calculation of integral electric and energy characteristics of the plasmatron at different sets of parameters of the process of straight and reverse polarity plasma-arc cutting (Figures 4 and 5).

As follows from Figure 4, $a$, calculated voltampere characteristic of the arc is a falling one in the considered plasmatron. Contrarily, dependence of arc voltage on plasma gas flow rate at constant $I_{\mathrm{a}}=315 \mathrm{~A}$ is a rising one. One can see from Figure 4, $b$ that at increase of plasma gas flow rate (above $5-6 \mathrm{~m}^{3} / \mathrm{h}$ ) restructuring of plasma flow in plasmatron channel occurs, that affects the change of flow parameters in the external region and in the cut area and, in its turn, leads to a change of the nature of voltage drop in these regions.

Influence of such geometrical parameters on arc voltage drop, as configuration of plasmatron working channel and distance to the item being cut, is given in Figure 4, $c-e$. It is shown that increase of arc column length leads also to increase of voltage drop value. Now, expansion of current channel, associated with increase of plasmatron outlet section diameter, leads to lowering of arc voltage.

Figure 5 gives the calculated dependencies of plasmatron electric power on its operation modes and geometrical parameters of working channel at plasmatron operation both at straight and at reverse polarity of the arc. Plasmatron electric power grows practically linearly at increase of arc current, as well as plasma gas flow rate (Figure $5, a, b)$. Drop of plasmatron power values occurs at increase of plasmatron outlet nozzle radius (Figure 5, c). This is related to increase of current channel dimensions and smaller voltage drop in the section, which corresponds to plasmatron working channel.

On the whole, derived results are indicative of the good prospects for application of the proposed approach to mathematical description of electric arc plasma, generated by cutting plasmatrons at their operation both at straight and 
at reverse polarity, as well as the possibility of application of the developed mathematical model and software for its computer realization, when retrofitting the design and selection of optimum operation modes of such plasmatrons.

\section{Conclusions}

1. A mathematical model of thermal, gas-dynamic and electromagnetic processes in arc plasma generated by cutting plasmatrons at their operation both at straight and reverse polarity was proposed. This model can be used for calculation of distributed and integral characteristics of arc plasma flow, generated by such plasmatrons inside the working channel, in open region of the arc, as well as in the cut cavity. The model allows conducting numerical analysis in broad ranges of variation of arc current and plasma gas flow rate, as well as geometrical parameters of plasmatron working channel and cut cavity.

2. Results of numerical studies of characteristics of arc plasma, generated by cutting plasmatron at reverse polarity, showed that these characteristics are significantly influenced by radius of plasmatron outlet nozzle, thickness of item being cut, as well as plasmatron operation parameters.

3. Thickness of item being cut has an essential influence on integral electric and energy characteristics of plasma arc. Therefore, cutting of thick items should be performed with application of power sources, providing operation in a broad range of working powers (up to $200 \mathrm{~kW}$ ) and voltages $(100-500 \mathrm{~V})$.

1. Shirshov, I.G. (1987) Plasma cutting. Leningrad: Mashinostroenie.

2. Kiselev, Yu.Ya. (2005) Investigation and development of technology and equipment for plasma-arc cutting of metals at reverse polarity: Syn. of Thesis for Dr. of Techn. Sci. Degree. Kishinev.

3. Shchitsyn, V.Yu. (2005) Improvement of plasmatron structures and technologies of plasma treatment of metals at reverse polarity: Syn. of Thesis for Cand. of Techn. Sci. Degree. Perm.

4. Engelsht, V.S., Asanov, D.S., Gurovich, V.Ts. et al. (1983) Mathematical modeling of electric arc. Frunze: Ilim.

5. Borisov, Yu.S., Chernyshov, A.V., Krivtsun, I.V. et al. (1994) Computer-aided simulation and experimental study of dusted plasma jets emitting into limited space. In: Proc. of Nat. Thermal Spray Conf. (Boston, USA, 1994), 361-366.

6. (1990) Theory of electric arc column. Ed. by M.F. Zhukov. Novosibirsk: Nauka.

7. Favalli, R.C., Szente, R.N. (1998) Physical and mathematical modeling of non transferred plasma torches. Brazilian J. Physics, 1(March), 25-34.

8. Kharlamov, M.Yu., Krivtsun, I.V., Korzhik, V.N. et al. (2007) Mathematical model of arc plasma generated by plasmatron with anode wire. The Paton Welding J., 12, 9-14.

9. Kharlamov, M.Yu., Krivtsun, I.V., Korzhik, V.N. et al. (2009) Refined mathematical model of the electric arc burning in plasmatron with external current-conducting wire. Ibid., 1, 42-45.

10. Lojtsyansky, L.G. (1973) Fluid and gas mechanics. Moscow: Nauka.

11. Boulos, M.I., Fauchais, P., Pfender, E. (1994) Thermal plasmas: Fundamentals and applications. Vol. 1. N.Y.; London: Plenum Press.

12. Launder, B.E., Spalding, D.B. (1990) The numerical computation of turbulent flows. Computer Methods in Appl. Mechanics and Eng., 8, 269-289.

13. Ievlev, V.M. (1975) Turbulent motion of high-temperature continua. Moscow: Nauka.

14. Wilcox, D.C. (1994) Turbulence modeling for CFD. La Canada:. DCW Ind. Inc.

15. Samarsky, A.A. (1971) Introduction to theory of difference schemes. Moscow: Nauka.

16. Anderson, D., Tannehill, J., Pletcher, R. (1990) Computational fluid mechanics and heat transfer. Vol. 1. Moscow: Mir.

17. Paskonov, V.M., Polezhaev, V.I., Chudov, L.A. (1984) Numerical modeling of processes of heat-, mass transfer. Moscow: Nauka.

Received 21.07.2015 


\title{
LASER-ARC WELDING OF HIGH-STRENGTH STEELS WITH YIELD STRENGTH OF MORE THAN 700 MPa
}

\author{
V.D. POZNYAKOV, V.D. SHELYAGIN, S.L. ZHDANOV, A.A. MAKSIMENKO, \\ A.V. ZAVDOVEEV and A.V. BERNATSKY \\ E.O. Paton Electric Welding Institute, NASU \\ 11 Bozhenko Str., 03680, Kiev, Ukraine. E-mail: office@paton.kiev.ua
}

\begin{abstract}
For the first time the prospects of using laser heat sources, namely for hybrid laser-arc welding, which allows improving the strength values of welded joints and their resistance to brittle and delayed fracture due to transformation of thermal cycle of welding, characteristic for arc processes, are shown for high-strength low-alloyed steels of small thicknesses on the example of steel 14KhGN2MDAFB. 8 Ref., 2 Tables, 3 Figures.
\end{abstract}

K e y words: hybrid laser-arc welding, high-strength steel, welding thermal cycles, structure, properties

Up to nowadays the use of arc discharge as one of the most widespread and cheap types of heat sources for welding encounters significant difficulties associated with insufficient concentration of energy in the electric-arc plasma and instability of arc burning at high welding speeds. Therefore, at the moment, the hybrid welding methods, such as laser-arc, laser-light beam, dual-beam, laser-induction and laser-plasma ones, are rapidly developed.

Among them the most perspective method for producing welded joints of high-strength steels is hybrid laser-arc welding (HLAW). This process is based on combination of technologies of laser welding and arc welding in shielding gases. The advantages of laser welding are determined by the possibility of joining metals of small thicknesses with a minimum introducing of heat into the product, the high accuracy and welding speed. At the same time, such disadvantages as need in providing minimum gap between the surfaces being welded and need in using high-power lasers are not inherent in hybrid laser welding [1]. Although the limited heat input in laser and HLAW leads to formation of hardening structures in the weld metal and HAZ of high-strength steel, the advantages of these methods before arc welding consist in the minimum deformation of welded joint under the effect of welding thermal cycle [2].

Due to its significant advantages the hybrid welding is a quite reliable method for joining materials, and the area of its application in recent years includes many fields of industry, such as shipbuilding, automotive, manufacture of containers, truck cranes and road building machinery [3].
Like in other welding processes the capabilities of hybrid laser-MAG welding are determined by appropriate selection of main parameters of the process, which can be obtained by varying the necessary operational characteristics, such as penetration depth, weld shape and metallurgical properties of welded joint. An important factor for hybrid welding is the choice of shielding gas. For Nd:YAG laser this choice is determined by the requirements of arc burning stability, quality of weld protection, as well as need in filler metal transfer without spattering. In work [4] it is noted that to meet such requirements it is optimal to use the shielding $\mathrm{Ar}+18 \% \mathrm{CO}_{2}$ gas mixture.

At the present time a sufficient number of publications has been already available regarding the use of laser and HLAW of low-carbon and low-alloy steels St3, 09G2S, X70 etc. [5-7]. This paper considers the use of laser heating sources for welding of hardening steels with bainiticmartensitic structure, the yield strength of which exceeds $700 \mathrm{MPa}$.

The main difficulties in welding of HSLA steels are associated with the need in preventing the cold crack formation in the HAZ metal of welded joint, as well as preventing the structures, which sharply reduce the resistance of welds to brittle fracture. Moreover, the required operational and technological properties of welded joints must be acquired in the postweld state without additional heat treatment [8]. In this regard, the aim of this work consists in the comparative evaluation of thermal cycles, structure and mechanical properties of joints of highstrength steel characteristic for laser, HLAW and arc welding.

Experimental procedure. As the object of investigations, 14KhGN2MDAFB high-strength 

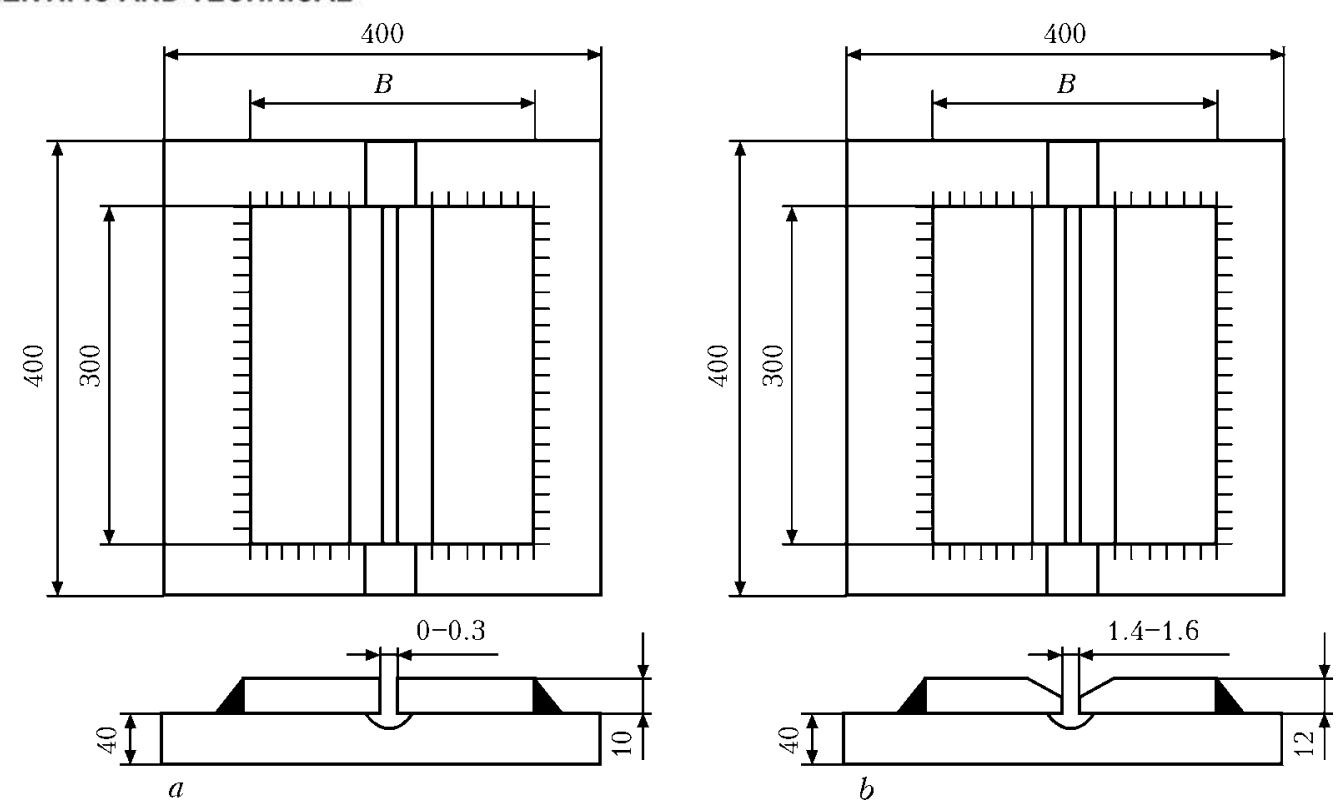

Figure 1. Technological sample with adjustable rigidity for hybrid and laser $(a)$ and arc $(b)$ welding

steel of $8 \mathrm{~mm}$ thickness was chosen of the following chemical composition, wt.\%: $0.14 \mathrm{C}$; $0.3 \mathrm{Si} ; 0.98 \mathrm{Mn} ; 1.19 \mathrm{Cr} ; 2.07 \mathrm{Ni} ; 0.22 \mathrm{Mo} ; 0.08 \mathrm{~V}$; $0.45 \mathrm{Cu} ; 0.06 \mathrm{Nb} ; 0.005 \mathrm{~S} ; 0.018 \mathrm{P}$. To determine the parameters of thermal cycles during heatingcooling the chromel-aluminum thermocouples of $0.5 \mathrm{~mm}$ diameter were used, the thermojunction of which was deepened into marks, where the overheat area of HAZ was supposed to be.

Applying the integrated method of investigations, which includes optic and electron microscopy, the structural and phase changes in welded joints were studied, and the mechanical tests of specimens for tension and impact bending were applied to study their properties.

The important factor is producing welded joints without cold cracks. In order to determine

Table 1. Conditions of $14 \mathrm{KhGN2MDAFB}$ steel welding

\begin{tabular}{||l|c|c|c|c|c||}
\hline \multirow{2}{*}{ Method } & \multicolumn{5}{|c||}{ Welding modes } \\
\cline { 2 - 6 } & $\begin{array}{c}v_{\mathrm{w}}, \\
\mathrm{m} / \mathrm{h}\end{array}$ & $I_{\mathrm{w}}, \mathrm{A}$ & $U_{\mathrm{a}}, \mathrm{V}$ & $\begin{array}{c}v_{\text {sh.g, }} \mathrm{l} / \mathrm{min} \\
\text { Arc }\end{array}$ & $\begin{array}{c}\text { Heat } \\
\text { input, } \\
\mathrm{J} / \mathrm{cm}\end{array}$ \\
\hline Arc & 30 & 230 & 31 & 14 & 10700 \\
\hline Arc & 40 & 230 & 31 & 14 & 4825 \\
\hline Arc & 50 & 230 & 31 & 14 & 3852 \\
\hline Laser & 40 & - & - & 14 & 3170 \\
\hline Laser & 50 & - & - & 14 & 2540 \\
\hline Hybrid & 72 & 125 & 23 & 30 & 2900 \\
\hline Hybrid & 90 & 150 & 25 & 30 & 2570 \\
\hline Hybrid & 110 & 200 & 26 & 30 & 2430 \\
\hline Note. Laser power - $4.4 \mathrm{~kW}$. \\
\hline
\end{tabular}

the opportunities for producing quality welded joints without formation of these inadmissible defects, the investigations were carried out using rigid butt technological sample with an adjustable fixing rigidity. The sample represented a massive slab of $400 \times 400 \times 40 \mathrm{~mm}$ in size, on which the butt joints of steel $14 \mathrm{KhGN} 2 \mathrm{MDAFB}$ of $300 \mathrm{~mm}$ length and $10 \mathrm{~mm}$ thickness without edge preparation (Figure 1, $a$ ) and with a gap of $0.1-0.3 \mathrm{~mm}$ were installed and welded by fillet weld around the perimeter for hybrid and laser welding, and for comparison with the arc welding method, the joint of $12 \mathrm{~mm}$ thickness with $\mathrm{V}$ shaped edges bevel and $5 \mathrm{~mm}$ root face (Figure 1, b) was produced to provide the technological lack of penetration, being a stress concentrator for initiating the cracks formation. The preset level of hardness was determined by width of butt joint (100 and $200 \mathrm{~mm}$ ).

To compare the conditions of heating-cooling, welded butt joints of steel 14KhGN2MDAFB were produced using automatic arc method in shielding gases, laser and HLAW. The welding conditions are shown in Table 1.

Automatic arc welding using solid wire Sv10KhN2GSMFTYu of $1.2 \mathrm{~mm}$ diameter in $\mathrm{Ar}+$ $+18 \% \mathrm{CO}_{2}$ mixture was carried out on the conditions providing the constancy of current, voltage and shielding gas mixture: $I_{\mathrm{w}}=220-240$ A, $U_{\mathrm{a}}=30-32 \mathrm{~V}, v_{\text {sh.g }}=14-16 \mathrm{l} / \mathrm{min}$. At the same time the welding speed was changed in the ranges of $18,30,40$ and $50 \mathrm{~m} / \mathrm{h}$.

In laser process the welding speed was in the ranges from 40 to $50 \mathrm{~m} / \mathrm{h}$. At $\mathrm{Nd}$ :YAG laser power of $4.4 \mathrm{~kW}$, deepening of focus was $\Delta F=$ $=-1.5 \mathrm{~mm}$. 
To provide the quality welded joint of $8 \mathrm{~mm}$ thickness with a required penetration depth the conditions of laser component in HLAW were similar to those in the laser process, and in arc component the electrical parameters were changed together with the welding speed at constant consumption of shielding gas $v_{\text {sh.g }}=$ $=30 \mathrm{l} / \mathrm{min}\left(\mathrm{Ar}+18 \% \mathrm{CO}_{2}\right)$. In HLAW for $v_{\mathrm{w}}=72 \mathrm{~m} / \mathrm{h} I_{\mathrm{w}}=125 \mathrm{~A}$ and $U_{\mathrm{a}}=23 \mathrm{~V}$; for $v_{\mathrm{w}}=90 \mathrm{~m} / \mathrm{h}-I_{\mathrm{w}}=150 \mathrm{~A}$ and $U_{\mathrm{a}}=25 \mathrm{~V}$; for $v_{\mathrm{w}}=110 \mathrm{~m} / \mathrm{h}-I_{\mathrm{w}}=200 \mathrm{~A}$ and $U_{\mathrm{a}}=26 \mathrm{~V}$.

Obtained results and their discussion. The analysis of thermal cycles, obtained in laser and HLAW methods, showed that as compared to the conventional process of automatic arc welding in shielding gases the heating rate of $\mathrm{HAZ}$ metal up to $1100-1300{ }^{\circ} \mathrm{C}$ and the cooling rate of overheat areas in the temperature range of $600-500{ }^{\circ} \mathrm{C}\left(w_{6 / 5}\right)$ are $4-5$ times increased ( $\mathrm{Fi}-$ gure 2).

Laser and HLAW are characterized by the tendency of increasing the cooling rate, but if in the first case (Figure $2, d$ ) the difference in $w_{6 / 5}$ is observed during the change of welding speed $\left(w_{6 / 5}=65{ }^{\circ} \mathrm{C} / \mathrm{s}\right.$ at $v_{\mathrm{w}}=40 \mathrm{~m} / \mathrm{h}$ and $103{ }^{\circ} \mathrm{C} / \mathrm{s}$ $T,{ }^{\circ} \mathrm{C}$
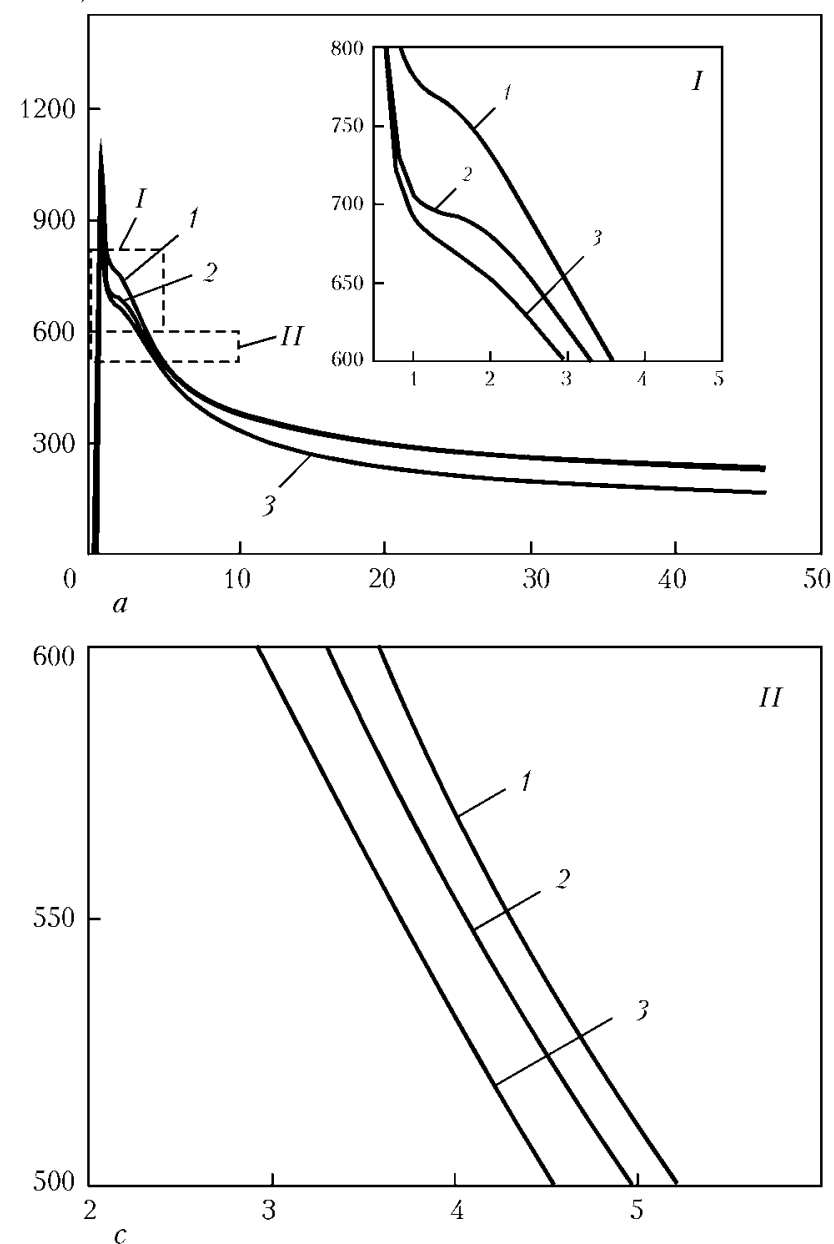

at $50 \mathrm{~m} / \mathrm{h})$, then at different speeds of HLAW: $v_{\mathrm{w}}=72,90$ and $110 \mathrm{~m} / \mathrm{h}$ (Figure $2, c$ ) $w_{6 / 5}$ are approximately the same and amount to 58$63{ }^{\circ} \mathrm{C} / \mathrm{s}$. Moreover, in laser welding at the range from 600 to $500{ }^{\circ} \mathrm{C}$, the cooling of metal occurs in 2 and $4 \mathrm{~s}$ for the welding speeds of 50 and $40 \mathrm{~m} / \mathrm{h}$, respectively, whereas for HLAW the time of passing the given temperature range is the same and amounts to $1.5 \mathrm{~s}$.

Also the temperature range from 800 to $600{ }^{\circ} \mathrm{C}$ should be noted. Whereas in laser welding a monotonous decrease of cooling curves (Figure 2, $b$, insert to the right) is observed, then in HLAW the S-shaped behavior of cooling curves is observed, moreover for $v_{\mathrm{w}}=90 \mathrm{~m} / \mathrm{h}$ the horizontal area is the most expressed (Figure 2, $a$, insert to the right). Apparently, it can be explained by different heat input into the welded joint and, hence, by different effect of power characteristics and the separately taken laser heating source, as well as the total effect of laser and arc, which even at increase in welding speed transforms thermal cycle towards decrease of the cooling rate.

It should be noted that in HLAW the cooling rate is approximately 2 times higher than that in
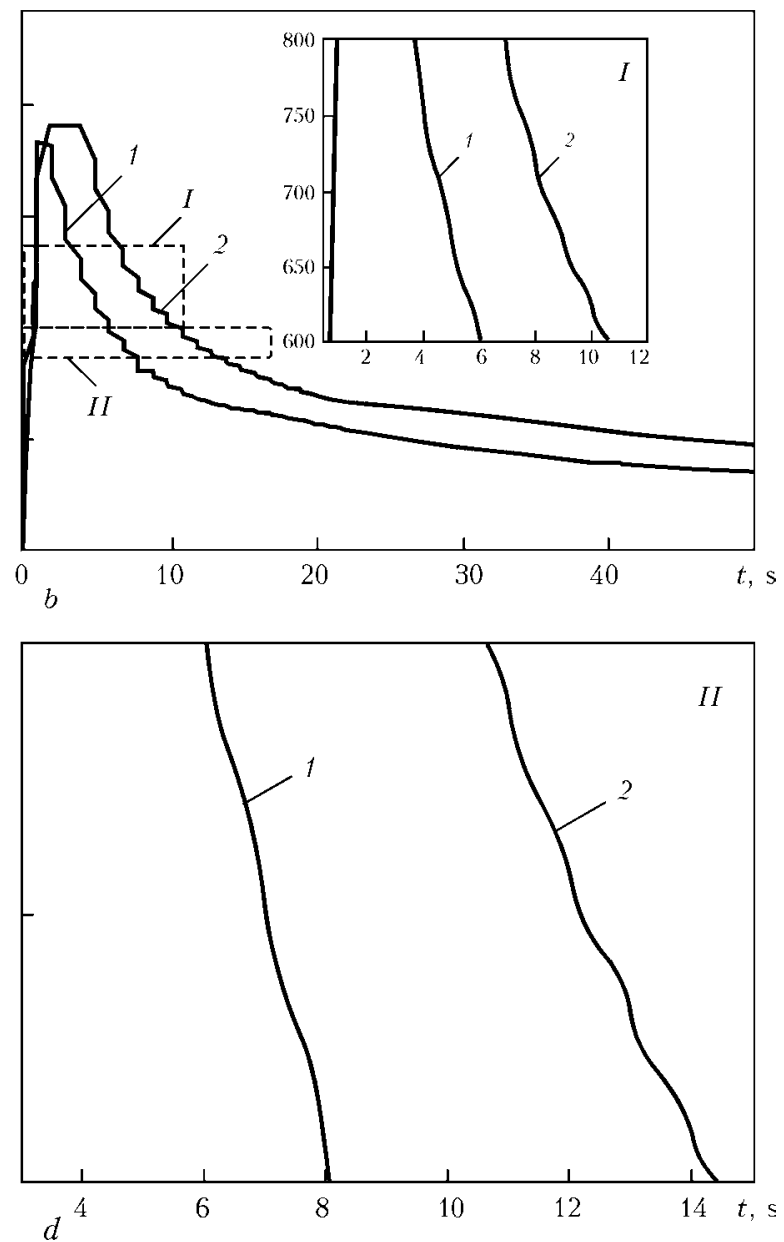

Figure 2. Thermal cycles in $\operatorname{HLAW}(a, c)$ at $v_{\mathrm{w}}=72(1), 90(2)$ and $110(3) \mathrm{m} / \mathrm{h}$, and in laser welding $(b, d)$ at $v_{\mathrm{w}}=$ $=50(1)$ and $40(2) \mathrm{m} / \mathrm{h}$ 
SCIENTIFIC AND TECHNICAL

Table 2. Mechanical properties of base and weld metal of steel 14HGN2MDAFB joints in different welding methods

\begin{tabular}{|c|c|c|c|c|c|c|c|c|}
\hline \multirow{3}{*}{\begin{tabular}{|l} 
Method \\
BM \\
\end{tabular}} & \multirow{3}{*}{$v_{\mathrm{w}}, \mathrm{m} / \mathrm{h}$} & $\sigma_{0.2}$ & $\sigma_{\mathrm{t}}$ & \multirow{3}{*}{$\begin{array}{c}\delta_{5} \\
\% \\
20 \\
\end{array}$} & \multicolumn{3}{|c|}{$K C V, \mathrm{~J} / \mathrm{cm}^{2}$, at $T,{ }^{\circ} \mathrm{C}$} & \multirow{3}{*}{$\begin{array}{c}\begin{array}{c}\text { Type of } \\
\text { structure } \\
\text { (weld } / \text { HAZ) }\end{array} \\
\text { B }\end{array}$} \\
\hline & & \multicolumn{2}{|c|}{$\mathrm{MPa}$} & & +20 & -20 & $\begin{array}{c}-40 \\
\text { (weld } / \mathrm{HAZ} \text { ) }\end{array}$ & \\
\hline & & 780 & 820 & & - & - & 35 & \\
\hline Arc & 30 & 625 & 739 & 20 & 75 & 50 & $37 / 42$ & $\mathrm{~B} / \mathrm{B}-\mathrm{M}$ \\
\hline Arc & 40 & 680 & 778 & 20 & 97 & 94 & $80 / 52$ & $\mathrm{~B} / \mathrm{B}-\mathrm{M}$ \\
\hline Arc & 50 & 798 & 911 & 16 & 103 & 95 & $53 / 148$ & $\mathrm{~B}-\mathrm{M} / \mathrm{B}-\mathrm{M}$ \\
\hline Laser & 40 & 858 & 925 & 11 & 53 & 23.8 & 14 & $\mathrm{~B}-\mathrm{M} / \mathrm{B}-\mathrm{M}$ \\
\hline Laser & 50 & 862 & 924 & 14 & 53 & 30.4 & 22.8 & $\mathrm{~B}-\mathrm{M} / \mathrm{B}-\mathrm{M}$ \\
\hline Hybrid & 72 & 907 & 1129 & 11 & 75.7 & 38.6 & $38.3 / 84$ & $\mathrm{~B} / \mathrm{B}$ \\
\hline Hybrid & 90 & 1147 & 1323 & 10 & 61.5 & 54 & $52.1 / 59$ & $\mathrm{~B}-\mathrm{M} / \mathrm{B}$ \\
\hline Hybrid & 110 & 987 & 1083 & 12 & 70 & 50.3 & $35.8 / 84$ & $\mathrm{~B} / \mathrm{B}$ \\
\hline
\end{tabular}

automatic arc welding performed at maximum speed of $50 \mathrm{~m} / \mathrm{h}$, at which the quality weld can be still produced. The experiments showed that the further increase in welding speed in arc welding processes in shielding gases using welding wire of $1.0-1.2 \mathrm{~mm}$ diameter is not rational.

Such differences of cooling conditions of the weld and HAZ metal of 14KhGN2MDAFB welded joints for the above-mentioned welding methods cause certain changes in their structure, and thus their mechanical properties are changed. The data presented in Table 2 show that with increase in arc welding speed the values of static strength of weld metal increase and its elongation decreases. This is explained by increase in cooling rate in $600-500{ }^{\circ} \mathrm{C}$ range and, consequently, by a more intensive hardening of metal.

In laser welding the values of elongation and impact toughness are reduced, as compared to those of the base metal at testing temperature of $-40{ }^{\circ} \mathrm{C}$ (by 30 and $50 \%$, respectively). The strength characteristics remain almost unchanged as compared to the initial state.

Unlike in laser method, in HLAW the growth of strength and impact toughness of weld metal by $30-40 \%$ as compared to the initial state of metal and the similar decrease (the same as in laser welding) of values of elongation are observed. Such regularities are characteristic for $v_{\mathrm{w}}=90 \mathrm{~m} / \mathrm{h}$. The increase in speed of hybrid welding of up to $110 \mathrm{~m} / \mathrm{h}$ results in decrease in strength and impact toughness to the level of values typical for $v_{\mathrm{w}}=72 \mathrm{~m} / \mathrm{h}$.

It was found in the process of carried out investigations of structural and phase changes in the weld and HAZ of $14 \mathrm{KhGN} 2 \mathrm{MDAFB}$ welded joints that with increase in speed of laser welding from 18 to $50 \mathrm{~m} / \mathrm{h}$ and in speed of HLAW from 72 to $90 \mathrm{~m} / \mathrm{h}$ the phase composition of weld metal is changed from bainitic (B) to bainiticmartensitic (B-M). For the base 14KhGN2MDAFB metal the bainitic-ferritic (BF) structure with grain size $D_{\mathrm{g}} \sim 5-24 \mu \mathrm{m}$ and microhardness $H V$ 2740-2850 $\mathrm{MPa}$ are characteristic. Using $\mathrm{CO}_{2}$-laser at low speeds of laser welding up to $18 \mathrm{~m} / \mathrm{h}$ the bainitic structure with $D_{\mathrm{g}} \sim 40-80 \times 150-400 \mu \mathrm{m}$ and microhardness $H V 2850-3510 \mathrm{MPa}$ is formed in the weld. The further increase in welding speed up to $50 \mathrm{~m} / \mathrm{h}$, as was shown by the present investigations using $\mathrm{Nd}$ :YAG laser, leads to the formation of M-B structure with the more uniform grains at coefficient of their shape $\chi=2-3$ and microhardness of up to $H V 4170 \mathrm{MPa}$ both in the weld, as well as in the HAZ metal. At the same time, according to the TEM data, the size of bainitic packets decreases in the overheat areas of HAZ by 1.5 times, and the width of laths in bainitic structures by 1.3-2 times. Such structural changes, apparently, lead to reduction in the values of ductility and impact toughness of weld metal in laser welding.

The use of HLAW process, as was already mentioned, results in increase of welding speeds and electrical parameters of arc component, which, in its turn, provides approximately the same heat input into the welded joint. The values of heat input of welding amounted to 2.4$2.9 \mathrm{~kJ} / \mathrm{cm}$, moreover, the parameters of the structure at different welding speeds were changed, which resulted in difference between the values of mechanical properties of the weld metal.

Thus, in HLAW at $v_{\mathrm{w}}=72 \mathrm{~m} / \mathrm{h}$ the phase composition of the weld and HAZ is bainitic (mostly the lower one), the gradients according to microhardness between the structural components are minimal at refinement of grain by approximately 3-4 times (Figure $3, a, b$ ). The in- 


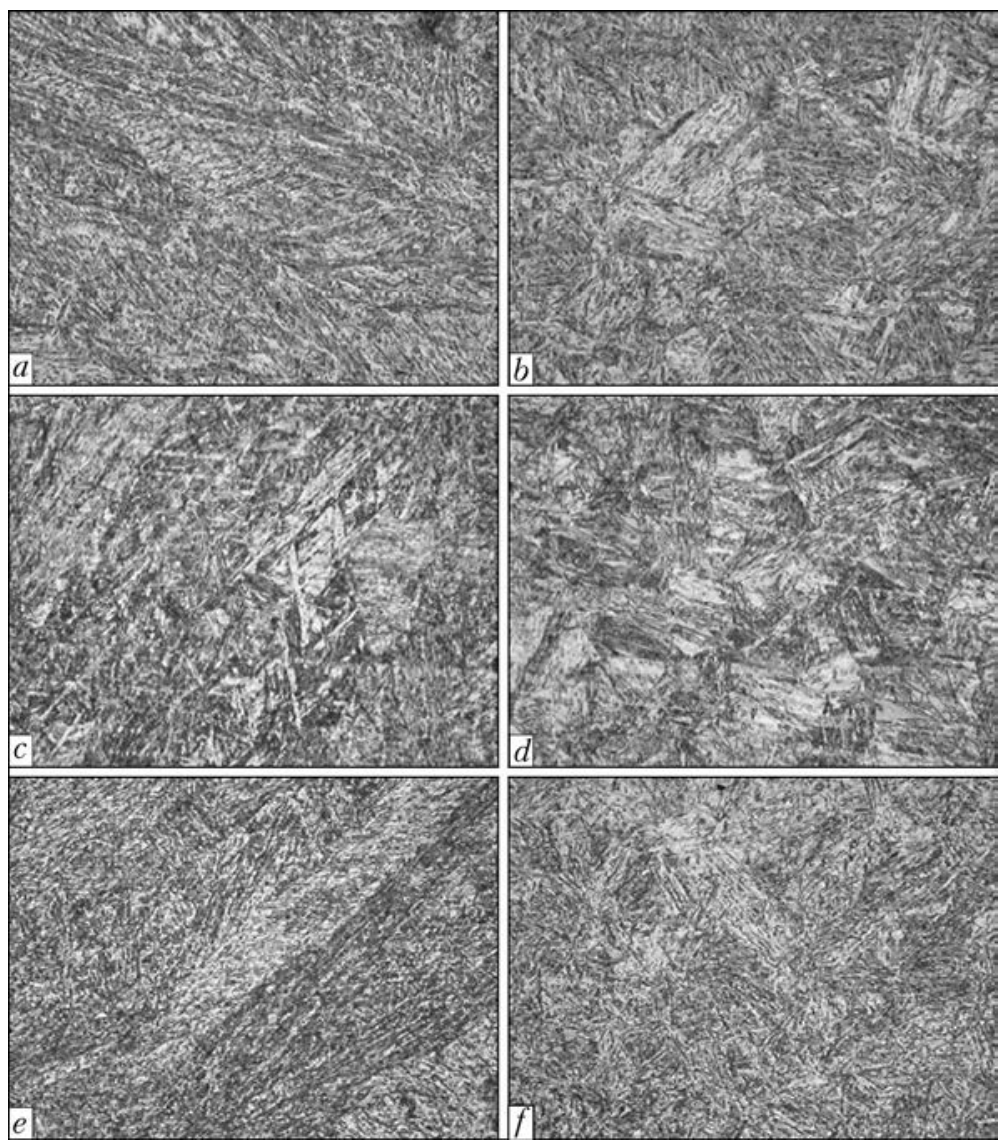

Figure 3. Microstructure $(\times 500)$ of weld and HAZ metal at different HLAW conditions: $a, c, e-$ weld; $b, d, f-$ HAZ; $a, b-v_{\mathrm{w}}=72 ; c, d-90 ; e, f-110 \mathrm{~m} / \mathrm{h}$

crease in welding speed up to $90 \mathrm{~m} / \mathrm{h}$ results in changing the phase composition at transition from the weld to HAZ from $\mathrm{B}-\mathrm{M}(\mathrm{M}>\mathrm{Bl}>\mathrm{Bu})$ in the weld to bainitic $(\mathrm{Bl}>\mathrm{Bu})$ in the HAZ (Figure 3, $c, d$ ). It causes increase in mechanical properties $\sigma_{0.2}, \sigma_{t}, K C V$ (see Table 2). In this case the martensitic component provides increment of strength characteristics, and the presence of lower bainite provides improvement of impact toughness. Apparently, such features of structure formation are caused by difference in behavior of the metal during cooling at $800-600{ }^{\circ} \mathrm{C}$. In hybrid welding at $v_{\mathrm{w}}=110 \mathrm{~m} / \mathrm{h}$ the phase composition at transition from the weld to $\mathrm{HAZ}$ is bainitic (Figure 3,e,f), moreover $\mathrm{Bl}<\mathrm{Bu}$, and gradients according to microhardness between the structural components both in the weld $(\triangle H V$ up to $310 \mathrm{MPa})$, as well as in the HAZ $(\Delta H V$ up to $510 \mathrm{MPa})$ are significant, which leads to reduction of strength and impact toughness of the weld metal (see Table 2).

As a result of carried out investigations on resistance to cold crack formation it was established that in arc welding of rigid butt joints of steel $14 \mathrm{KhGN} 2 \mathrm{MDAFB}$ with width of 100 and $200 \mathrm{~mm}$ at $v_{\mathrm{w}}=18 \mathrm{~m} / \mathrm{h}$, they damage the weld along the whole length and the whole cross-section. Under the given conditions of cooling of
HAZ metal at $w_{6 / 5}=20{ }^{\circ} \mathrm{C} / \mathrm{s}$ the unfavorable factors from the point of view of cold crack formation are the concentration of diffusion hydrogen in the deposited metal of up to 1.5$2.0 \mathrm{ml} / 100 \mathrm{~g}$, and the features of fine structure formation, being nonuniform according to grain size, the values of microhardness and dislocation density, varied from (2-3) $10^{10}$ to $10^{11} \mathrm{~cm}^{-2}$ and characterized by a nonuniform distribution. Such differences in the distribution of dislocations and their density result in the formation of essential microstresses in the metal that probably, has a negative affect on resistance of welded joints to cold crack formation.

As was shown by the experiments, the increase in resistance to cold crack formation in welded joints of steel $14 \mathrm{KhGN2MDAFB}$ is possible by increase in arc welding speed up to $50 \mathrm{~m} / \mathrm{h}$, at the same time reducing the heat input by $1.7-2.6$ times. The similar effect is achieved in laser welding at the same speed and in HLAW at $v_{\mathrm{w}}=72$, 90 and $110 \mathrm{~m} / \mathrm{h}$. Moreover, the content of diffusion hydrogen in the deposited metal decreases to $0.2-0.4 \mathrm{ml} / 100 \mathrm{~g}$, and in laser welding it decreases in the molten metal to $0.07 \mathrm{ml} / 100 \mathrm{~g}$. From the point of view of structure the dislocations are uniformly distributed in the volume of metal, and their density is within $(5-6) \cdot 10^{10} \mathrm{~cm}^{-2}$, more- 
over, due to the lower density of dislocations and their uniform distribution the microstresses are decreased in values.

Thus, the optimum way to provide the high mechanical properties and values of impact toughness of weld metal of joints of steel $14 \mathrm{KhGN} 2 \mathrm{MDAFB}$ is HLAW performed at $v_{\mathrm{w}}=$ $=90 \mathrm{~m} / \mathrm{h}$. The use of HLAW at the abovementioned conditions at $v_{\mathrm{w}}=72$ and $110 \mathrm{~m} / \mathrm{h}$ satisfies the conditions providing values of impact toughness at the level of $K C V_{-40}>30 \mathrm{~J} / \mathrm{cm}^{2}$.

\section{Conclusions}

As a result of carried out investigations the advantages and disadvantages of HLAW are shown as compared to laser and arc welding. Thus, it was established that the benefit of HLAW is the most economical efficiency at high technological values. In particular, despite the higher values of metallurgical and mechanical properties of welded joints of steel 14KhGN2MDAFB, HLAW provides a significant increase in welding speeds, at the same time maintaining a high level of properties of welded joints. Moreover, the use of the laser source in hybrid process allows significant reduction of diffusion hydrogen content and den- sity of dislocations in weld metal. The combinations of such characteristics are impossible to be achieved using only laser or arc welding.

1. Grigoriants, A.G., Shiganov, I.N., Chirkov, A.M. (2004) Hybrid technologies of laser welding: Manual. Moscow: N.E. Baumana MGTU.

2. Shelyagin, V.D., Khaskin, V.Yu., Garashchuk, V.P. et al. (2002) Hybrid $\mathrm{CO}_{2}$-laser and $\mathrm{CO}_{2}$ consumablearc welding. The Paton Welding J., 10, 35-37.

3. Kah, P., Salminen, A., Martikainen, J. (2010) Laserarc hybrid welding processes (Review). Ibid., 6, 32-40.

4. Shelyagin, V.D., Khaskin, V.Yu., Siora, A.V. et al. (2007) Gas-shielded laser and laser-arc welding of steels. Ibid., 1, 27-30.

5. Atabaki, M., Ma, J., Yang, G. et al. (2014) Hybrid laser /arc welding of advanced high-strength steel in different butt joint configurations. Materials and $D e-$ sign, 54, 573-587.

6. Unta, A., Lappalainena, E., Salminen, A. (2013) Autogenous laser and hybrid laser arc welding of Tjoint low alloy steel with fiber laser systems. Phys. Proc., 41, 140-143.

7. Sathiya, P., Mishra, M.K., Shanmugrarajan, B. (2012) Effect of shielding gases on microstructure and mechanical properties of super austenitic stainless steel by hybrid welding. Materials Design, 33, 203-215.

8. Musiyachenko, V.F., Mikhoduj, L.I. (1987) Arc welding of high-strength alloyed steels. Moscow: Mashinostroenie.

Received 01.07.2015 


\title{
INVESTIGATION OF STRUCTURE AND PROPERTIES OF THERMAL COATINGS OF WC-Co-Cr SYSTEM PRODUCED BY HIGH-VELOCITY METHODS OF SPRAYING
}

\author{
Yu.S. BORISOV, E.A. ASTAKHOV, A.P. MURASHOV, A.P. GRISHCHENKO, \\ N.V. VIGILYANSKAYA and M.V. KOLOMYTSEV \\ E.O. Paton Electric Welding Institute, NASU \\ 11 Bozhenko Str., 03680, Kiev, Ukraine. E-mail: office@paton.kiev.ua
}

\begin{abstract}
Spraying of coatings of $\mathrm{WC}-9 \mathrm{Co}-4 \mathrm{Cr}$ powder was performed by high-velocity procedures of thermal spraying, using the methods of detonation, supersonic air-gas plasma (SAGP) and oxy-fuel HVOF spraying. Microstructure and properties of produced coatings were investigated. Analysis of results of the coating structure examination showed that during spraying with these methods the dense coatings are formed, consisting of inclusions of tungsten carbide, uniformly distributed in $\mathrm{Co}-\mathrm{Cr}$ matrix. Porosity of coatings is less than $1 \%$. Microhardness of SAGP- and HVOF-sprayed coatings is 11.0-11.7 GPa. As to the values of microhardness these coatings are superior to those of the galvanic chromium (10 GPa). Microhardness of the detonation coating is $8.5 \mathrm{GPa}$. The cause of decrease in hardness of the detonation coating is a partial loss of carbon and appearance of oxide inclusions in it, that is caused by the oxidizing medium of the detonation products. By the complex of characteristics of hardness, adhesion strength (more than $50 \mathrm{MPa}$ ) and porosity the coatings of $\mathrm{WC}-9 \mathrm{Co}-4 \mathrm{Cr}$ system, sprayed by SAGP and HVOF methods, are advantageous as compared with the galvanic chrome-plating. Among the investigated methods of high-velocity thermal spraying of coatings of $\mathrm{WC}-9 \mathrm{Co}-4 \mathrm{Cr}$ system the SAGP method is characterized by the highest efficiency (15 kg/h). 16 Ref., 2 Tables, 2 Figures.
\end{abstract}

Keywords: thermal spraying, coating, galvanic chrome-plating, detonation spraying, supersonic air-gas plasma spraying, high-velocity oxy-fuel coating of WCCo-Cr system, microstructure, porosity, microhardness

The high-velocity methods of spraying allow widening greatly the possibility of traditional gasthermal spraying (GTS) of coatings used for protection of parts from wear and corrosion. Due to reducing the time of particles staying in the hightemperature flow and decreasing their overheating in high-velocity methods of GTS the oxidation of particles and, respectively, coating is reduced. At the same time, due to the high rate of particles the margin of their kinetic energy is increased, that leads to the increase in coating density and strength of coating adhesion with the base [1]. The typical peculiarities of coatings, produced by the high-velocity spraying, is a low porosity (less than $1.5 \%$ ) and retaining of chemical composition of the initial powder, as well as high strength of adhesion (more than 50$70 \mathrm{MPa}$ ). The gas-thermal high-velocity methods of coating producing include the methods of detonation, supersonic air-gas plasma (SAGP) and high-velocity oxy-fuel (HVOF) spraying. The rate of particles in spraying is up to $1000 \mathrm{~m} / \mathrm{s}$ at detonation spraying, $500-1000 \mathrm{~m} / \mathrm{s}$ at SAGP and up to $800 \mathrm{~m} / \mathrm{s}$ at HVOF spraying [2].

One of the most spread coatings in GTS is the coatings on the tungsten carbide base, which are widely used in different branches of industry for increase in resistance of parts against the wear and corrosion. High wear resistance of gas-thermal WC-Co coatings is provided by combination of $\mathrm{WC}$ as a hard component and Co as a ductile binder. In case of spraying of $\mathrm{WC}-\mathrm{Co}$ coatings the high-velocity methods are preferred in comparison with other GTS methods, as the higher rates and lower temperatures of the powder particles decrease the degree of $\mathrm{WC}$ decomposition, thus preventing the decrease in hardness and wear resistance [3]. For spraying, WC-Co powders are used with 6-17\% Co content, produced by different methods $[4,5]$. To increase the resistance of $\mathrm{WC}-\mathrm{Co}$ coatings against corrosion, $\mathrm{WC}-\mathrm{Co}$ powders are alloyed with chromium, as $\mathrm{Co}-\mathrm{Cr}$ matrix provides the high resistance against corrosion as compared with WC-Co materials. The chromium content in powders is 4$8 \%$ (WC-10Co-4Cr; WC-6Co-8Cr) [4]. Depending on powder composition, type of equipment and conditions of spraying, the microhard- 


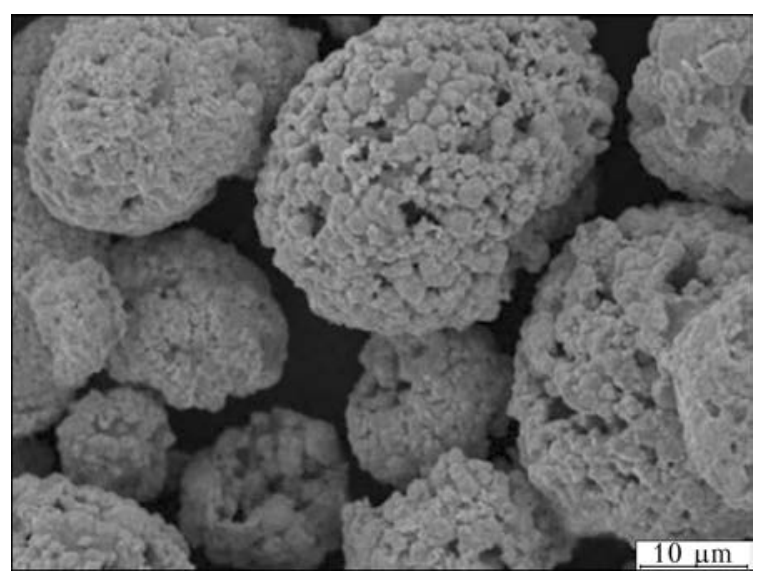

Figure 1. Appearance of $\mathrm{WC}-9 \mathrm{Co}-4 \mathrm{Cr}$ powder

ness of produced $\mathrm{WC}-\mathrm{Co}$ coatings is $6-12 \mathrm{GPa}$ at detonation spraying [6, 7], 10-15 $\mathrm{GPa}$ at SAGP [8, 9] and HVOF spraying [10, 11]. Porosity of these coatings, produced by high-velocity methods, usually does not exceed $1.5 \%$.

The high-velocity spraying of coatings on tungsten carbide base is one of the alternatives to the galvanic chrome-plating. Except such advantages as producing coatings, characterized by the resistance against wear, corrosion, erosion, GTS, unlike the technology of the chrome-plating, it is ecologically clean process, whereas hexivalent chromium, main element of electrolytes of chrome-plating, is a carcinogen, hazardous for health even at low concentrations [12]. $\mathrm{WC}^{-} \mathrm{Co}^{-}$ $\mathrm{Cr}$ coatings have a high hardness, low coefficient of friction, and their wear resistance, as compared with hard chromium, is 3-5 times higher [13]. $\mathrm{WC}-\mathrm{Co}-\mathrm{Cr}$ coatings are not inferior to hard chromium by the corrosion resistance due to presence of chromium [14, 15]. Thermal coatings of tungsten carbide as an alternative to the galvanic chrome-plating found the wide application in aircraft industry on parts of hydraulic drives and landing gears [16].

Table 1. Modes of spraying $\mathrm{WC}-9 \mathrm{Co}-4 \mathrm{Cr}$ coatings

\begin{tabular}{||l|c|c|c||}
\hline \multirow{2}{*}{$\begin{array}{c}\text { Consumption of working gas, } \\
\mathrm{m}^{3} / \mathrm{h}\end{array}$} & \multicolumn{3}{|c||}{ Spraying method } \\
\cline { 2 - 4 } & Detonation & SAGP & HVOF \\
\hline $\mathrm{C}_{3} \mathrm{H}_{8}$ & 0.42 & - & - \\
\hline $\mathrm{O}_{2}$ & 1.7 & - & 15 \\
\hline Air & 0.53 & 26 & 36 \\
\hline $\mathrm{CH}_{4}$ & - & - & 7.2 \\
\hline $\mathrm{N}_{2}$ & - & - & 0.18 \\
\hline $\mathrm{Current} \mathrm{A}$ & - & 220 & - \\
\hline Voltage, V & - & 350 & - \\
\hline Powder consumption, $\mathrm{kg} / \mathrm{h}$ & 0.65 & 15 & 0.78 \\
\hline Spraying distance, $\mathrm{mm}$ & 110 & 180 & 150 \\
\hline
\end{tabular}

The aim of the present work consisted in comparison of different high-velocity methods of spraying in producing of $\mathrm{WC}-\mathrm{Co}-\mathrm{Cr}$ coatings. Spraying was carried out by using detonation, SAGP and HVOF method.

Materials and procedure of investigations. For spraying the «Praxair» $\mathrm{WC}-\mathrm{Co}-\mathrm{Cr}$ powder (9 \% Co; 4 \% Cr; $5.2 \%$ C) (grade WC$731 / 1350 \mathrm{VF}$ ) was used produced by agglomeration with subsequent sintering. The powder particles predominantly have a spherical shape. Figure 1 shows the appearance of the powder.

The characteristics of powder $\mathrm{WC}-9 \mathrm{Co}-4 \mathrm{Cr}$ are the following: size of particles is $10-38 \mu \mathrm{m}$; fluidity is $18 \mathrm{~s}$; bulk density is $4.6 \mathrm{~g} / \mathrm{cm}^{3}$. The detonation spraying was carried out in installation Perun-S, SAGP - in installation Kiev-S, and HVOF - in installation HIPOTET 2700M. In Table 1 the parameters of spraying of the $\mathrm{WC}-$ $9 \mathrm{Co}-4 \mathrm{Cr}$ powder coatings are shown.

To carry out the metallographic examinations the coatings were sprayed on the specimens of steel St3, to determine the adhesive strength on the specimens of steel 30KhGSN2MA and titanium alloy VT22. The roughness of coatings after spraying was determined using the profilograph-profilometer. In carrying out the investigations on microstructure, microhardness and porosity of coatings the complex procedure was used, including metallography: optical microscope «Neophot-32» with the device for digital photography; for durometric analysis, durometer PMT-3 at load of $50 \mathrm{~g}$ was used. Measurements of microhardness were carried out across the whole section of coatings ( 50 measurements for each type of coating). The determination of porosity of the coatings was carried out by the analysis of images consisting in determination of the area of detected pores relatively to the whole area of the coating section. The manufacture of sections was carried out according to standard procedures.

Results of investigations. As a result of powder $\mathrm{WC}-9 \mathrm{Co}-4 \mathrm{Cr}$ spraying using high-velocity methods at the given modes, the coatings with a dense structure without cracks and fractures tightly adjacent to the base were produced. Figure 2 shows microstructure of the produced coatings $200-400 \mu \mathrm{m}$ thick.

Roughness $R_{a}$ of the sprayed coatings at detonation GTS method is 6.15, at SAGP -5.40 and at $\mathrm{HVOF}-6.75 \mu \mathrm{m}$.

The coatings produced using SAGP and HVOF methods have the same microstructure consisting of tungsten carbide particles uniformly distributed in $\mathrm{Co}^{-} \mathrm{Cr}$ matrix. The microhardness 


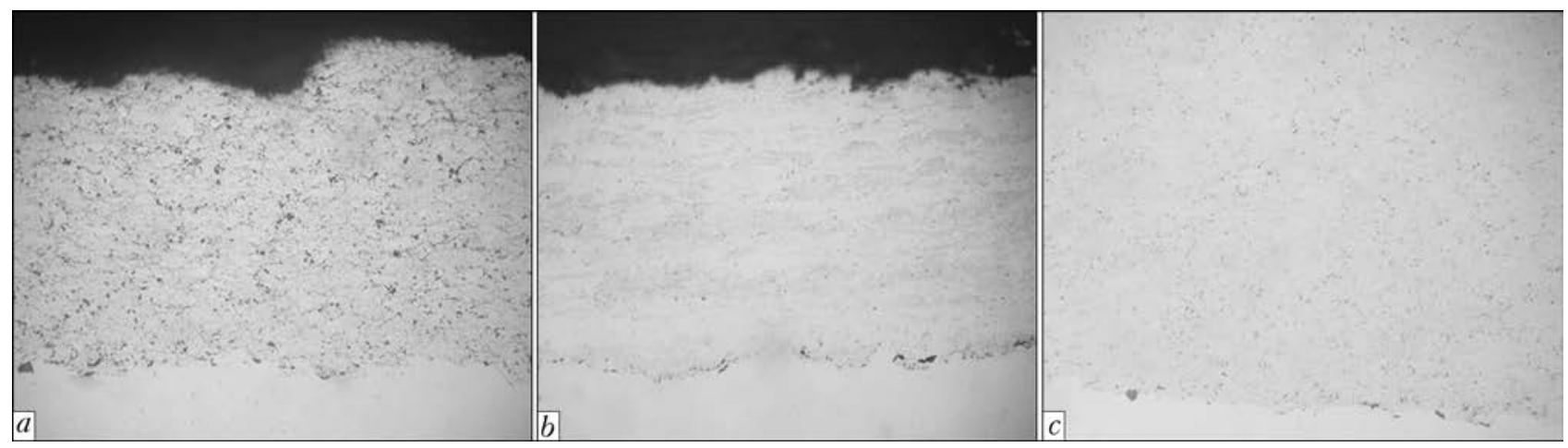

Figure 2. Microstructure $(\times 200)$ of $\mathrm{WC}-9 \mathrm{Co}-4 \mathrm{Cr}$ coatings produced using detonation $(a)$, SAGP $(b)$ and HVOF $(c)$ spraying

is $H V-0.0511 \pm 1.3 \mathrm{GPa}$ for HVOF-sprayed coatings and $H V 0.05$ is $11.7 \pm 1.7 \mathrm{GPa}$ for SAGPsprayed coatings. The porosity of coatings is less than $1 \%$.

The coating produced by detonation spraying has a lamellar structure composed of $\mathrm{Co}^{-} \mathrm{Cr}$ matrix, inclusions of tungsten carbide and oxide interlayers. The oxide content in the coating is about $5 \%$. The microhardness of the coating $H V 0.05$ is $8.5 \pm 1.2 \mathrm{GPa}$. The porosity of the coating is less than $1 \%$.

As is seen from the results, the microhardness of detonation coating is about $3 \mathrm{GPa}$ lower than that of the coatings produced by other methods due to application of oxidizing environment of detonation products of oxygen-propane-butane mixture during spraying, resulting in a more intensive interaction of WC with oxygen. This results in a partial loss of carbon and conversion of $\mathrm{WC}$ into $\mathrm{W}_{2} \mathrm{C}$, which has a lower hardness. The presence of oxides in the coating is also resulted by this.

The adhesion strength of coating $\mathrm{WC}^{-} 9 \mathrm{Co}^{-}$ $4 \mathrm{Cr}$, produced by HVOF method, was studied according to the adhesive method with testing on normal detachment of ISO 14916:1999 using adhesive VK-27 with tensile strength of $50 \mathrm{MPa}$. It was established that the adhesive strength of the coating of powder $\mathrm{WC}-9 \mathrm{Co}-4 \mathrm{Cr}$ with steel $30 \mathrm{KhGSN2MA}$ and titanium alloy VT-22 is more than $50 \mathrm{MPa}$ (in both cases the detachment occurred along the adhesive).

In Table 2 the summary results of the properties of coatings of $\mathrm{WC}-9 \mathrm{Co}-4 \mathrm{Cr}$ powder are shown produced by high-velocity spraying method. For comparison the properties of the coating of galvanic chromium are given.

\section{Conclusions}

1. Microstructure of $\mathrm{WC}-9 \mathrm{Co}-4 \mathrm{Cr}$ coatings produced using GTS high-velocity methods, represents the tungsten carbide particles uniformly distributed in $\mathrm{Co}-\mathrm{Cr}-$ matrix. The porosity of the
Table 2. Properties of coatings of $\mathrm{WC}-9 \mathrm{Co}-4 \mathrm{Cr}$, produced by high-velocity spraying method, and galvanic chromium coating

\begin{tabular}{||l|c|c|c||}
\hline \multicolumn{1}{|c|}{ Spraying method } & $\begin{array}{c}\text { Microhardness } \\
H V, \mathrm{GPa}\end{array}$ & Porosity, \% & $\begin{array}{c}\text { Adhesion } \\
\text { strength, } \\
\mathrm{MPa}\end{array}$ \\
\hline Detonation & $8.5 \pm 1.2$ & $<1$ & - \\
\hline Supersonic plasma & $11.7 \pm 1.7$ & $<1$ & - \\
\hline HVOF & $11 \pm 1.3$ & $<1$ & $>50$ \\
\hline Galvanic chrome-plating & $7.5 \pm 12$ & $3-20$ & $20-25$ \\
\hline
\end{tabular}

coatings is less than $1 \%$. In the structure of coating produced by detonation method the oxide interlayers are present (about $5 \%$ ).

2. Microhardness of $\mathrm{WC}-9 \mathrm{Co}-4 \mathrm{Cr}$ coatings produced by HVOF and SAGP method is 11.0$11.7 \mathrm{GPa}$; the microhardness of detonation coating is $8.5 \mathrm{GPa}$.

3. Decreased microhardness of detonation coating (approximately by $3 \mathrm{GPa}$ ) and presence of oxide interlayers in the microstructure are connected with the use of oxidizing environment of the detonation products of oxygen-propane-butane mixture during spraying, which leads to the development of oxidation processes of the sprayed material and, as a result, to partial loss of carbon and oxidation of matrix material.

4. Due to high hardness of $\mathrm{WC}-9 \mathrm{Co}-4 \mathrm{Cr}$ coatings produced using the HVOF and SAGP methods (11.0-11.7 GPa), in combination with a low porosity of less than $1 \%$, adhesion strength of more than $50 \mathrm{MPa}$ and environmentally friendly process of GTS technology, represent an alternative to the application of coatings, of galvanic chromium. Among the investigated GTS methods of $\mathrm{WC}-9 \mathrm{Co}-4 \mathrm{Cr}$ coatings SAGP spraying has the highest efficiency $(15 \mathrm{~kg} / \mathrm{h})$.

1. Borisov, Yu.S., Petrov, S.V. (1995) Application of supersonic jets in technology of thermal spraying. Avtomatich. Svarka, 1, 41-44.

2. Borisov, Yu.S., Kharlamov, Yu.A., Sidorenko, S.L. et al. (1987) Thermal coatings of powder materials: Refer. Book. Kiev: Naukova Dumka. 
3. Chivavibul, P., Watanabe, M., Kuroda, S. (2008) Development of WC-Co coatings deposited by warm spray process. J. Thermal Spray Technology, $17(5 / 6), 750-756$.

4. http:/ /www.tecnospray.net/download/HCST/ AMPERITBrochure.pdf AMPERIT Thermal Spray Powders

5. http://www.fisherproductsllc.com/pdf/Powder-Br ochure.pdf Praxair Surface Technology, Powder Technology Catalog

6. Shtertser, A.A., Smurov, I.Yu., Ulianitsky, V.Yu. et al. (2008) Comparative analysis of tribological properties of cermet detonation sprayed coatings. In: Proc. of ITSC (Maastricht, Netherlands, June 2-4, 2008), 125-131

7. Knapp, J.K., Nitta, H. (1997) Fine-particle slurry wear resistance of selected tungsten carbide thermal spray coatings. Tribology Int., 30(3), 225-234.

8. Du, L., Xub, B., Dong, S. (2008) Sliding wear behavior of the supersonic plasma sprayed $\mathrm{WC}-\mathrm{Co}$ coating in oil containing sand. Surface and Coatings Technology, 202(15), 3709-3714.

9. Ma, S., Li, C., Ye, X. (2005) Microstructure and properties of nanostructured WC/Co coating deposited by supersonic plasma spraying. In: Proc. of ITSC (Basel, Switzerland, 2-4 May, 2005), 794797.

10. Matthaeus, G., Brandl, W., Secosan, I.F. (2008) Standard HVOF process compared to the HVOF process for internal coating with fine powders. In: Proc. of ITSC (Maastricht, Netherlands, June 2-4, 2008), 473-476.

11. Kirsten, A., Oechsle, M., Moll, R.F. (2005) Carbide containing materials for hard chromium replacement by HVOF-spraying. In: Proc. of ITSC (Basel, Switzerland, 2-4 May, 2005), 957-962.

12. Legg, K.O., Graham, M., Chang, P. (1996) The replacement of electroplating. Surface and Coatings Technology, 81(1), 99-105.

13. Murthy, J.K.M., Venkataraman, B. (2006) Abrasive wear behavior of $\mathrm{WC}-\mathrm{Co}-\mathrm{Cr}$ and $\mathrm{Cr}_{3} \mathrm{C}_{2}-20(\mathrm{NiCr})$ deposited by HVOF and detonation spray processes. Ibid., 200(8), 2642-2652.

14. Bobzin, K., Kopp, N., Warda, T. (2013) Investigation and characterization of $\mathrm{HVOF} \mathrm{WC}-\mathrm{Co}^{-} \mathrm{Cr}$ coatings and comparison to galvanic hard chrome coatings. In: Proc. of ITSC (Busan, South Korea, May 13-15, 2013), 389-394.

15. Bolleli, G., Giovanardi, R., (2006) Corrosion resistance of HVOF sprayed coatings for hard chrome replacement. Corrosion Sci., 48(11), 3375-3397.

16. Peter, F. (2005) Ruggiero tungsten carbide coatings replace chromium. Advanced Materials and Processes, 7, 39-40.

Received 26.11.2015 


\title{
PECULIARITIES OF CONTACTLESS IGNITIONS OF ALTERNATING CURRENT ARC
}

\author{
N.M. MAKHLIN \\ SE Research Engineering Center of Welding and Control in Power Engineering \\ of E.O. Paton Electric Welding Institute, NASU \\ 11 Bozhenko Str., 03680, Kiev, Ukraine. E-mail: electro@paton.kiev.ua
}

\begin{abstract}
Considered are some important peculiarities of processes of contactless initial and repeated ignitions of alternating current arc in arc and plasma welding as well as electron voltage boosters. The latter generate the pulses of high and increased voltage being injected in inter-electrode gap for process realizing. It is shown that the most reasonable way for improvement of arc exciters and stabilizers is development of voltage boosters so called exciter-stabilizers. They differ by possibility to function in initial and repeated arc ignition modes, i.e. in the mode of stabilizing of alternating current arc burning. Optimized requirements on parameters of pulses generated by these devices are given based on multiple investigations, experience of development and application of voltage boosters. Some peculiarities of designing of combined arc exciter-stabilizers are considered. 32 Ref., 2 Tables.
\end{abstract}

Keywords: arc and plasma welding, alternating current, arc stability, glow and arc discharge, ignition voltage, electron arc exciter-stabilizers, energy, amplitude and duration of pulses

Advantages of alternating current (AC) welding, such as absence of magnetic blow, possibility of producing finer grain structure of weld metal and HAZ, simplicity, reliability and comparatively low price of welding power sources, provoked wide application of alternating current in manual coated-electrodes arc welding (MMA), in inert gases welding with non-consumable electrode (TIG) and other methods of arc and plasma welding. However, there are some disadvantages typical for AC welding. Low stability of arcing is the main. It is in particular characteristic for sine-wave welding current of industrial frequency. This is related with periodic arc extinctions due to de-ionization of inter-electrode gap, appearing at every change of arc current polarity. Therefore, researches on methods and means of increase of stability of AC welding arcs [1-9] have been carrying out for many decades.

Methods of increase of stability of burning of AC welding arcs can be conventionally divided on metallurgical and electrical.

Metallurgical methods are based on injection of elements with low ionization potential in the arc gap using electrode coating, welding wire, shielding medium and by other methods or via increase of thermionic current due to alloying of coated electrode rod or welding wire by elements with low electron work function [8, 10-13]. However, results of investigations and practice

(ㄷ) N.M. MAKHLIN, 2015 determined that possibility of increase of arcing process stability is limited by sufficiently narrow areas of welding modes.

Electrical methods of increase of AC arc stability in comparison with metallurgical ones are more available, varied and provide wider technological possibilities. Results of carried investigations $[5,6,8-10,14,15]$ showed that the following can be used for increase of $\mathrm{AC}$ arc stability:

- providing high rate of change of voltage and arc current in change of this current polarity;

- increase to 90-130 V of value of open-circuit voltage $U_{\text {op.cc }}$;

- using of free-burning pilot arc in TIG and plasma welding;

- application of pulse welding oscillators or generators of high-voltage pulses, amplitude value of output voltage of which makes from 3 to $10 \mathrm{kV}$ or generators of increased voltage pulses of $400-1000 \mathrm{~V}$ amplitude injected in the interelectrode gap at the moments corresponding to beginning of cathode formation on the part or at each change of welding current polarity.

Application of pulse voltage boosters [5, 6, $8-10,14-19]$ is the most widespread among the methods for increase AC arc stability due to low expenses and material consumption. There are number of developments and technical solutions. Nevertheless, problem of development of versatile solutions functioning in the mode of initial arc ignition as well as re-ignitions for arc burning stabilizing is still relevant.

Aim of the present work is study and generalisation of peculiarities of contactless initial ig- 
nition and re-ignitions of welding arc based on application of reference data and author's own experience and, taking into account peculiarities mentioned above, determination of requirements to high-voltage pulses and increased voltage pulses which should be generated by combined exciter-stabilizers.

Main peculiarities of initial arc ignition. The most widespread method for contactless initial $\mathrm{AC}$ arc ignition in the inter-electrode gap is its impact ionization by means of electric breakdown of this gap by high-voltage pulses.

There are Townsend and streamer-type breakdown mechanisms [3, 6, 8, 15, 20]. Breakdown of streamer-type takes place in the range of typical for arc and plasma welding values of $p d$ product (where $p$ is the gas pressure in the inter-electrode gap, and $d$ is the length of this gap). At that thin plasma channel, i.e. streamer, comes from anode to cathode. A streamer head has positive charge and intensifies field density close to the electrode at cathode approaching. This promotes for secondary electron emission. Due to this ohmic bridge is formed between electrodes of the gap, using which conduction electrons move from cathode to anode and provisions for appearance and development of spark discharge are created. The latter is a nonsteady discharge in gas, which is characterized by high temperature of plasma electrons in discharge channel and high level of gas ionization [6, 15, 20]. Formation of spark channel provides for step-wise increase of conductivity of the inter-electrode gap. Moreover, if welding source connected to this gap has sufficient power, electric spark can transform in stationary arc discharge with typical for it cathode and anode spots.

It is obvious that designing of the devices for initial arc ignition in arc and plasma welding requires taking into account the minimum necessary values of breakdown voltage of inter-elec-

Table 1. Approximation of values of breakdown voltage depending on gas content

\begin{tabular}{||l|c|c|}
\hline \multicolumn{1}{|c|}{ Gas content } & Breakdown voltage, V & $\begin{array}{c}\text { Length of gap between } \\
\text { welding electrodes, } \\
\text { mm }\end{array}$ \\
\hline Argon & $2400+150 d$ & $0.5-8.0$ \\
\hline \multirow{2}{*}{ Helium } & $3250+390 d$ & $0.5-8.0$ \\
\hline Nitrogen & $2940+920 d$ & $0.5-5.5$ \\
\cline { 2 - 4 } & $520+1360 d$ & $>5.5$ \\
\hline \multirow{2}{*}{ Carbon dioxide } & $3200+1200 d$ & $0.5-4.0$ \\
\cline { 2 - 4 } & $2400+1400 d$ & $>4.0$ \\
\hline \multirow{2}{*}{ Air } & $3050+1100 d$ & $0.5-4.5$ \\
\cline { 2 - 4 } & $1835+1370 d$ & $>4.5$ \\
\hline
\end{tabular}

trode gaps (ignition voltage of arc discharge). It should be noted that there is no rigid theory of arc discharge, explaining all complex of known factors [6, 8, 15, 20, 21]. In some important cases approximated theories $[6,15]$ can be used for description of mainly initial stage of arc discharge. One of which is based on Toepler hypothesis that conductivity of channel is proportional to charge passed though the gap, and the second grounds on Rompe and Weizel hypothesis. According to the latter all energy emitted in the channel is spent for increase of internal plasma energy and proportional to it channel conductivity.

Analytical calculation of values of breakdown voltage is significantly complicated since it requires experimental determination of values of several specific coefficients. For particular cases the results of work [15] can be considered as valid trial of analytical determination of breakdown voltage in the inter-electrode gaps in TIG or plasma welding. However, expressions given in [15] can be of minor applicability in engineer calculations. Practice of determination of necessary values of breakdown is based on data of experimental works, among which work [21] can be outlined. In it G.I. Leskov and V.P. Lugin made a conclusion that material of welding electrodes, composition of their coating and typical for welding rates of gas outflow do not effect breakdown voltage values under other things being equal. These researchers did not find any noticeable effect of pulse repetition rate (in the range from 100 to $3000 \mathrm{~Hz}$ ) and shape of highvoltage pulses being fed in the inter-electrode gap. It was determined that the main factors, determining value of breakdown voltage, are gas composition in the inter-electrode gap, its length and level of electric field inhomogeneity in the near-electrode areas. At that, the main molecular-kinetic gas characteristic, from which depends breakdown voltage, is section of electrons scattering on gas atoms and molecules.

The author based on results of works [21, 22] and own experiments has received the empiric expressions given in Table 1. They are used for determination of approximated averaged values of minimum necessary breakdown voltage in some gas media for technologically grounded gaps between welding electrodes and typical durations of high-voltage pulses.

Effect of breakdown pulse voltage on the inter-electrode gap provokes delay in charge formation [6, 15, 20], which mainly depends on concentration of gas particles in gap volume and exceed of applied pulse voltage in comparison with breakdown voltage in static field. This pre- 
determines the dependence (volt-second characteristic) of breakdown voltage on duration of pulse voltage, applied to the inter-electrode gap, at fixed breakdown possibility. If breakdown possibility makes $50 \%$ under conditions existing in plasma and arc welding, than volt-second characteristic can be represented as [6, 15]

$$
U_{\mathrm{br}}=\left(1+\sqrt[3]{\frac{a}{t_{\mathrm{p}} p d}}\right) U_{\mathrm{br.st}}
$$

where $a$ is the constant depending on type of gas in the inter-electrode gap; is the duration of voltage pulse applied to the inter-electrode gap; $U_{\text {br.st }}$ is the breakdown voltage in $t_{\mathrm{p}}$ uniform static field In real welding machines $t_{\mathrm{p}}$ usually does not exceed several milliseconds, and $U_{\text {br.st }}$ value can be determined using Cooper or Ritz data [20, 22].

If pulse voltage energy $W_{\mathrm{p}}$ applied to the inter-electrode gap is sufficient, than spark discharge takes place directly after gap breakdown, that, as was determined by B.Ya. Temkin [6, 15], is accompanied by significant rise of conductivity of the inter-electrode gap at its initial stage and its drop at final stage. Extinction of discharge or appearance of glow or arc discharge can take place at the end of spark discharge depending on conditions in the inter-electrode gap and characteristics of welding power source connected to it. The investigations showed that arc in the inter-electrode gap appears only when resistance of current conducting channel $R_{\mathrm{ch}}$ formed by spark discharge is less than some threshold value $R_{\mathrm{thr}}$. The latter depends on rate of power input from welding power source in the channel, voltage on gap $u(t)$ and other factors.

Values of pulse energy $W_{\mathrm{p}}$, providing arc ignition by spark discharge and received by us experimentally and approved by experience of application of voltage boosters, were recommended for different gas media and technologically grounded inter-electrode gaps. They make, J: $0.01-0.15$ for argon, $0.10-0.25$ for helium, $0.15-$ 0.40 for nitrogen, $0.30-0.50$ for carbon dioxide and for air.

Theory of AC arc ignition is not well developed. Alternating current of mainly industrial and close to it frequencies (from 50 to $200 \mathrm{~Hz}$ ) is used for arc and plasma welding, therefore, it can be assumed that $R_{\mathrm{ch}}<R_{\mathrm{thr}}$ condition is valid for the case of alternating current. Since arc discharge ignition mainly depends on voltage applied to the inter-electrode gap, than arc ignition pulse shall be injected in the inter-electrode gap close to $U_{\text {op.-c }}$ amplitude of arc power source. Multiple investigations found that start of generation of arc ignition pulse should make 75-
80 el. deg relatively to the moment corresponding to $U_{\text {op.-c }}$ value of arc supply source at sinewave of arc current. At that, condition of sufficiently high rate of increase of current of arc discharge should be fulfilled. Besides, conditions of emission from the electrodes are of high importance for performance of initial arc ignition. They can be very different for AC arc and depend on electrode material and on the fact whether the electrode is anode or cathode at the moment of arc ignition. This is in particular typical for TIG welding of aluminum and its alloys, in which arc ignition always takes place at time intervals when part being welded is the cathode.

Some peculiarities of re-ignitions of $\mathrm{AC}$ arc. Significant experience was accumulated as a result of multi-year extensive theoretical and experimental investigations generalized, for example, in [5, 6, 8-10, 23-25]. It allows explaining series of phenomena and peculiarities of $\mathrm{AC}$ arc as well as arc discharge stability.

Presence of pauses in arc discharge of the inter-electrode gap not far from current zero crossing value is typical peculiarity of $\mathrm{AC}$ welding arc. Temperature of gas in arc at the end of each current alternation before arc extinction and after it is significantly reduced and level of its ionizing, and, respectively, conductivity of gap considerably drops. At that, temperature of anode and cathode spots decline $[6,8,26]$. As a result of this after arc extinction at the end of previous alteration its repeated ignition in the beginning of the next period can take place at ignition voltage (peak) $U_{\mathrm{i}}$, value of which exceeds the value of arcing voltage $U_{\mathrm{a}}$. Analytical determination of $U_{\mathrm{i}}$ value is not possible up to the moment.

It was experimentally determined that $U_{\mathrm{i}}$ value is mainly determined by electrophysical properties of the electrodes and conditions in the inter-electrode gap. Besides, characteristics of processes in the inter-electrode gap, and, respectively, $U_{\mathrm{i}}$ values differ depending on electrode type. It was also determined that during the alternations, when welding electrode is the anode, $U_{\mathrm{i}}$ value in the most cases exceeds value of this voltage for alternations, in course of which the electrode is the cathode. The main factor determining $U_{\mathrm{i}}$ is the time of presence of residual plasma in the inter-electrode gap (time of plasma arc deionization $\left.t_{\text {deion }}\right)$ after arc discharge extinction not far from current zero crossing. It was experimentally proved that the lower potential of ionization of the inter-electrode gap and the higher $d t_{\mathrm{a}} / d t$ are, the longer $t_{\mathrm{deion}}$ and, respectively, lower $U_{\mathrm{i}}$ value will be. The same effect 
is achieved in the case of introduction of elements with low work function in the electrode composition. According to [10], $U_{\mathrm{i}}$ value makes 120 $165 \mathrm{~V}$ for electrodes of UONI-13/45 type at arc burning pauses not more than $2 \cdot 10^{-2} \mathrm{~s} . U_{\mathrm{i}}=40-$ $80 \mathrm{~V}$ for electrodes of OMM-5 and TsM-7 type containing easy-ionizing elements (potassium and sodium), and $U_{\mathrm{i}}>200-250 \mathrm{~V}$ for electrodes without coating at arc burning pauses not exceeding $1 \cdot 10^{-2} \mathrm{~s}$.

Peculiarities of processes taking place in the inter-electrode gap not far from current zero crossing in TIG welding become the most apparent in welding of parts from aluminum and its alloys. High values of $U_{\mathrm{i}}$ are typical for this case at transfer from straight polarity, when tungsten electrode is the cathode, to reversed one, at which part from aluminum or its alloy is the cathode, and $U_{\mathrm{i}}$ low value at transfer from reversed polarity to straight one. This phenomenon can have quality explanation by the fact that temperature of heated in pervious alternation non-consumable electrode does not have time for substantial changes at transfer from reversed polarity to straight one due to it low temperature conductivity and, thus, arc current appear even at very low values of voltage at the inter-electrode gap.

Transfer from straight polarity back to reversed one provides for the processes of another nature in the inter-electrode gap. Due to the fact that outer surface of the part from aluminum and its alloys being virtually always covered with oxide film, aluminum work function is rapidly reduced, and already at $60-80 \mathrm{~V}$ voltage at the inter-electrode gap provokes appearance of diffusion glow discharge. It is transferred in subnormal stage, and then in normal at further voltage recovery in the inter-electrode gap and rise of current through it. At that current rise takes place with constant voltage at normal stage of glow discharge.

This stage is also accompanied by cathode spraying that provokes local breaking of $\mathrm{Al}_{2} \mathrm{O}_{3}$ film and cleaning of weld pool from it. Further current growth through the inter-electrode gap promotes transfer of glow discharge in its abnormal stage. It is characterized by quick growth of voltage in the inter-electrode gap, achieving 220$240 \mathrm{~V}$ at $1 \mathrm{~A}$ current. Then, at further current growth, it is transferred in arc discharge with typical for it low burning voltage, which is 10-12 $\mathrm{V}$ more in comparison with values of arcing voltages at straight polarity alternations $[6,15,20]$.

Consideration of the peculiarities of processes taking place in the inter-electrode gap not far from current zero crossing in TIG welding shows that $U_{\mathrm{i}}$ value at change of polarity from straight to reversed one is determined by voltage peak in the inter-electrode gap at abnormal stage of glow discharge, proceeding to arc one. Taking this into account, $U_{\mathrm{i}}=240-250 \mathrm{~V}$ in the case of argon application as shielding gaps in TIG welding of parts from aluminum and its alloys, and $U_{\mathrm{i}}$ can make 300-350 V in the case of application of other gases in accordance with data given, for example, in [8, 20].

Since $U_{\text {op.-c }}$ of AC source should not exceed $80 \mathrm{~V}$ of effective value (113 V of amplitude value) according to the safety requirements in arc welding, than reliable repeated re-ignitions on practice can be provided only if easy-ionizing elements are present in the coating or electrode material. In all other cases stable arcing without taking special measures is impossible.

The most versatile and effective method for providing AC arc stability is short-time (pulse) increase of voltage in the inter-electrode gap at each change of polarity of current passing through this gap with the help of special devices. These devices are called arcing stabilizers and they represent itself increased voltage pulse generators, amplitude of which equals or exceed $U_{\mathrm{i}}$ value $[1,3,5,6,8,15-19,27]$. It was experimentally determined that duration of such pulses shall make $(0.05-0.10) \cdot 10^{-3} \mathrm{~s}$, and in separate cases $(0.2-1.0) \cdot 10^{-3} \mathrm{~s}$, for example, in consumable-electrode $\mathrm{CO}_{2}$ welding, depending on properties of welding power source and conditions in the inter-electrode gap. Energy $W_{\text {p.st }}$ of these pulses in all cases should provide transfer from abnormal glow discharge to arc one. Table 2 shows experimentally received by us and other researchers $[5,6,8,10] W_{\text {p.st }}$ values for pulses generated by arc burning stabilizers, which are recommended for different shielding media and technologically grounded inter-electrode gaps in welding of some metals and alloys.

Peculiarities of designing and ways of improvement of combined exciter-stabilizers. Structures of designing of special exciters and stabilizers of arcing are close between themselves, but these devices differ from each other by amplitude parameters of output pulses as well as algorithms and modes of work of their control assemblies.

Experience of application of arc exciters prove that all these devices fundamentally can provide effective stabilizing of burning process to the most AC welding arcs $[4,8,16,17,27]$. However, it requires significant enlargement of insulation of welding tool (for example, electrode 
Table 2. Value of pulse energy providing arc re-ignitions

\begin{tabular}{|c|c|c|c|}
\hline Material of part to be welded & Welding method & Gas composition or coating type & $W_{\text {p.st }}, \mathrm{J}$ \\
\hline \multirow[t]{5}{*}{ Low-carbon and alloyed steels } & \multirow[t]{2}{*}{ TIG } & Argon & $0.05-0.35$ \\
\hline & & Helium & $0.20-0.40$ \\
\hline & \multirow[t]{2}{*}{ MMA } & Lime fluorspar coating & $0.40-0.90$ \\
\hline & & Organic coating without iron powder & $0.20-0.35$ \\
\hline & MAG & Carbon dioxide & $0.60-1.20$ \\
\hline \multirow[t]{2}{*}{ Copper and copper-containing alloys } & \multirow[t]{6}{*}{ TIG } & Argon & $0.35-0.70$ \\
\hline & & Nitrogen & $0.50-1$ \\
\hline \multirow{2}{*}{$\begin{array}{l}\text { Non-ferrous metals and alloys } \\
\text { (except for cooper and aluminum) }\end{array}$} & & Argon & $0.25-0.50$ \\
\hline & & Helium & $0.35-0.65$ \\
\hline \multirow[t]{2}{*}{ Aluminum and its alloys } & & Argon & $0.45-0.90$ \\
\hline & & Helium & $0.50-1$ \\
\hline
\end{tabular}

holders for MMA) and welding circuit wires. More serious structural problems appear in the case of application of arc exciters for stabilizing the process of its burning in AC welding using MIG/MAG method. Besides, as shown above, energy of pulses necessary for arc burning stabilizing and injected in the inter-electrode gap exceeds energy necessary for initial arc ignition. Due to this, application of arc exciters for stabilizing of its burning requires to overstate the level of energy accumulated in the capacitive storages of generator of increased voltage pulses (GVP) of arc exciter. This provokes a necessity of increase of mass-dimension indices of these devices and their price.

Besides, application of arc exciters for stabilizing of $\mathrm{AC}$ arc burning demands complication of their control circuit due to differences of the moments of beginning of output pulse generation in exciters and stabilizers. For example, it was experimentally determined that pulse generated by arc exciter and injected in the inter-electrode gap at sine-wave welding current shall be generated at the moments corresponding to $75^{-}$ $80 \mathrm{el}$. deg phase relatively to zero wire moment of open-circuit voltage of arc power supply. At the same time, pulses stabilizing arc burning is good to be injected at the moments corresponding to $68-72$ el. deg phase $[4,6,8,10,15,27]$. It should be noted that application of arc exciters for stabilizing the process of its burning in TIG welding can promote accelerated erosion of nonconsumable electrode, thus providing rise of possibility of formation of defects in welded joint.

In order to provide arc re-ignitions the special burning stabilizers shall provide transfer from glow discharge in arc one via glow discharge abnormal stage at each shift of voltage polarity in the inter-electrode gap. For this the stabilizer pulses injected in the inter-electrode gap shall have sufficient energy and duration corresponding to peculiarities of arc re-ignitions as well as amplitude $U_{\text {st.p.m }}$, fulfilling $U_{\text {st.p.m }} \geq K_{c} U_{\text {ch }}$ condition, where $K_{c}=1.10-1.25$. As a rule, $U_{\text {st.p.m }}=$ $=400-600 \mathrm{~V}$, and in separate special models of arc burning stabilizers $U_{\text {st.p.m }}=700-950 \mathrm{~V}$.

The necessary condition for providing welding arc re-ignitions is correct selection of moment for injection of stabilizing pulse in the inter-electrode gap. For example, energy of pulse at it preliminary injection will be dissipated before appearance of glow discharge, due to what transfer of voltage via ignition peak will be virtually unrealizable.

Analysis of available reference data indicate that researchers do not have common opinion on a problem of selection of the moment of stabilizing pulse injection. It is an opinion of authors' of work [1] that the most appropriate moments for stabilizing pulse injection are the moments, when voltage in the inter-electrode gap after current zero crossing achieves $15-20 \mathrm{~V}$, and by opinion of author of work [28] it is 20-50 V value. The investigations, results of which are given in work [6], showed that stabilizing pulse shall be injected after formation of glow discharge in the inter-electrode gap, i.e. with some delay relatively to the moment of polarity change in the inter-electrode gap. Duration of this delay is determined by time of development of glow discharge, depends on current and rate of its change not far from zero values and on rate of voltage recovery in the inter-electrode gap. It makes from several microseconds to $200 \cdot 10^{-6} \mathrm{~s}$.

Delay of $(60-100) \cdot 10^{-6} \mathrm{~s}$ is usually achieved in arc stabilizers with the help of their control circuits. It provides for necessary delay of beginning of stabilizing pulse injection in the inter- 
electrode gap [4, 6, 10, 15 ] taking into account turning of switching key of stabilizer GVP. Repetition of stabilizing pulses injected in the interelectrode gap can equal the voltage frequency of supply mains or its double value, that is typical for most of arc burning stabilizers in MMA and TIG welding $[4,6,8,10]$.

One of the distinctive peculiarities of existing special arc burning stabilizers lies in the fact that output of their power circuit is as a rule connected directly to the inter-electrode gap, i.e. parallel to welding source output. The power circuit of such a stabilizer includes charging device, energy storage (mainly capacitive), current-limiting resistance or inductive element and discharge key (mainly thyristor). At that, capacitive storage can have parallel or series connection to charging device $[4,6,8]$.

Although such a connection of output of power circuit of the stabilizer is the simplest and cheapest one, however, it has significant disadvantage. Depending on nature, i.e. resistance or inductive, of current-limiting element, the discharge of stabilizer capacitive storage can be aperiodic or oscillating respectively. Electromagnetic processes, taking place in the circuit of discharge of stabilizer capacitive storage, are well studied and analyzed in series of works with the help of linear differential equations of the second order with non-zero initial conditions [5, 8, 29-31]. At that the assumptions were taken about full discharge (in each its cycle) of preliminary charged capacitive storage of stabilizer GVP and on invariance of conductivity of the inter-electrode gap during all discharge time. Analysis of solutions of known equations show that, first of all, discharge circuit Q-factor and current $i(t)$ in this circuit are proportional to conductivity of the inter-electrode gap. For the second, providing of necessary duration values of stabilizing pulse and amplitude of $i(t)$, making 60-100 A at capacitive storage charge voltage $U_{\mathrm{c} 0}=400-600 \mathrm{~V}$, requires that capacity of condensers of stabilizer capacitive storage shall be not less than several tens of microfarads. Parallel connection of stabilizer to the inter-electrode gap necessitates input or output transformer for galvanic separation with supply mains circuits [5, 8]. Besides, parallel connection of stabilizers significantly reduces its efficiency due to shunting effect of output impedance of welding power source or loss of higher frequencies (HF-filter) in a guard filter, preventing components of output circuits of welding source from effect of increased voltage pulses generated by stabilizer. Usually, HF-filter represents itself L inductance-capacitance section. It consists of se- ries arc high-frequency choke with coil calculated for passing of full arc current, and frequency condenser, which has parallel connection to welding power source output [6]. Significant disadvantage of parallel stabilizers with direct connection to the inter-electrode gap is fundamental impossibility of their application for contactless initial welding arc ignition.

Series arc exciters and stabilizers are more effective. They provide emission in the inter-electrode gap of almost all energy accumulated in forming circuits of their GVP (negligibly small part of this energy is dissipated in guard condenser, shunting output of welding source, and in welding circuit wires). Series connection of pulse voltage boosters in welding or auxiliary arc circuit has no need in HF-filter and application of guard condenser [6,15-17] is enough to prevent effect of pulses of high or increased voltage on welding or auxiliary power supply. Important advantage of series pulse voltage boosters is their characteristics from point of view of electromagnetic compatibility [16, 32].

Thus, consideration and analysis of indicated peculiarities of initial and repeated ignitions and special voltage boosters for realization of these processes show that development of combined exciter-stabilizers is possible under condition of series connection of these devices to arc circuit and improvement of circuit and design solutions of functional assemblies in their power circuit, in particular GVP, as well as algorithms of their control circuits.

\section{Conclusions}

1. Further theoretical and experimental investigations, in particular in the direction of nearelectrode phenomena, are necessary for more complete explanation of all collection of processes related with initial and repeated welding arc ignition, including $\mathrm{AC}$ arc.

2 . Results of consideration and generalization of peculiarities of contactless initial and repeated welding arc ignitions, received based on application of known reference data, theoretical and experimental works of different authors and own experience of development and use of means of these processes realizing, allowed determining the requirements for parameters of high-voltage pulses and pulses of increased voltage that shall be generated by combined exciter-stabilizers, as well as moments of beginning of injection of these pulses in the inter-electrode gap.

3. The main parameters of output high-voltage pulses generated by exciter-stabilizers shall have the following values in the mode of initial arc 
ignition depending on conditions in the interelectrode gap (its length, nature and gas pressure, shape and frequency of treatment of working tip of welding electrode and part to be welded), namely pulse energy from 0.01 to $0.50 \mathrm{~J}$, amplitude $3-10 \mathrm{kV}$, and duration (at the level of 0.05 of amplitude value) from 3 to $20 \mu$ s.

The values of main parameters of increased voltage pulses generated by exciter-stabilizers in the mode of AC arc stabilizing (at its re-ignitions) depending on degree of deionization and related with it reduction of conductivity of the interelectrode gap at each change of arc current polarity shall make from $0.2-1.0 \mathrm{~J}$ for pulse energy, from 400 to $950 \mathrm{~V}$ for amplitude, from 50 to $100 \mu$ s for duration (at the level of 0.05 of amplitude value), and in separate cases (for example, in consumable-electrode $\mathrm{CO}_{2}$ welding) from 0.2 to $1.0 \mu \mathrm{s}$.

4. Development of combined exciter-stabilizers is possible under condition that their designing provides for series connection of output circuits of these devices to welding or auxiliary arc circuit.

The author expresses his thanks to Engs A.G. Skirta and V.Yu. Buryak for valuable help in preparation of this work.

1. Paton, B.E., Zavadsky, V.A. (1956) Pulse arc ignition in gas-arc and manual arc welding. Avtomatich Svarka, 3, 26-35

2. Lauzhadis, A.I. (1967) Effect of current frequency on stability of arc and manual arc welding process. Ibid., 9, 29-32.

3. Leskov, G.I., Lugin, V.P. (1969) Alternating cur rent: Way to welding. Tula: Priok. Kn. Izd.

4. Troitsky, V.A. (1981) Method of smooth control of power sources containing longitudinal-capacitive compensation. Avtomatich. Svarka, 5, 8-12.

5. Dymenko, V.V. (1985) Increase in process stability and expansion of technological possibilities of alternating current consumable electrode welding: Syn. of Thesis for Cand. of Techn.-Sci. Degree. Kiev.

6. (1986) Equipment for arc welding: Refer. Book. Ed. by V.V. Smirnov. Leningrad: Energoatomizdat.

7. Pentegov, I.V., Dymenko, V.V., Rymar, S.V. (1995) Selection of open-circuit voltage in sources for alternating current manual arc welding. Avtomatich. Svarka, 5, 35-40.

8. Paton, B.E., Zaruba, I.I., Dymenko, V.V. et al. (2007) Welding sources with pulse stabilizing of arc burning. Kiev: Ekotekhnologiya.

9. Korotynsky, O.E. (2007) High-efficient power sources for arc welding based on inductance-capaci tive converters: Syn. of Thesis for Dr. of Techn. Sci. Degree. Kiev.

10. Leskov, G.I. (1970) Electric welding arc. Moscow: Mashinostroenie.
11. Morozkin, I.S. (2003) Control of welding arc ignition in mechanized modes of surfacing. Rostov-naDonu: RostGUPS.

12. Farson, D., Courardy, C., Talkington, J. et al. (1998) Arc initiation in gas metal arc welding. Welding Research Suppl., 8, 315-321.

13. Weinshenk, H.E., Schellhase, M. (1971) Wiederzundugscharakreristiken von Schweisslichtbogen mit abschmelzen der Elektrode. ZIS-Mitt., 13(12), 17061720 .

14. (1974) Technology of fusion electric arc welding of metals and alloys. Ed. by B.E. Paton. Moscow: Mashinostroenie.

15. Temkin, B.Ya. (1981) Theory and design of arc welding exciters: Syn. of Thesis for Cand. of Techn. Sci. Degree. Leningrad.

16. Dudko, D.A., Fedotenkov, V.G., Makhlin, N.M. (1980) Thyristor generators of current pulses of UPD-1 type. Avtomatich. Svarka, 6, 61-63.

17. Makhlin, N.M., Korotynsky, A.E. (2014) Analysis and procedure of calculation of series connection electronic devices for contactless arc excitation. The $\mathrm{Pa}^{-}$ ton Welding J., 1, 30-40.

18. Makhlin, N.M., Korotynsky, A.E. (2015) Asynchronous exciters and stabilizers of welding arc. Analysis and design procedure. Part 1. Ibid., 3/4, 24-35.

19. Makhlin, N.M., Korotynsky, A.E. (2015) Asynchronous exciters and stabilizers of arc. Analysis and calculation procedure. Part 2. Ibid., 7, 26-37.

20. Rajzer, Yu.P. (1987) Physics of gas discharge. Moscow: Nauka.

21. Leskov, G.I., Lugin, V.P. (1971) Investigation of electrical breakdown of gaps between welding electrodes. Svarochn. Proizvodstvo, 2, 10-11.

22. Mick, J., Kregs, J. (1960) Electrical breakdown in gases. Moscow: Inostr. Lit.

23. Paton, B.E., Lebedev, V.K. (1966) Electrical equipment for arc and slag welding. Moscow: Mashinostroenie.

24. Novikov, O.Ya. (1978) Stability of electric arc. Leningrad: Energiva.

25. Pokhodnya, I.K. (1967) Melting of electrode and interaction of metal with gases in arc welding: Syn. of Thesis for Dr. of Techn. Sci. Degree. Kiev.

26. Kirdo, I.V. (1956) About mechanism of re-ignition of welding arc. Avtomatich. Svarka, 6, 39-54.

27. Shmakov, E.I., Makhlin, N.M., Fedotenkov, V.G. et al. (1978) Application of alternating current for welding of low-alloy and alloy steels, aluminium and its alloys. Montazh. $i$ Spets. Raboty $v$ Stroitelstve, 4, 20-22.

28. Aldenhoff, B.J. Alternating current arc power source. Pat. 3328637 A1 USA. Int. Cl. B23K $9 / 06$. Publ. 27.06.1967.

29. (2008) Theoretical principles of electrical engineering: Refer. Book on theory of electric circuits. Ed. by Yu.A. Bychkov et al. St.-Petersburg: Piter.

30. Andrianov, A.A., Sidorets, V.N. (2009) Optimization of modes for stabilizing of alternating current welding arc. Elektrotekhnika $i$ Elektromekhanika, 2, 5-8.

31. Shcherba, A.A., Suprunovskaya, I.N. (2012) Principles of increase in rate of discharge currents rise in loading in limitation of their maximum values. Tekhnichna Elektrodynamika, 5, 3-9.

32. Makhlin, N.M., Fedotenkov, V.G., Livshits, D.M. et al. (1979) Suppression of radio interference generated by arc exciter of UPD-1 type. Avtomatich. Svarka, $12,55-57$

Received 13.05.2015 


\title{
MODERN COMPOSITE MATERIALS FOR SWITCHING AND WELDING EQUIPMENT. Information 1. POWDERED COMPOSITE MATERIALS
}

\author{
E.V. KHOMENKO, N.I. GRECHANYUK and V.Z. ZATOVSKY \\ I.M. Frantsevich Institute of Problems of Materials Science, NASU \\ 3 Krzhizhanovsky Str., 03142, Kiev, Ukraine. E-mail: homhelen@mail.ru
}

\begin{abstract}
The paper presents modern developments in the field of powdered composite materials of pseudoalloy type based on $\mathrm{Cu}(\mathrm{Ag})$ and refractory metals W ( $\mathrm{Mo}, \mathrm{Cr})$, used as electric contact materials and welding electrodes. Main requirements made of materials of arcing contacts and resistance welding electrodes are briefly described. Main data from world manufacturers on compositions and regulated characteristics of this material type are given, and main process schematics of their manufacturing are listed. Certain technological difficulties of producing nanodispersed composites are pointed out that slow down their production on an industrial scale. It is noted that application of mechanical alloying method during high-energy milling of powders allows producing copper, dispersion-strengthened by refractory oxides and carbides $\left(\mathrm{Al}_{2} \mathrm{O}_{3}\right.$, $\mathrm{TiO}_{2}, \mathrm{Cr}_{2} \mathrm{O}_{3}, \mathrm{SiO}_{2}$, etc.) with recrystallization temperature close to that of copper melting and higher level of electric conductivity, strength and oxidation resistance, compared to chromium and chromium-zirconium bronzes. 41 Ref., 5 Tables, 4 Figures.
\end{abstract}

Key words: copper-based powdered composite materials, switching and welding equipment

At present it is difficult to imagine an engineering field, not using composite materials. Their wide application area is due to high performance level, being greatly superior to that of metals and alloys, as well as a combination of high strength and stiffness, fatigue fracture resistance with high-temperature strength and wear resistance [1-3].

Powdered composite materials (PCM) of metal matrix type based on copper and silver, strengthened by particles of refractory metals and chemical compounds, have been the most widely accepted in switching and welding equipment. Owing to a unique combination of properties, metal-matrix $\mathrm{CM}$ are used as contacts and electrodes operating under the conditions of simultaneous impact of high temperatures, mechanical stresses, and impact loads in different gas media. Matrix provides a high level of heat- and electric conductivity, and refractory phase - high hardness, erosion, mechanical and thermal resistance. These systems belong to pseudoalloys, produced mostly by powder metallurgy methods. Pseudoalloy term is commonly understood as a heterogeneous system, represented by components, which do not interact or weakly interact with each other in a broad temperature range, thus preserving their individual properties in the mixture [4].

(c) E.V. KHOMENKO, N.I. GRECHANYUK and V.Z. ZATOVSKY, 2015
CM based on copper or silver and refractory metals of VIa group ( $\mathrm{Cr}, \mathrm{Mo}, \mathrm{W})$ have found application as arcing contacts for switching high (25 kA and higher) currents in high voltage networks (up to $570 \mathrm{kV}$ ) [5-8]. Arcing contacts are the most critical parts of switching devices, taking up the main impact of closing and opening electric arc [9-11]. For effective operation these contacts should have good heat- and electric conductivity, high melting and boiling temperatures, high values of electron work function and ionization potential, considerable fatigue strength and high-temperature oxidation resistance, low values of contact resistance, low solubility of gases and other properties [4, 10].

Metals with good conducting properties (Ag, $\mathrm{Cu}, \mathrm{Au}, \mathrm{Pt}$, etc.) are characterized by low melting and recrystallization temperatures, high susceptibility to welding, low strength and low thermal stability, resulting in their quite limited application. Such refractory metals, as W, Mo, Re, Ta, Cr, etc., featuring high mechanical characteristics, have insufficient heat and electric conductivity. Fusion of low-melting and refractory metals, usually, involves technological difficulties, associated with significant differences in their physico-chemical characteristics [12, 13]. Moreover, partial dissolution of elements in liquid and solid phases occurs at fusion that may lead to loss of their individual properties [14].

Production of powdered pseudoalloys is an example of effective application of powder metallurgy method, allowing regulation of material 


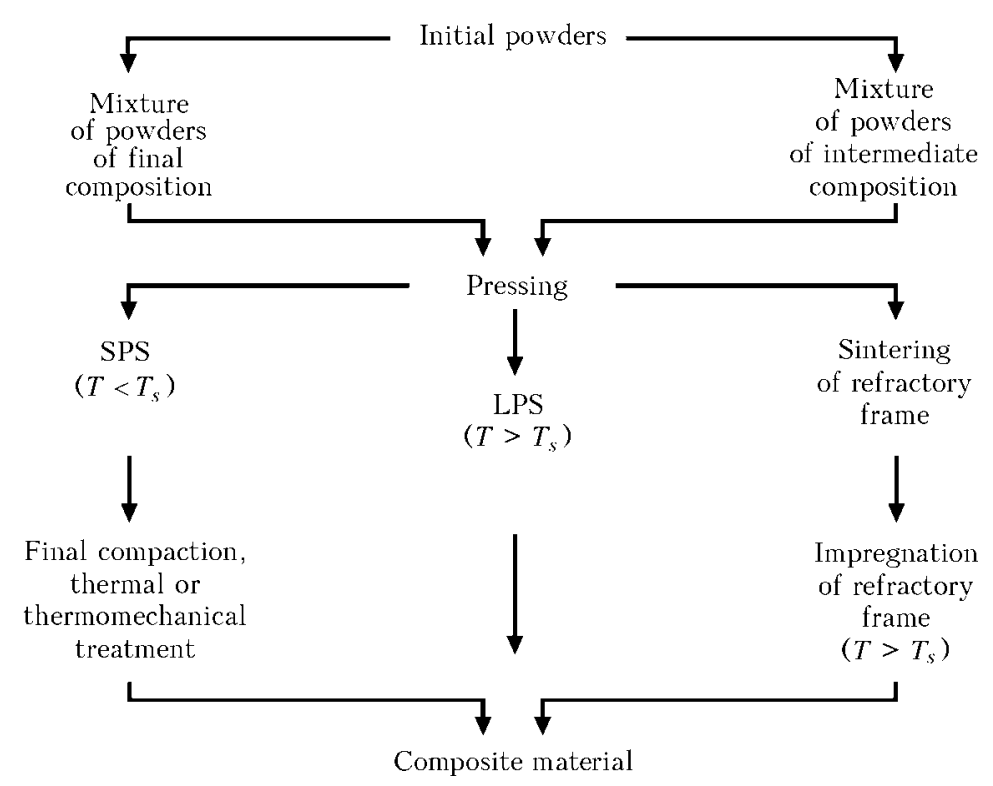

Figure 1. Technological schematic of producing Ag $(\mathrm{Cu})-\mathrm{W}(\mathrm{Mo}, \mathrm{Cr}) \mathrm{CM}\left(T_{s}-\right.$ low-melting phase melting temperature)

properties by quite cost-effective and relatively simple means, due to selection of initial raw material and technological manufacturing schematic.

Technology of producing these materials includes [1-17] the stages of powder mixing and pressing, subsequent heat treatment (sintering) and final compaction to achieve maximum density close to theoretical one (Figure 1).

Pre-compacted mechanical mixture of powders can be sintered in the solid state (SPS) or in the presence of the liquid phase (LPS).

SPS advantages consist in that composite composition is not limited by low-melting phase content. As a rule, however, maximum density cannot be achieved in one cycle, and deformational or thermodeformational treatment is required. LPS technology allows acceleration of the processes of component diffusion in the material and provides the possibility of its maximum compaction during sintering. Sintering atmosphere depends on item purpose, and, as a rule, is a reducing or degassing medium (hydrogen, vacuum). Such alloying additives as $\mathrm{Fe}, \mathrm{Co}, \mathrm{Ni}, \mathrm{Ti}, \mathrm{Zr}$, etc. (up to 1-3 wt.\%) are used to improve wetting of refractory phase surface by the liquid phase during LPS [4, 18, 19]. This technology limits liquid phase content (not more than 50 vol.\%) to prevent item shape loss. An optimum technological measure is impregnation by melts of $\mathrm{Al}$ $(\mathrm{Cu})$ or their alloys of refractory frame, formed with addition of low-melting component or without it (see Figure 1, on the right). This process does not require limitation of liquid phase volume, and provides the density, close to the theoretical one. Moreover, liquid phase excess at impregnation can be used as a transition conducting layer on the contact reverse surface for welding to the unit current-conducting components.

As regards CM, correlations are often found between contact performance and refinement of refractory phase particle size to micron and submicron dimensions [20-22]. In this connection, hot dynamic pressing is a promising technology of producing $\mathrm{Ag}(\mathrm{Cu})-\mathrm{W}(\mathrm{Mo}, \mathrm{Cr}) \mathrm{CM}$, at which mechanical mixture of powders of final composition is subjected to high-speed pressing and heat treatment in vacuum in one operation. Such combined treatment provides degassing of powders, preservation of their high dispersity, formation of highly-dense material of higher strength and hardness and satisfactory level of electric conductivity [23].

In production, $\mathrm{CM}$ technical characteristics are usually regulated as to their composition, density, specific electric resistance and hardness (Tables 1-3). Selection of material and technological production sequence is determined by contact service conditions. All the materials are characterized by a general tendency of increase of the characteristics of hardness and erosion resistance and lowering of heat- and electric conductivity with increase of refractory phase content. Nature of refractory filler and schematic of CM manufacturing also influence the nature of its property change.

Ag-WC CM are characterized by higher hardness and lower specific electric resistance, compared to $\mathrm{Ag}-\mathrm{W} \mathrm{CM}$ in a similar concentration range of matrix content. Here, the impregnation schematic provides high-density material with high values of hardness, heat- and electric conductivity, compared to materials produced by SPS schematic with final compaction (see Ta- 
INDUSTRIAL

Table 1. Main properties of $\mathrm{Ag}-\mathrm{W}, \mathrm{Ag}-\mathrm{WC}$ and $\mathrm{Ag}-\mathrm{Mo}$ composite materials (DODUCO materials [24])

\begin{tabular}{|c|c|c|c|c|c|}
\hline \multirow{2}{*}{ Material } & \multirow{2}{*}{ Ag content, wt. $\%$} & \multirow{2}{*}{ Density, $\mathrm{g} / \mathrm{cm}^{3}$} & \multicolumn{2}{|c|}{ Specific electric conductivity } & \multirow{2}{*}{ Hardness $H V 10$} \\
\hline & & & $\%$ IACS & $\mathrm{MSm}^{-1}$ & \\
\hline $\begin{array}{l}\text { AgW 50/50 } \\
\text { SIWODUR 50-1 }\end{array}$ & $48-52$ & $13.0-13.4$ & 45 & 26 & $120-140$ \\
\hline $\begin{array}{l}\text { AgW } 40 / 60 \\
\text { SIWODUR 60-1 }\end{array}$ & $38-42$ & $14.0-14.4$ & 41 & 24 & $140-160$ \\
\hline $\begin{array}{l}\text { AgW } 30 / 70 \\
\text { SIWODUR 70-1 }\end{array}$ & $28-32$ & $15.0-15.4$ & 34 & 20 & $160-190$ \\
\hline $\begin{array}{l}\text { AgW } 20 / 80 \\
\text { SIWODUR 80-1 }\end{array}$ & $18-22$ & $15.8-16.3$ & 31 & 18 & $180-230$ \\
\hline $\begin{array}{l}\text { AgWC } 60 / 40 \\
\text { SIWODUR C 40-1 }\end{array}$ & $58-62$ & $11.6-11.9$ & 41 & 24 & $130-160$ \\
\hline $\begin{array}{l}\text { AgWC 50/50 } \\
\text { SIWODUR C 50-1 }\end{array}$ & $48-52$ & $12.0-12.4$ & 38 & 22 & $140-170$ \\
\hline $\begin{array}{l}\text { AgWC } 40 / 60 \\
\text { SIWODUR C 60-1 }\end{array}$ & $38-42$ & $12.4-12.8$ & 36 & 21 & $150-180$ \\
\hline $\begin{array}{l}\text { AgWC 84/16C2 } \\
\text { SIWODUR C16/C2-2 }\end{array}$ & $80-84$ & 9.8 & 60 & 35 & 55 \\
\hline $\begin{array}{l}\text { AgWC } 73 / 27 \mathrm{C} 3 \\
\text { SIWODUR C16/C3-2 }\end{array}$ & $68-72$ & 9.6 & 36 & 21 & 50 \\
\hline $\begin{array}{l}\text { AgMo } 50 / 50 \\
\text { SILMODUR 50-1 }\end{array}$ & $48-52$ & $9.9-10.2$ & 34 & 20 & $120-140$ \\
\hline $\begin{array}{l}\text { AgMo } 40 / 60 \\
\text { SILMODUR 60-1 }\end{array}$ & $38-42$ & $9.9-10.2$ & 31 & 18 & $130-170$ \\
\hline $\begin{array}{l}\text { AgMo } 30 / 70 \\
\text { SILMODUR 70-1 }\end{array}$ & $28-32$ & $10.0-10.4$ & 29 & 17 & $140-180$ \\
\hline
\end{tabular}

ble 1). $\mathrm{W}-\mathrm{Cu} \mathrm{CM}$ are characterized by an essential improvement of strength properties at reduction of tungsten grain dimensions (see Table 2). Structure of $\mathrm{Ag}(\mathrm{Cu})-\mathrm{W}(\mathrm{Mo}, \mathrm{Cr})$ PCM is characterized by presence of two or more phases based on refractory and low-meting components with particles from submicron size up to $300-500 \mu \mathrm{m}$ (Figure 2). Depending on requirements to the level of heat- and electric conductivity, as well as erosion resistance and mechanical wear, $\mathrm{CM}$ can consist of conducting phase frame with refractory particles dispersed in it, or of refractory frame, the capillaries of which are filled with low-melting phase. Simultaneous existence of two interpenetrating frames of low-melting and refractory components is also possible.

Producing CM with ultradispersed particles of refractory phase involves technological difficulties, associated with the need for powder protection from oxidation, producing a uniform distribution of components in the mixture, preservation of specified dispersity of the structure and achievement of maximum possible density [2729]. This requires performance of preparatory

Table 2. Main properties of $\mathrm{W}-\mathrm{Cu}$ composite materials (Plansee Group materials [25])

\begin{tabular}{|c|c|c|c|c|c|c|c|c|}
\hline \multirow{2}{*}{ Material } & \multicolumn{2}{|c|}{ Composition, wt.\% } & \multirow{2}{*}{$\begin{array}{l}\text { Density, } \\
\mathrm{g} / \mathrm{cm}^{3}\end{array}$} & \multirow{2}{*}{$\begin{array}{c}\text { Electric } \\
\text { conductivity, } \\
\mathrm{MSm}^{-1}\end{array}$} & \multirow{2}{*}{$\begin{array}{c}\text { Hardness } \\
\text { HV30 }\end{array}$} & \multirow{2}{*}{$\begin{array}{c}\text { Compression } \\
\text { strength, } \mathrm{MPa}\end{array}$} & \multirow{2}{*}{ Melting resistance } & \multirow{2}{*}{ Grain size, $\mu \mathrm{m}$} \\
\hline & W & $\mathrm{Cu}$ & & & & & & \\
\hline $\mathrm{A} 15 \mathrm{Ni}$ & 85 & 15 & 15.7 & 17 & 205 & 250 & Excellent & Up to 50 \\
\hline $\mathrm{A} 20 \mathrm{Ni}$ & 80 & 20 & 15.2 & 18 & 200 & 200 & Very good & Up to 50 \\
\hline $\mathrm{A} 20 \mathrm{NiF}$ & 80 & 20 & 15.2 & 18.5 & 190 & 240 & Same & 2025 \\
\hline FG20 & 80 & 20 & 15.2 & 18.5 & 220 & 350 & Excellent & 48 \\
\hline $\mathrm{A} 25 \mathrm{NiF}$ & 75 & 25 & 14.5 & 21 & 190 & 160 & Good & 2025 \\
\hline $\mathrm{A} 30 \mathrm{Ni}$ & 70 & 30 & 14.0 & 23 & 135 & 60 & Same & Up to 50 \\
\hline
\end{tabular}


Table 3. Main properties of $\mathrm{Cr}-\mathrm{Cu}$ composite materials and qualitative evaluation of performance of arcing contacts from them (Plansee Group materials [26])

\begin{tabular}{|c|c|c|c|c|}
\hline \multirow{2}{*}{ Characteristic } & \multicolumn{4}{|c|}{ Material } \\
\hline & CC-98 & CC-75 & CC-70 & CC-57 \\
\hline Cr, wt.\% & 2 & 25 & 30 & 43 \\
\hline $\mathrm{Cu}$, wt. $\%$ & 98 & 75 & 70 & 57 \\
\hline O, wt.\% & 0.15 & 0.65 & 0.675 & 0.7 \\
\hline H, wt.\% & 0.005 & 0.005 & 0.005 & 0.01 \\
\hline $\mathrm{N}$, wt.\% & 0.015 & 0.1 & 0.105 & 0.11 \\
\hline Density, $\mathrm{g} / \mathrm{cm}^{3}$ & 8.70 & 8.05 & 7.90 & 7.60 \\
\hline Hardness $H V 30$ & $110(H B 2.5)$ & 70 & 75 & 85 \\
\hline Electric conductivity & Excellent & Excellent & Very good & Good \\
\hline Melting resistance & o & Very good & Excellent & Excellent \\
\hline Current interruption ability & o & Excellent & Same & Same \\
\hline Interrupt current & o & Good & Very good & $\gg$ \\
\hline Wear resistance & o & Same & Same & $\gg$ \\
\hline Welding resistance & o & Very good & 》 & » \\
\hline
\end{tabular}

technological operations, such as, for instance, refractory component cladding by interphase active elements to improve adhesion characteristics on matrix-refractory phase interphase [30], longtime high-energy milling with the purpose of mechanical alloying and producing composite pow-
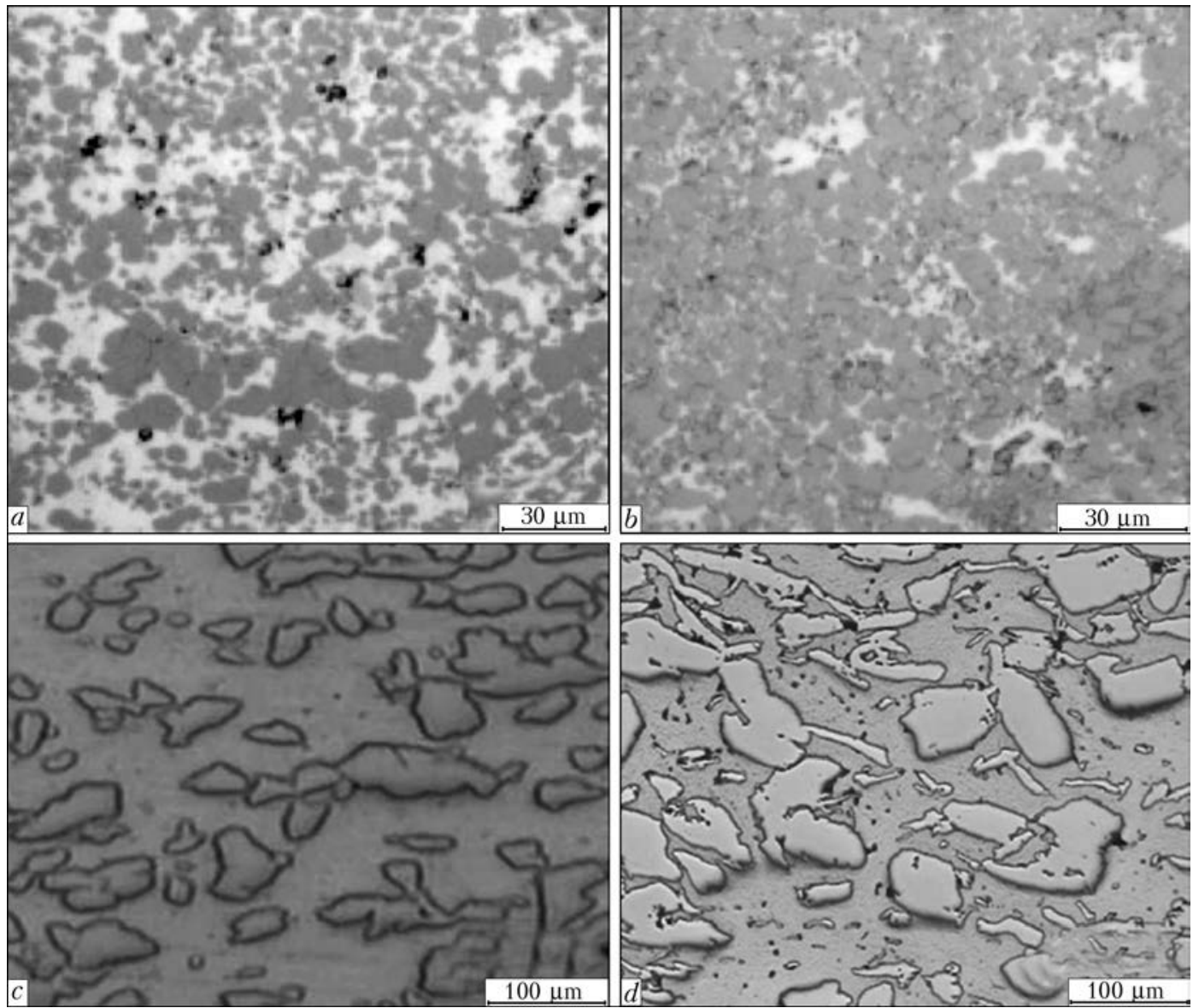

Figure 2. Typical microstructure of DUDUCO SIWODUR 75-1 (Ag/W 25/75) (a), SILMODUR 65 (Ag/Mo 35/65) $(b), \mathrm{CC}-75(\mathrm{Cu} / \mathrm{Cr} 75 / 25)(c)$ and CC-57 HMA $(\mathrm{Cu} / \mathrm{Cr} 57 / 43)(d)$ composite materials [24, 26] 


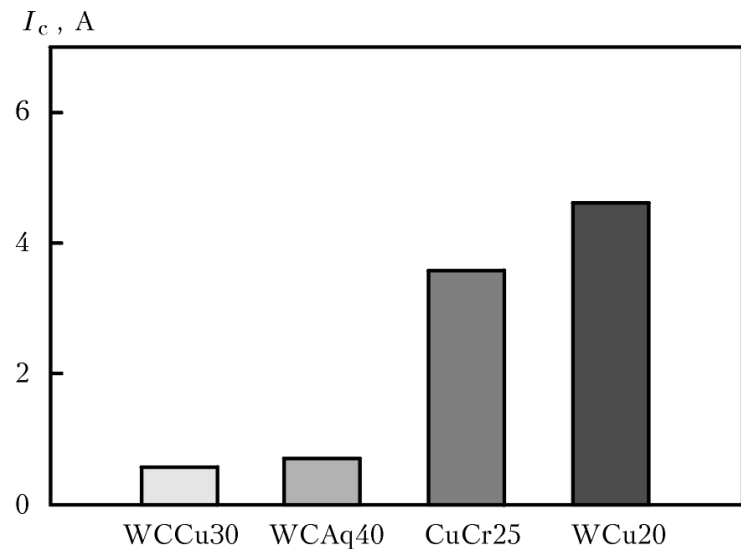

Figure 3. Cut-off current for different contact materials at testing $24 \mathrm{kA} / 24 \mathrm{kV}$ vacuum contactor at maximum current of $30 \mathrm{~A}$ [26]

ders of intermediate composition [31], simultaneous reduction of oxygen-containing compounds of refractory and low-melting components [32].

Selection of composition for contacts also allowed for specific requirements, arising from service conditions of contact-parts. In particular, to switch-off high currents in vacuum, the material of arcing contacts should have minimum content of gas-forming impurities, in particular, oxygen, nitrogen and hydrogen (see Table 3). By changing CM composition, emission properties of the contacts can be controlled, in order to ensure current cutting-off near zero value ( $\mathrm{Fi}$ gure 3).

The disadvantages of this CM class consist in that their machinability deteriorates with increase of refractory component content, and with increase of low-melting component content, the tendency to welding at short-circuiting currents becomes stronger. Moreover, the environments, in which arc extinguishing takes place, should be taken into account. So, at operation of $\mathrm{Ag}-\mathrm{W}$ contact in oxygen-containing environments silver tungstates $\left(\mathrm{Ag}_{2} \mathrm{WO}_{2}\right)$ form on their surface that increases the contact resistance [33]. In [34] it is shown that in the presence of weak electro-

Table 4. Technical characteristics of Elkonite composite materials of CMW Inc. (USA) [38]

\begin{tabular}{|c|c|c|c|c|c|c|}
\hline \multirow{2}{*}{ Elkonite materials } & \multirow{2}{*}{ Composition, wt.\% } & \multirow{2}{*}{ Density, $\mathrm{g} / \mathrm{cm}^{3}$} & \multicolumn{2}{|c|}{ Specific electric conductivity } & \multirow{2}{*}{$\begin{array}{l}\text { Ultimate bending } \\
\text { strength, MPa }\end{array}$} & \multirow{2}{*}{$\begin{array}{c}\text { Hardness } \\
\quad H R B\end{array}$} \\
\hline & & & $\%$ IACS & at $20^{\circ} \mathrm{C}, \mathrm{W} /(\mathrm{m} \cdot \mathrm{K})$ & & \\
\hline $\begin{array}{c}1 \mathrm{~W} 3 \\
3 \mathrm{~W} 3 \\
5 \mathrm{~W} 3 \\
10 \mathrm{~W} 3 \\
\text { 10W53 } \\
\text { 30W3 }\end{array}$ & $\begin{array}{l}55 \mathrm{~W} / 45 \mathrm{Cu} \\
68 \mathrm{~W} / 32 \mathrm{Cu} \\
70 \mathrm{~W} / 30 \mathrm{Cu} \\
75 \mathrm{~W} / 25 \mathrm{Cu} \\
75 \mathrm{~W} / 25 \mathrm{Cu} \\
80 \mathrm{~W} / 20 \mathrm{Cu}\end{array}$ & $\begin{array}{l}12.50 \\
13.93 \\
14.18 \\
14.84 \\
14.79 \\
15.56 \\
\end{array}$ & $\begin{array}{l}53 \\
50 \\
48 \\
43 \\
28 \\
41\end{array}$ & $\begin{array}{l}310 \\
280 \\
280 \\
260 \\
150 \\
250 \\
\end{array}$ & $\begin{array}{c}758 \\
896 \\
965 \\
1030 \\
1380 \\
1170 \\
\end{array}$ & $\begin{array}{c}77 \\
90 \\
95 \\
98 \\
109 \\
103 \\
\end{array}$ \\
\hline $\begin{array}{l}\text { TCS } \\
\text { TC10 } \\
\text { TC20 }\end{array}$ & $\begin{array}{l}50 \mathrm{WC} / 50 \mathrm{Cu} \\
56 \mathrm{WC} / 44 \mathrm{Cu} \\
70 \mathrm{WC} / 30 \mathrm{Cu}\end{array}$ & $\begin{array}{l}11.26 \\
11.64 \\
12.65\end{array}$ & $\begin{array}{l}45 \\
42 \\
30\end{array}$ & $\begin{array}{l}290 \\
280 \\
240\end{array}$ & $\begin{array}{l}1100 \\
1240 \\
1380\end{array}$ & $\begin{array}{c}94 \\
100 \\
H R C 37\end{array}$ \\
\hline
\end{tabular}

Table 5. Technical properties of Cu-based dispersion-strengthened composite materials of Discom-Welding (Russia) [40]

\begin{tabular}{|c|c|c|c|c|c|c|c|}
\hline \multirow{3}{*}{ Material characteristics } & \multicolumn{7}{|c|}{ Material type } \\
\hline & \multicolumn{2}{|c|}{$\mathrm{Cu}-\mathrm{Al}-\mathrm{C}-\mathrm{O}$} & \multicolumn{4}{|c|}{$\mathrm{Cu}-\mathrm{Ti}-\mathrm{C}-\mathrm{O}$} & \multirow{2}{*}{$\frac{\mathrm{Cu}-\mathrm{Al}-\mathrm{Ti}-\mathrm{C}-\mathrm{O}}{\mathrm{C} 16.404}$} \\
\hline & C16.101 & C16.106 & C16.201 & C16.202 & C16.204 & C16.205 & \\
\hline Density, $\mathrm{g} / \mathrm{cm}^{3}$ & 8.70 & 8.57 & 8.69 & 8.55 & 8.67 & 8.55 & 8.65 \\
\hline Hardness $H B 5 / 750 / 30$ & 185 & 140 & 159 & 147 & 218 & 228 & 193 \\
\hline Electric conductivity, \% IACS & 50 & 85 & 73 & 79 & 56 & 55 & 65 \\
\hline Heat conductivity, $\mathrm{W} /(\mathrm{m} \cdot \mathrm{K})$ & 185 & - & 302 & 305 & 265 & 230 & 271 \\
\hline Ultimate compressive strength, $\mathrm{MPa}$ & 1010 & 1410 & 1170 & 1040 & 1060 & 1070 & 955 \\
\hline Relative shrinkage to fracture, $\%$ & 36 & 59 & 45 & 42 & 27.5 & 26.5 & 30 \\
\hline $\begin{array}{l}\text { Ultimate tensile strength: } \\
\text { at } 20{ }^{\circ} \mathrm{C}\end{array}$ & 717 & 492 & 490 & 510 & 740 & 785 & 700 \\
\hline at $500{ }^{\circ} \mathrm{C}$ & 154 & - & 118 & 128 & 199 & 233 & 220 \\
\hline $\begin{array}{l}\text { Relative elongation, \%: } \\
\text { at } 20{ }^{\circ} \mathrm{C} \\
\end{array}$ & 8.7 & 15.0 & 17.0 & 10.2 & 8.7 & 6.5 & 10.9 \\
\hline at $500{ }^{\circ} \mathrm{C}$ & 5.2 & - & 3.2 & 6.5 & 5.1 & 4.0 & 7.3 \\
\hline Recrystallization temperature, ${ }^{\circ} \mathrm{C}$ & 930 & 870 & 930 & 880 & 960 & 970 & 940 \\
\hline
\end{tabular}


magnetic fields, arising, for instance, at opening of $\mathrm{Ag}-\mathrm{W}$ arcing contacts, formation of the socalled Taylor cones is observed on the tungsten surface, which increases the breakdown probability after arc re-striking. It is supposed that surface tension of liquid tungsten in an oxygencontaining environment can have a value lower by several orders of magnitude than that of tungsten in vacuum, as such experiments with other metals ( $\mathrm{Ta}, \mathrm{Mo}, \mathrm{Nb}, \mathrm{Cu}$ ) in air and with tungsten in vacuum did not reveal the presence of Taylor cones. Ag-Mo CM are characterized by a more stable contact resistance in air, compared to $\mathrm{Ag}-$ W CM, owing to the fact that molybdenum oxides are less stable, and the effect of working layer surface self-cleaning occurs during current switching.

In welding engineering $\mathrm{Cu}$-based $\mathrm{PCM}$ are a special material group, often used in flash-butt and resistance butt welding of mould inserts, in spot welding of ferrous metals and stainless steel, projection welding of casting moulds, etc. In the general case, welding electrodes should have high heat- and electric conductivity, good high-temperature strength, hardness and recrystallization temperature, as well as low susceptibility to mass transfer through electrode-part contact. Coldworked copper or its alloys with additives of $\mathrm{Cr}$, $\mathrm{Cd}, \mathrm{Ni}, \mathrm{Be}, \mathrm{Si}$, etc. (bronzes) often meet these requirements [35, 36].

However, in welding of low-deformable metals with low conductivity, different thickness, dissimilar or thick-walled materials, etc., there is a need for electrodes of higher hardness, strength and oxidation resistance in combination with relatively low electric conductivity $(\sim 75 \%$ of copper).

Combined electrodes are often used under such conditions, consisting of electrode-insert from refractory metal (W, Mo) or CM on its base, placed into a copper base with cooling system. Such a design provides an essentially longer service life, compared to solid copper electrodes. W (WC)$\mathrm{Cu} \mathrm{CM}$ with 55 wt.\% and greater content of refractory component are often used for welding electrodes. This type of $\mathrm{CM}$ are applied also as electrodes for electroerosive machining, and they are sometimes called by a general term of Elkonite [37, 38]. By varying the composition, it is possible to essentially increase CM strength, while preserving a high level of electric conductivity (Table 4).

A relatively new class for resistance welding electrodes are dispersion-strengthened materials based on powdered copper with dispersed in it refractory phase particles: oxides and carbides

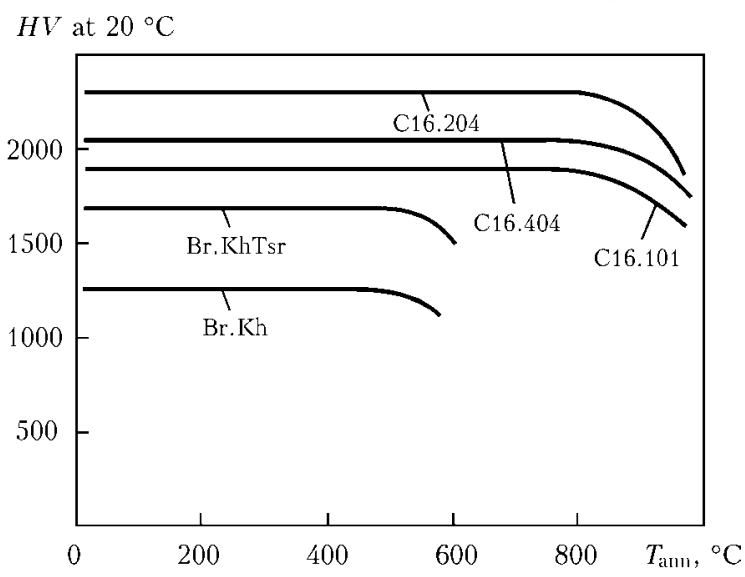

Figure 4. Change of hardness of various $\mathrm{Cu}$-based materials depending on annealing temperature [40]

$\left(\mathrm{Al}_{2} \mathrm{O}_{3}, \mathrm{TiO}_{2}, \mathrm{Cr}_{2} \mathrm{O}_{3}, \mathrm{SiO}_{2}, \mathrm{SiC}\right.$, etc.) [39-41]. Application of the method of high-energy powder milling with mechanical alloying of copper by oxides enabled producing CM with a high level of strength characteristics and recrystallization temperature, close to copper melting temperature (Table 5). Thermal stability and dispersity of oxides provides higher oxidation resistance of dispersion-strengthened CM, compared to $\mathrm{Cr}-$ and $\mathrm{Cr}-\mathrm{Zr}$ bronzes (Figure 4).

\section{Conclusions}

Powdered composite materials of metal-matrix type, based on copper with refractory filler, belong to the class of pseudoalloys and efficiently operate under the conditions of high temperatures, mechanical and electroerosive wear and impact of various media. Owing to uniqueness of their properties, these materials are used for production of arcing contacts of high-voltage switches and for manufacturing welding electrodes for resistance welding.

The main technological production schemes applying powder metallurgy methods include preliminary mixing of powders of initial components of intermediate or final composition with their subsequent sintering at temperatures below or above the melting temperature of low-meting component. Manufacture of nanodispersed CM of this class involves certain difficulties, arising from the need for protecting powders from oxidation, achieving a uniform distribution of components in the mixture, preserving the dispersed structure, and achieving maximum possible density.

A relatively new class for resistance welding electrodes are dispersion-strengthened materials based on powdered copper, containing dispersed oxides and carbides $\left(\mathrm{Al}_{2} \mathrm{O}_{3}, \mathrm{TiO}_{2}, \mathrm{Cr}_{2} \mathrm{O}_{3}, \mathrm{SiO}_{2}\right.$, $\mathrm{SiC}$, etc.), with increased level of strength and oxidation resistance. 
1. (1978) Composite materials. Vol.3: Application of composite materials in engineering. Moscow: Mashinostroenie.

2. Tuchinsky, L.I. (1986) Composite materials produced by impregnation method. Moscow: Metallurgiva.

3. (1990) Composite materials: Refer. Book. Ed. by V.V. Vasiliev, Yu.M. Tarnopolsky. Moscow: Mashinostroenie.

4. Gnesin, G.G., Dubok, V.A., Braterskaya, G.N. et al (1981) Sintered materials for electrical engineering and electronics: Refer. Book. Moscow: Metallurgiya.

5. Evdokunin, G.A., Tiler, G. (2000) Modern vacuum switching equipment of medium voltage. St.-Petersburg: M.P. Sizov Publ.

6. Vacuum switching equipment and components for medium voltage networks. Siemens. http: //w3.siemens.com / powerdistribution / global/SiteCollection Documents / en / mv /indoor-devices / vacuum-switchi ng-technology-and-components_ru.pdf

7. Slade, P.G. (1998) Electric contacts for power interruption: A review. In: Proc. of 19th Int. Conf. on Electric Contact Phenom. (Nuremberg, Germany, 1998), 239-245.

8. Contact materials for electrical engineering. Electrical contacts Wiki. http://www.electrical-contactswiki.com/index.php/Contact_Materials_for_Electri cal_Engineering

9. Bregel, T., Kraussvogt, W., Michal, R. et. al (1991) On the application of $\mathrm{W} / \mathrm{Cu}$ materials in the fields of power engineering and plasma technology. IEEE Transact. on Copmonents Hybrids and Manufact. Technology, 14, 8-13.

10. Namitokov, K.K. (1978) Electroerosion phenomena. Moscow: Energiya.

11. Minakova, R.V., Khomenko, E.V., Kopylova, G.E. et al. (2012) Secondary structure in working layer of electrical contacts from composite materials and their functional properties. In: Electrical contacts and electrodes, 38-47. Kiev: IPMS.

12. Livshits, B.G. (1980) Physical properties of metals and alloys. Moscow: Metallurgiya.

13. Fedorchenko, I.M., Frantsevich, I.N., Radomyselsky, I.D. (1985) Powder technology: Materials, technology, properties, fields of application: Refer. Book. Kiev: Naukova Dumka.

14. Zakharov, A.M. (1990) Constitutional diagrams of binary and ternary systems. Moscow: Metallurgiva.

15. Plansee Group. Fields of competence. Technologies http: / / www.plansee.com / en / About-us-Expertise-T echnology-118.htm

16. Hula, R.Ch., Edmaier, Ch. (2000) Silver coated tungsten carbide powders for composite electrical contact application. Powder Metallurgy Progress, 9(1) 34-41; http: / / www.imr.saske.sk / $\mathrm{pmp} /$ is sue/1-2009/PMP Vol09 No1 p034-041.pdf

17. Slade, P. (2007) The vacuum interrupter. Theory, design and application. London: Taylor and Francis Books.

18. Najdich, Yu.V. (1972) Contact phenomena in metal melts. Kiev: Naukova Dumka.

19. Avraamov, Yu.S., Shlyapin, A.D. (1999) Novel composite materials based on immiscible components. Producing, structure and properties. Moscow: MGU.

20. Smaga, N.N., Yudin, B.A., Markov, E.V. (1965) Method of producing and test results of fine-dispersed metal-ceramic compositions for contacts of electric apparatuses. In: Electrical metal-ceramic products. Moscow: VNIIEM

21. Kornienko, V.P., Yudin, B.A., Kolesnikov, V.N (1977) Fine-grained composite contacts for low-voltage equipment. In: Electrical contacts and electrodes, 70-79. Kiev: Naukova Dumka.
22. Rieder, W.F., Schussek, M., Glatzle, W. et al. (1989) The influence of composition and Cr-particle size of $\mathrm{Cu} / \mathrm{Cr}$ contacts on chopping current, contact resistance and breakdown voltage in vacuum interrupters. IEEE Transact. on Components Hybrids and Manufact. Techology, 12(2), 273-283.

23. Laptiev, A., Tolochyn, O., Khomenko, O. et al. (2014) Solid state impact sintering in vacuum of composites based on copper and silver. In: Proc. of 27th Conf. on Electrical Contacts (Dresden, Germany, June 22-26, 2014), 457-462.

24. Tungsten and molybden based materials. Powered by Doduco. http: www.electrical-contacts-wiki.com index.php/Tungsten_and_Molybdenum_Based_Mate rials

25. Plansee Group. http://www.plansee.com/ru/Products-Electrical-contacts-Tungsten-copper-WCu-58.htm

26. Plansee Group. http:/ www.plansee.com/ru/Products-Electrical-contacts-Copper-chromium-CuCr-59.htm

27. Najdich, Yu.V., Lavrinenko, I.A., Evdokimov, V.A. (1974) Study of compaction process in liquid-phase sintering under pressure in tungsten-copper system. Poroshk. Metallurgiya, 1, 34-39.

28. Panichkina, V.V., Sirotyuk, M.M., Skorokhod, V.V. (1982) Liquid-phase sintering of high-dispersed tungsten-copper mixtures. Ibid., 6, 27-31.

29. Grill, R., Klausler, P., Mueller, E.-H. et al. (2005) WC Ag contact materials with improved homogeneity. In: Proc. of 16th Int. Plansee Seminar (Reutte, Austria), 200-211.

30. Amirjan, M., Zangeneh-Madar, K., Parvin, N. (2009) Evaluation of microstructure and contiguity of $\mathrm{W} / \mathrm{Cu}$ composites prepared by coated tungsten powders. Refractory Metals and Hard Materials, 27, 729-733.

31. Dorfman, L.P., Scheithauer, M.J., Paliwal, M. et al. Alloy for electrical contacts and electrodes and method of making. Pat. US 6375708 B1. Publ. 23.04.2002

32. Moon-Hee Hong, Ja-Ho Choi, Seoung Lee et al. $W-$ $\mathrm{Cu}$ alloy having homogeneous micro-structure and manufacturing method thereof. Pat. US 7172725 B2. Publ. 6.02.2007.

33. Wingert, P.S. (1993) The effect of Ni on the switching performance of AgW based on contacts. In: Proc. of 39th IEEE Holm Conf., 111-115.

34. Batrakov, A.V., Popov, S.A., Proskurovsky, D.I. (1996) Electrodynamic phenomena in exploding tungsten electrical contacts. In: Proc. of $42 n d$ IEEE Holm Conf., 129-136.

35. Gulyaev, A.I. (1985) Technology and equipment for resistance welding. Moscow: Mashinostroenie.

36. (1986) Technology and equipment of resistance welding. Moscow: Mashinostroenie.

37. Toshiba materials Co Ltd. Elkonite. http:/ / www. toshiba-tmat.co.jp/eng/list/ta elc.htm

38. Contacts metals welding. Typical properties of Elkonite materials. http://www.tjsnow.com/supplies/ $\mathrm{cmw} / \mathrm{w} 49 \mathrm{f}$.pdf

39. Kos, M., Fercec, J., Bruncko, M. et al. (2014) Pressing of partially oxide-dispersion-strengthened copper using the ECAP process. Mater. and Technology, 48, Issue 3, 370-384.

40. Discom-welding. Nanostructural materials and their products. http: / discom-svarka.ru/dukm

41. Anoshin, V.A., Ilyushenko, V.M., Minakova, R.V. (2010) Heat-resistant materials based on copper. Method of producing. Properties. Applications. In: Transact. of IPMS, 212-218.

Received 27.04.2015 


\title{
INFLUENCE OF ABRASIVE MASS FRACTIONAL COMPOSITION ON DEPOSITED METAL WEAR RESISTANCE
}

\author{
V.V. PEREMITKO ${ }^{1}$ and V.D. KUZNETSOV ${ }^{2}$ \\ ${ }^{1}$ Dneprodzerzhinsk State Technical University \\ 2 Dneprostroevskaya Str., 51918, Dneprodzerzhinsk, Ukraine. E-mail: welding@dstu.ua \\ ${ }^{2}$ NTUU «Kiev Polytechnic Institute» \\ 37 Pobeda Ave., 03056, Kiev, Ukraine
}

\begin{abstract}
Abrasive wear of samples, surfaced with Sv-08G2S and Np-65 solid wires, using a mixture of fused and alloying agglomerated fluxes was studied. It is shown that selection of metal composition for surfacing parts of machines operating under abrasive wear conditions should be performed allowing for granulometric composition of abrasive medium. Values of optimum chemical and phase composition of metal recommended for surfacing parts of this type are given. Hardness values and ratios of its values for two contacting processed surfaces of parts have been determined, which allow part service life to be extended under the condition of allowing for abrasive granulometric composition. 7 Ref., 2 Tables, 4 Figures.
\end{abstract}

Keywords: arc surfacing, deposited metal, phase composition, abrasive wear, abrasive granulometric composition, wear resistance

Many parts of road-construction and agricultural machinery fail as a result of abrasive wear. One of the important factors in this process is wearing ability of treated soils, technological mixtures, etc. The above characteristic is determined by hardness, dimensions and shape of abrasive, degree of fastening of its particles, the hardness and shape of which determine the nature of fracture of surface layer of parts - microcutting or fatigue fracture as a result of multiple redeformation [1, 2].

General principles of alloying deposited metal, designed for restoration and hardening of parts operating under the conditions of different types of abrasive wear, have been quite completely formulated [3-6]. It should be noted, however, that these studies practically did not give any attention to the problem of influence of abrasive mass fractional composition on surfaced part wear resistance. Therefore, the objective of this work was investigation of the influence of abrasive fractional composition on deposited metal wear resistance.

Welding wire Sv-08G2S (GOST 2246-70) and surfacing wire Np-65 (GOST 10543-75), fused flux AN-348A and agglomerated alloying fluxes ANK-18 and ANK-19 were used in the investigations. Metal, deposited with low-carbon wire Sv-08G2S and ANK-18 flux, has chemical composition corresponding to steel 30Kh3G1,

(C) V.V. PEREMITKO and V.D. KUZNETSOV, 2015 and that deposited with ANK-19 flux has the composition of steel 60Kh4GS [7].

Test samples were cut out of surfaced cylindrical hollow billet $200 \mathrm{~mm}$ long (outer diameter of 36 , inner diameter of $16 \mathrm{~mm}$ ). Billets were surfaced in 3-4 layers up to achievement of billet outer diameter of $50 \mathrm{~mm}$. Modes of sample surfacing using flux mixture were as follows: $1.2 \mathrm{~mm}$ wire diameter; 160-180 A current; 27$28 \mathrm{~V}$ voltage; surfacing pitch of $3 \mathrm{~mm}$; surfacing speed of $24-33$ and $27-38 \mathrm{~m} / \mathrm{h}$.

Rollers of $10 \mathrm{~mm}$ thickness were cut out of surfaced billets. The roller outer processed surface was polished up to $45 \mathrm{~mm}$ diameter. Data on composition of deposited layers and their hardness are given in Table 1.

Wear resistance investigations were conducted by roller-roller schematic in MI-1M machine. Roller press-down force was $1 \mathrm{kN}$, roller rotation speed was approximately $200 \mathrm{rpm}$, duration of one test was $2 \mathrm{~h}$. Abrasive was quartz sand, which was fed through skeep into the gap between the rollers in fractions of different granulometric composition, with the ability to adjust the sand flow rate. Samples were weighed before and after testing in laboratory scales with $0.0001 \mathrm{~g}$ accuracy. Data on sample testing for wear with and without the abrasive are given in Table 2. It is found that wear of rollers surfaced with Sv-08G2S wire at testing without abrasive changes from 0.013 (experiment 4, upper roller) to $0.053 \mathrm{~g}$ (experiment 1, lower roller).

At application of Np-65 wire, roller wear decreases even more significantly at increase of 
INDUSTRIAL

Table 1. Deposited metal characteristics

\begin{tabular}{|c|c|c|c|c|c|c|c|c|}
\hline \multirow{2}{*}{$\begin{array}{c}\text { Exp. } \\
\text { number }\end{array}$} & \multirow{2}{*}{ Wire grade } & \multirow{2}{*}{ Flux, flux mixture } & \multicolumn{5}{|c|}{ Deposited metal chemical composition, wt.\% } & \multirow{2}{*}{$H B$} \\
\hline & & & $\mathrm{C}$ & $\mathrm{Mn}$ & $\mathrm{Si}$ & $\mathrm{Cr}$ & $\mathrm{Ni}$ & \\
\hline 1 & \multirow[t]{5}{*}{ Sv-08G2S } & AN-348A & 0.06 & 2.11 & 0.93 & 0.04 & 0.07 & 170 \\
\hline 2 & & AN-348A $+25 \%$ of ANK- 18 & 0.12 & 2.37 & 0.77 & 0.70 & 0.13 & 220 \\
\hline 3 & & AN-348A $+50 \%$ of ANK-18 & 0.17 & 2.35 & 0.63 & 1.49 & 0.09 & 283 \\
\hline 4 & & AN-348A $+75 \%$ of ANK- 18 & 0.22 & 3.14 & 0.60 & 1.57 & 0.13 & 367 \\
\hline 5 & & ANK-18 & 0.37 & 2.88 & 0.39 & 3.18 & 0.11 & 409 \\
\hline 6 & \multirow[t]{5}{*}{$\mathrm{Np}-65$} & AN-348A & 0.34 & 1.22 & 0.59 & 0.05 & 0.08 & 230 \\
\hline 7 & & AN-348A $+25 \%$ of ANK- 18 & 0.29 & 2.04 & 0.48 & 0.98 & 0.07 & 245 \\
\hline 8 & & AN-348A $+50 \%$ of ANK- 18 & 0.29 & 1.87 & 0.37 & 1.19 & 0.07 & 332 \\
\hline 9 & & AN-348A $+75 \%$ of ANK- 18 & 0.43 & 2.09 & 0.28 & 1.57 & 0.12 & 417 \\
\hline 10 & & ANK-18 & 0.63 & 1.20 & 0.29 & 2.57 & 0.08 & 547 \\
\hline
\end{tabular}

Table 2. Surfaced sample mass loss after wear testing

\begin{tabular}{|c|c|c|c|c|c|c|c|c|c|c|}
\hline \multirow{3}{*}{$\begin{array}{l}\text { Exp. } \\
\text { number }\end{array}$} & \multicolumn{10}{|c|}{ Roller wear, $\mathrm{g}$, depending on abrasive fraction, $\mathrm{mm}$} \\
\hline & \multicolumn{2}{|c|}{ Without abrasive } & \multicolumn{2}{|c|}{0.315} & \multicolumn{2}{|c|}{0.4} & \multicolumn{2}{|c|}{0.63} & \multicolumn{2}{|c|}{1} \\
\hline & Lower roller & Upper roller & Lower roller & Upper roller & Lower roller & Upper roller & Lower roller & Upper roller & Lower roller & Upper roller \\
\hline 1 & 0.053 & 0.010 & 0.340 & 0.728 & 0.674 & 0.621 & 1.577 & 2.349 & 0.344 & 0.318 \\
\hline 2 & 0.043 & 0.048 & 0.470 & 0.780 & 1.025 & 0.971 & 0.227 & 0.167 & 0.230 & 0.284 \\
\hline 3 & 0.035 & 0.071 & 0.174 & 0.145 & 0.953 & 0.801 & 0.762 & 0.837 & 0.134 & 0.136 \\
\hline 4 & 0.021 & 0.013 & 0.143 & 0.103 & 0.678 & 0.590 & 0.735 & 0.701 & 0.219 & 0.146 \\
\hline 5 & 0.023 & 0.024 & Spallation & Spallation & Spallation & Spallation & Spallation & Spallation & Spallation & Spallation \\
\hline 6 & 0.006 & 0.010 & 1.078 & 1.059 & 2.836 & 2.780 & 0.147 & 0.125 & 0.404 & 0.486 \\
\hline 7 & 0.046 & 0.029 & 0.851 & 0.790 & 1.440 & 1.253 & 0.978 & 0.886 & 0.317 & 0.243 \\
\hline 8 & 0.058 & 0.019 & 1.183 & 1.158 & 0.960 & 1.050 & 0.718 & 0.729 & 0.244 & 0.259 \\
\hline 9 & 0.079 & 0.050 & 0.376 & 0.417 & 0.773 & 0.838 & 0.869 & 0.840 & 0.345 & 0.485 \\
\hline 10 & 0.035 & 0.108 & 1.191 & 0.148 & 0.705 & 0.544 & 0.796 & 0.832 & 0.309 & 0.226 \\
\hline
\end{tabular}

layer alloying level, and it also reaches a minimum for metal deposited only with alloying flux ANK-18 (reduction of upper and lower roller wear in this case by 11 and 6 times, respectively, experiments $6-10$ ).

In the case of feeding abrasive of $0.315 \mathrm{~mm}$ fraction the greatest weight loss is shown by rollers surfaced with Np-65 wire (experiment 8), and the smallest weight loss is found in those surfaced with Sv-08G2S wire (experiment 4). At testing with abrasive of $0.4 \mathrm{~mm}$ fraction the smallest wear is observed in rollers, surfaced with $\mathrm{Sv}$ 08G2S wire using AN-348A flux (minimum alloying, experiment 1) or using a mixture of fluxes with $75 \%$ ANK-18 fraction in it (experiment 4).

Testing with abrasive of $0.63 \mathrm{~mm}$ fraction showed that all the roller pairs wore similarly in terms of quality. In contrast to the previous case, however, maximum mass loss is shown by the most ductile metal (experiment 1). Analysis of results of wearing by abrasive of $1 \mathrm{~mm}$ fraction is indicative of identical nature of wear of metal deposited with both the wires.

Working surface of rollers surfaced with Sv08G2S wire using ANK-18 flux (experiment 5) spalls off in the presence of abrasive particles (no spallation is found at testing without abrasive). Abrasive quartz particles with microhardness on the level of 10,000 MPa are embedded into roller surface layer, creating stress raisers in the form of pits, hairlines and scratches. At continued cyclic force load, the crack, caused by the above stress raisers, propagates fast.

Dependence of the ratio of lower and upper roller wear $\left(i_{1} / i_{\text {up }}\right)$ on their surface hardness ratio $\left(H B_{1} / H B_{\text {up }}\right)$ is of interest. Such a dependence for the case of wear without abrasive feeding is shown in Figure 1. It is characteristic that these dependencies have minimums for all the deposited metal compositions, and can be described by a parabolic function. 


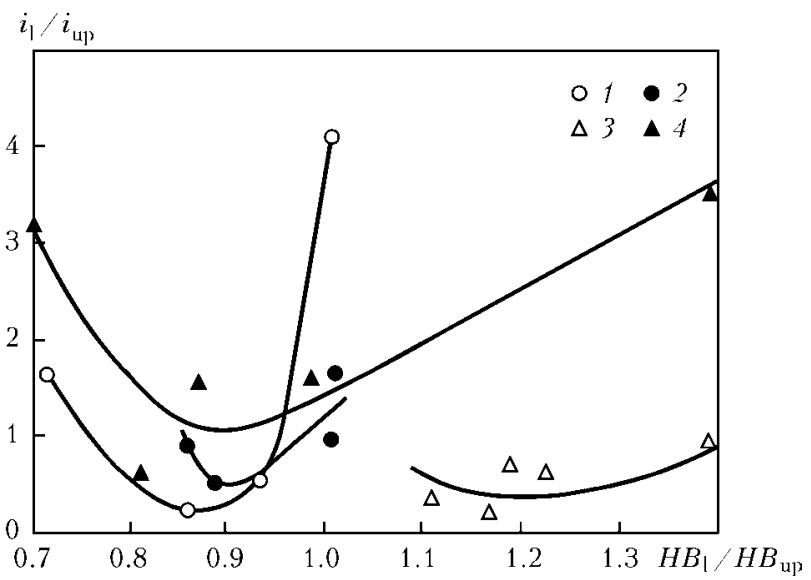

Figure 1. Dependencies of the ratio of roller wear $i_{1} / i_{\text {up }}$ and hardness $H B_{1} / H B_{\text {up }}$ at wear testing at metal-on-metal rolling friction without abrasive in surfacing with Sv-08G2S wire using ANK-19 (1) and ANK-18 (2) flux and in surfacing with Np-65 wire using ANK-19 (3) and ANK-18 (4) flux

For samples surfaced with Sv-08G2S wire using ANK-18 flux, minimum $i_{1} / i_{\text {up }}$ ratio is observed at $H B_{1} / H B_{\text {up }}$ ratio close to 0.85 . Similar wear of rollers $\left(i_{1} / i_{\mathrm{up}}=1\right)$ is recorded at hardness ratios of 0.75 and 0.95 . It is probable that in the first case wear of drive lower roller occurs by plastic shear (cut-off), and in the second case it results from brittle separation. Change of wear mechanism is manifested in all the considered cases.

At $H B_{1} / H B_{\text {up }}=1$, lower and upper roller wear ratio is equal to 3.7 and is indicative of a more intensive wear of drive roller.

It can be assumed that optimum ratio of wear values close to 0.25 at $H B_{1} / H B_{\text {up }}=0.85$ is achieved under the condition when both the rollers wear through elasto-plastic redeformation. This state can be regarded as a transition from tough to brittle fracture. Dependence $i_{1} / i_{\text {up }}=$ $=f\left(H B_{1} / H B_{\text {up }}\right)$ for layers, deposited with Sv08G2S wire using ANK-18 flux, is characterized by a narrow range of $H B_{1} / H B_{\text {up }}$ variation and the most probable mixed mechanism of roller wear. Hardness ratio, close to 0.9 , can be regarded as the optimum one. Equality of wear for both the rollers is achieved at hardness ratios of 0.85 and 0.98 .

A wide range of $H B_{1} / H B_{\text {up }}$ values is characteristic for metal deposited with Np-65 wire using ANK-18 flux. Optimum hardness ratio of 0.9 is in good agreement with earlier established values for metal deposited with Sv-08G2S wire. Characteristically, equality of roller wear is achieved only at optimum value of $H B_{1} / H B_{\text {up }}$ ratio. Layers, deposited with Np-65 wire using ANK-19 flux, differ from earlier considered ones by greater $H B_{1} / H B_{\text {up }}$ values and poorly defined optimum. It can be considered that the latter cor-

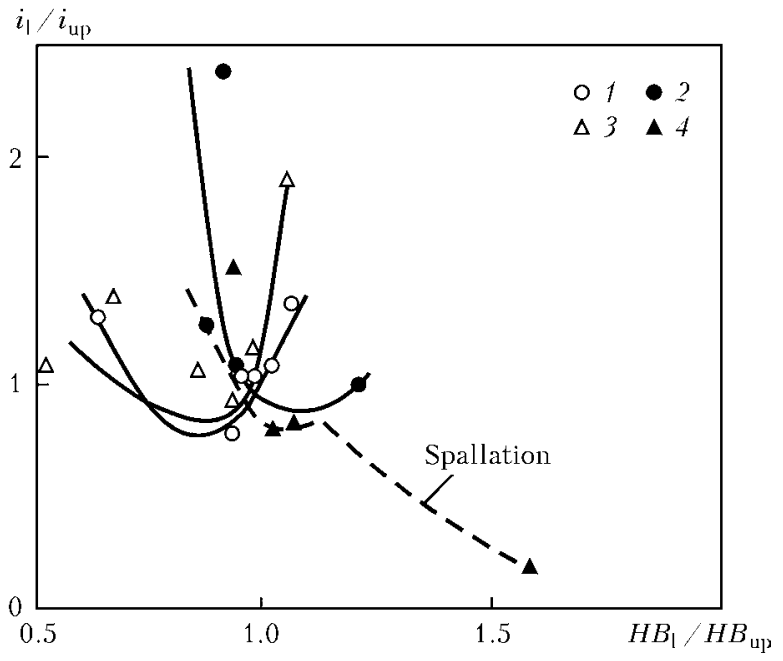

Figure 2. Dependencies of the ratio of roller wear $i_{1} / i_{\text {up }}$ and hardness $H B_{1} / H B_{\text {up }}$ at wear testing at metal-on-metal rolling friction with abrasive in surfacing with Sv-08G2S wire and AN-348A flux: 1 - abrasive from particles of fraction $d=0.315 ; 2-0.4 ; 3-0.63 ; 4-1 \mathrm{~mm}$

responds to hardness ratio of the order of 1.2. Here, wear value ratio is equal to $0.25-0.30$. Equality of wear values is possible at hardness ratio of about 1.4 .

Analyzing the derived dependencies and initial values of deposited metal hardness, it should be noted that at surfacing with $\mathrm{Sv}-08 \mathrm{G} 2 \mathrm{~S}$ wire using AN-348A and ANK-18 fluxes the lower rollers wear more intensively at equal hardness. This fact is attributable to leading role of lower roller at torque transmission and inevitable slipping of upper roller. The latter causes the higher degree of drive roller work-hardening that is confirmed experimentally.

Assuming $H B_{1} / H B_{\text {up }}=0.9$ hardness ratio as the optimum one, and considering the possibility of producing deposited metal layers of hardness from $H B 170$ up to $H B$ 547, the following recommendations can be made: at minimum hardness of upper sample ( $H B$ 170), optimum hardness of the lower one should be $H B 153$, at maximum hardness of upper sample ( $H B$ 547) it should be $H B 508$.

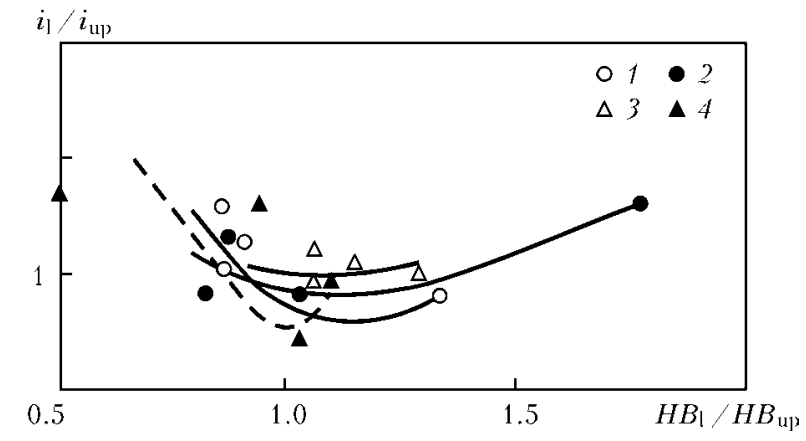

Figure 3. Dependencies of the ratio of wear $i_{1} / i_{\text {up }}$ and hardness $H B_{1} / H B_{\text {up }}$ of rollers surfaced with Np-45 wire and AN-348A flux at wear testing at metal-on-metal rolling friction with abrasive (designations are similar to Figure 2) 


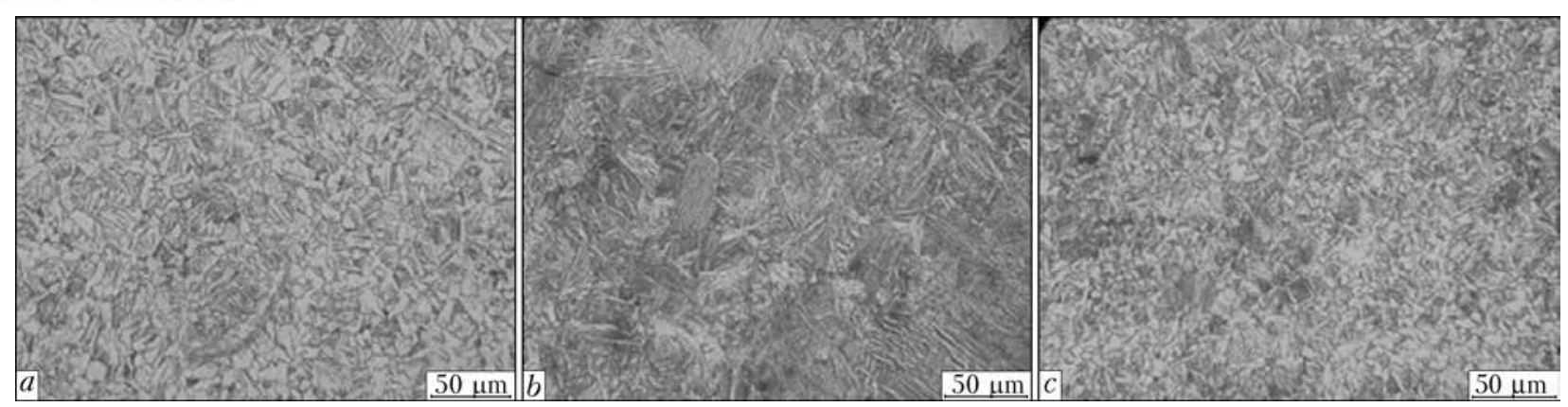

Figure 4. Microstructure of deposited metal providing higher wear resistance at contact with particles of $0.01-0.03(a)$, $0.31-0.80(b)$ and $0.81-1.20(c) \mathrm{mm}$

At abrasive testing of samples surfaced with Sv-08G2S wire using AN-348A flux (Figure 2), it was established that minimum value $i_{1} / i_{\text {up }}=$ $=0.6-0.7$ is found at optimum hardness ratio $\left(H B_{1} / H B_{\text {up }}=0.9\right)$ only at wearing by abrasive of 0.315 and $0.63 \mathrm{~mm}$ fraction. Wearing in the presence of abrasive of $0.4 \mathrm{~mm}$ fraction is characterized by shifting of optimum hardness ratio to values of 1.10-1.15. At application of abrasive of $1 \mathrm{~mm}$ fraction, minimum $i_{1} / i_{\mathrm{up}}$ value is reached at hardness ratio of 1.1 , at higher values macroscopic spallation of deposited metal is recorded.

At abrasive testing of samples surfaced with Np-65 wire using AN-348A flux (Figure 3), it is found that optimum hardness ratio is equal to $1.0-1.1$, that corresponds to $i_{1} / i_{\text {up }}=0.7-1.0$. No brittle fracture is observed. Thus, in order to minimize $i_{1} / i_{\text {up }}$ ratio it is necessary to ensure $H B_{1} / H B_{\text {up }}$ values on the level of $0.85-0.90$ for samples surfaced with Sv-08G2S wire, and 11.15 for samples surfaced with $\mathrm{Np}-65$ wire. In the presence of abrasive of $1 \mathrm{~mm}$ fraction at wearing of samples surfaced with $\mathrm{Sv}-08 \mathrm{G} 2 \mathrm{~S}$ wire, $H B_{1} / H B_{\text {up }}>1.2$ ratio should be avoided to prevent brittle fracture. Correlating the obtained experimental data on wearing intensity with deposited layer phase composition allows making the following recommendations.

At prevalence of finer $(0.01-0.30 \mathrm{~mm})$ abrasive, better wear resistance is provided by deposited metal having predominantly ferrite-pearlite structure (bainite fraction up to $5-10 \%)\left(\mathrm{Fi}^{-}\right.$ gure $4, a)$.

At increase of abrasive particle size (0.31$0.80 \mathrm{~mm}$ ), it is recommended to apply higher alloyed deposited metal with bainite-martensite structure (up to $5 \%$ fraction of martensite phase) (Figure $4, b$ ). In the case of prevalence of coarsegrained abrasive $(0.82-1.20 \mathrm{~mm})$, preference should be given to more ductile deposited metal with ferrite-pearlite structure (bainite fraction up to $10-20 \%$ ) (Figure $4, c$ ).

\section{Conclusions}

1. Correlation between abrasive fractional composition and deposited metal wear resistance was established.

At prevalence of fine $(0.01-0.30 \mathrm{~mm})$ abrasive, it is rational to deposit metal $(\%$ : $0.17 \mathrm{C}$; $2.35 \mathrm{Mn} ; 0.63 \mathrm{Si} ; 1.49 \mathrm{Cr} ; 0.09 \mathrm{Ni}$ ) having ferritepearlite structure with 5-10\% fraction of bainite. At increase of abrasive particle size (0.31$0.80 \mathrm{~mm}$ ), it is recommended to deposit higher alloyed metal (\%: 0.37C; $2.88 \mathrm{Mn} ; 0.39 \mathrm{Si}$; $3.18 \mathrm{Cr} ; 0.11 \mathrm{Ni})$ with bainite-martensite structure (up to $5 \%$ martensite phase fraction). In the case of prevalence of coarse-grained abrasive $(0.81-1.20 \mathrm{~mm})$, it is rational to deposit ductile ferrite-pearlite layers with bainite fraction of 10$20 \%(\%$ : $0.22 \mathrm{C} ; 2.09 \mathrm{Mn} ; 0.6 \mathrm{Si} ; 1.57 \mathrm{Cr} ; 0.13 \mathrm{Ni})$.

2. Hardness values and its value ratios for contacting deposited layers of parts are proposed, which are capable of increasing the part service life by 1.8 to 2.2 times under the condition of allowing for granulometric composition of abrasive flow.

1. Vinogradov, V.N., Sorokin, G.M., Kolokolnikov, M.G. (1990) Abrasive wear. Moscow: Mashinostroenie.

2. Lvov, P.N. (1970) Principles of abrasive wear resistance of road machine parts. Moscow: Strojizdat.

3. Livshits, L.S., Grinberg, N.A., Kurkumelli, E.G. (1969) Fundamentals of alloying of deposited metal. Moscow: Mashinostroenie.

4. Chigarev, V.V., Malinov, V.L. (2000) Selection of sparcely-alloyed surfacing materials for different impact-abrasive conditions. The Paton Welding J., 5, 55-57.

5. Mazel, Yu.A., Kuskov, Yu.V., Polishchuk, G.N. (1999) Classification of alloys on iron base for repair and strengthening surfacing. Svarochn. Proizvodstvo, 4, 35-38.

6. Balin, A.N., Berezovsky, A.V., Vishnevsky, A.A. et al. (2006) Surfacing consumables for hardening of parts operating under impact-abrasive wear conditions. The Paton Welding J., 2, 44-45.

7. (1974) Technology of fusion electric welding of metals and alloys. Ed. by B.E. Paton. Moscow: Mashinostroenie. 


\title{
METHOD OF EVALUATION OF THERMAL RESISTANCE OF MULTILAYER DEPOSITED METAL
}

\author{
A.A. BABINETS \\ E.O. Paton Electric Welding Institute, NASU \\ 11 Bozhenko Str., 03680, Kiev, Ukraine. E-mail: office@paton.kiev.ua
}

\begin{abstract}
At the present time there is no generally-accepted procedure of testing the thermal resistance of multilayer deposited specimens. The existing sufficiently widely used method of evaluation of thermal resistance, based on determination of number of heating-cooling cycles up to the appearance of a network of thermal cracks, does not allow carrying out a precise evaluation of thermal resistance during testing of multilayer deposited specimens possessing a rather high thermal resistance. The aim of the work consists in development or improvement of the procedure of evaluation of thermal resistance of the multilayer deposited metal, which could allow investigating the dynamics of propagation of thermal cracks in depth of the deposited layer and its change depending on characteristics of the deposited layers. The procedure, developed at the E.O. Paton Electric Welding Institute, was improved that made it possible to carry out the precise evaluation of thermal resistance of the deposited metal. It was found that the fusion line nature has a definite effect on thermal resistance of the specimen as a whole. In this case the surfacing of a ductile sublayer by wire Sv-08A contributes to arresting the growth of the thermal fatigue cracks and increase in total thermal resistance approximately by $20 \%$. The improved procedure can be used for the precise evaluation of thermal resistance of surfacing materials, used in manufacture or restoration surfacing of tools for hot deforming. 12 Ref., 1 Table, 7 Figures.
\end{abstract}

$\boldsymbol{K} \boldsymbol{e} \boldsymbol{y} \boldsymbol{w} \boldsymbol{o} \boldsymbol{r} \boldsymbol{d} \boldsymbol{s}:$ arc surfacing, multilayer deposited metal, procedure of tests

Thermal fatigue resistance (thermal resistance) is one of the main properties of tool steels, which are used in the process of manufacture or restoration of a wide assortment of tools for hot deforming of metals [1-3]. Among them there are different rolls of hot rolling mills, rollers of machines for continuous casting of billets, dies of hot stamping, etc.

As a result of cyclic thermal loads a network of relatively fine thermal cracks is appeared at the surface of these tools. These cracks cause the extraction of metal particles, accelerate wear and promote the rapid wear development [4, 5]. These damages, developing under complex service conditions, can lead not only to the rejection of products, but also to a premature damage of the tool, thus leading to the significant cost losses.

At present there is no generally-accepted procedure for testing the thermal resistance of the multilayer deposited specimens. The standard method of testing materials at thermal-mechanical loading [6] is impossible to apply to the materials, which are used for the restoration of parts of the metallurgical equipment, as the specimens, used in this method, have a cylindrical solid (up to $22 \mathrm{~mm}$ thickness) or hollow (2 mm wall thick- ness, up to $12 \mathrm{~mm}$ diameter) section. The specimens of this shape and sizes do not allow evaluating the effect on thermal resistance of the multilayer deposited metal of the specimen as a whole.

In this connection such tests are carried out more often by using different experimental procedures, in most of which the criterion of thermal resistance is a number of heating-cooling cycles up to the appearance of a network of thermal fatigue cracks [1, 2, 7-10]. The E.O. Paton Electric Welding Institute presents one of these procedures, as well as the designed laboratory equipment [10] which is characterized by the following advantages:

- sizes of the used specimens provide a required temperature gradient and stressed state, close to those occurring during service of real parts of the metallurgical equipment. In this case the specimens have a simple and convenient shape for manufacture without sharp transitions, playing role of stress raisers;

- method of heating and cooling is provided, which is mostly close to the real service conditions;

- possibility of adjustment and monitoring of heating and cooling temperature and reproducibility of these conditions for all the tested specimens is provided.

The process of testing by this procedure is as follows (Figure 1). As-deposited specimen 1 of 


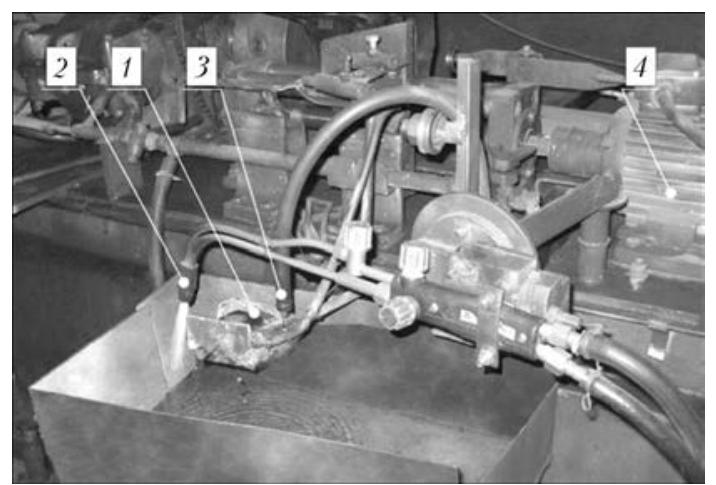

Figure 1. Equipment for testing the deposited metal thermal resistance (for designations see the text)

$40 \times 40 \times 40 \mathrm{~mm}$ size is installed into a mandrel of the equipment so that the grinded surface was faced to a heat source, i.e. gas-flame cutter 2 . During testing the mandrel with a specimen fixed in it is moved cyclically from the heat source to cooling source 3 (water supply hose) by means of drive 4 of mandrel reciprocal movement. Here, the uniform heating of the surface is provided in spot of $15-20 \mathrm{~mm}$ diameter. The heating duration is $11 \mathrm{~s}$, and cooling by a water jet is $8 \mathrm{~s}$.

At the mentioned duration of heating and cooling the temperature in the spot is growing during the first 8-10 test cycles, and then it is stabilized within $700-800{ }^{\circ} \mathrm{C}$ during heating and within $20-60{ }^{\circ} \mathrm{C}$ after cooling. Monitoring of temperature during tests is realized by using thermocouples. The thermal resistance is evaluated by the number of heating-cooling cycles up to the appearance and development of thermal crack net-

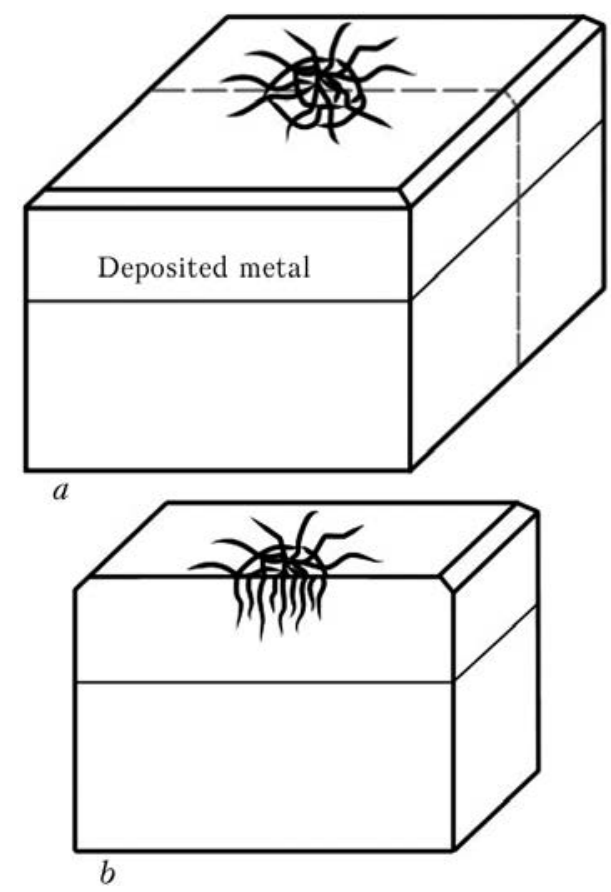

Figure 2. Scheme of specimen cutting for manufacture of macrosection: $a$ - specimen after testing; $b$ - after cutting work, visible by a naked eye, in the heat spot. To obtain the valid test results, 3-5 specimens of each type of the deposited metal are tested. After tests the specimens are cut in some cases in a transverse direction in the heat spot for evaluating the depth of crack propagation on the macrosections.

However, the investigations of thermal resistance of the deposited metal, made according to the mentioned procedure, showed $[4,11,12]$ that in the majority of cases the maximum number of heating-cooling cycles up to the appearance of the network of thermal cracks does not exceed 200 . Here, depth of crack propagation is $0.2-0.5$ $\mathrm{mm}$ and is not almost increased, at the further increase in cycle numbers only the crack opening is increased. Thus, during testing according to this procedure it is impossible to evaluate the dynamics and nature of development of the thermal fatigue cracks by thickness of the deposited layers.

The aim of the present work is the development and improvement of the procedure of evaluation of thermal resistance of the multilayer deposited metal, which would allow investigating the dynamics of thermal crack propagation in the depth of the deposited layer and its change depending on characteristics of the deposited layers.

To reach the put aim, the above-described test procedure was taken as a basis, which was improved in the following way. It was suggested to perform the test of specimens in several stages, each by duration of 200 heating-cooling cycles with the next grinding of surface after each stage. Grinding was made until the complete removal of thermal cracks, at the same time recording here their depth, that allowed evaluating the dynamics of crack propagation across the deposited metal thickness. These operations were repeated up to attaining the minimum possible thickness of the deposited working layer, $(1.5-2.0 \mathrm{~mm})$, after which the final stage of thermocycling without post grinding was performed. Further, the specimens were cut in heat spot (Figure 2) and then the depth and nature of thermal crack propagation were examined on the macrosections.

According to the mentioned procedure the thermal resistance of specimens of the multilayer deposited metal of four types was evaluated. For this, on billets of steel $40 \mathrm{Kh}$ electric arc surfacing of the working layer was performed by flux-cored wire PP-Np-25Kh5FMS using the following variants: surfacing without a sublayer, and surfacing of the working layer with a sublayer deposited 


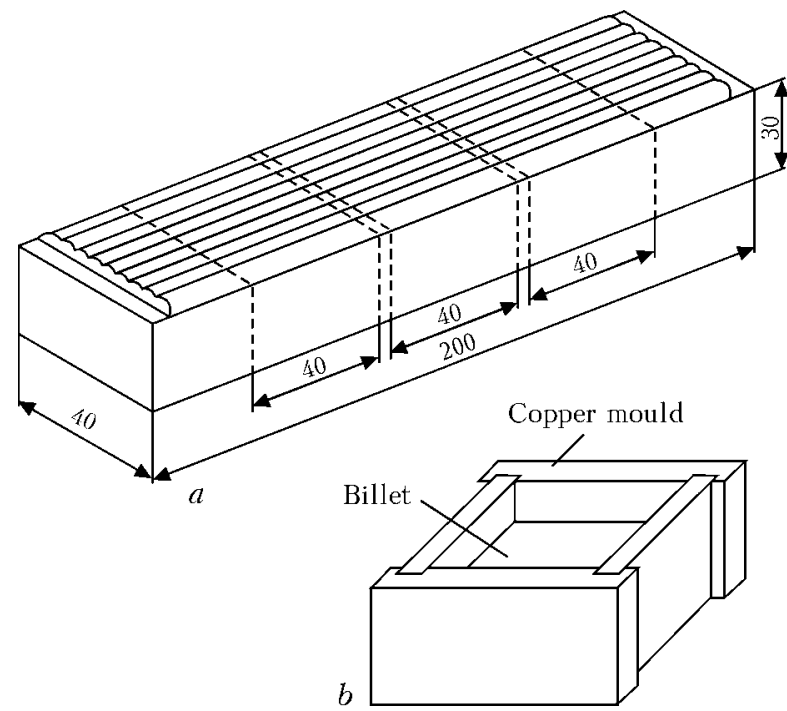

Figure 3. Scheme of manufacture of multilayer deposited specimens for investigation of thermal resistance in automatic submerged arc surfacing $(a)$ and semiautomatic surfacing with self-shielding flux-cored wires $(b)$

by wire $\mathrm{Sv}-08 \mathrm{~A}$. Taking into account that the thermal fatigue is greatly affected by stress raisers, sharp transitions of the shape, structural heterogeneity, etc. [1, 2], it was supposed that the depth and shape of penetration also have effect on the metal thermal resistance. Coming from this, surfacing of experimental specimens was performed using two technologies:

- automatic multibead multilayer surfacing was performed on plates of $30 \times 40 \times 200 \mathrm{~mm}$ sizes, whereupon the test specimens of $40 \times 40 \times$ $\times 40 \mathrm{~mm}$ size were cut from the surfaced billets (Figure 3, a);

- billet of $30 \times 40 \times 40 \mathrm{~mm}$ size was placed into a dismountable copper mould and semi-automatic electric arc multilayer surfacing with selfshielding flux-cored wires was performed $\left(\mathrm{Fi}^{-}\right.$ gure $3, b)$.

Automatic surfacing on the plates by solid wire Sv-08A was made under flux AN-348A, and surfacing by wire PP-Np-25Kh5FMS was made under flux AN-26P. Diameter of all the wires was $2.0 \mathrm{~mm}$. Surfacing conditions were as follows: $I_{\mathrm{s}}=300-350 \mathrm{~A}, U_{\mathrm{s}}=28-30 \mathrm{~V}, v_{\mathrm{s}}=$ $=20 \mathrm{~m} / \mathrm{h}$. Surfacing pitch was equal to $40 \%$ of the deposited bead width.

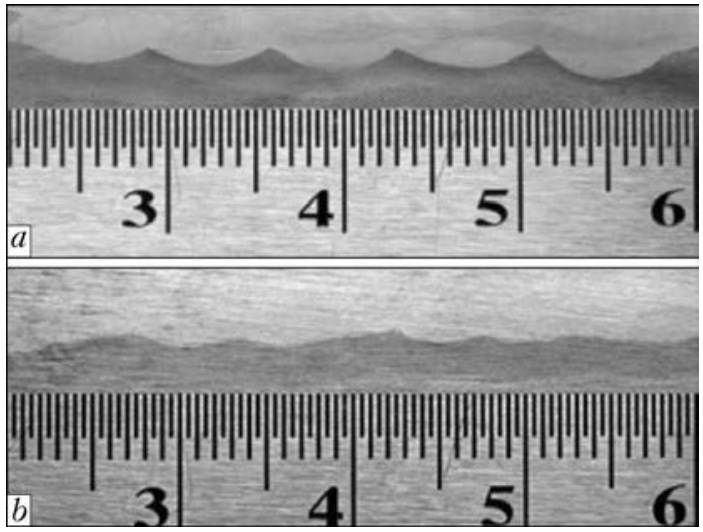

Figure 4. Transverse macrosections deposited by automatic (a) and semiautomatic (b) method

Semiautomatic surfacing in the cooper mould by solid wire $\mathrm{Sv}-08 \mathrm{~A}$ was performed in $\mathrm{CO}_{2}$ shielding gas, wire diameter was $0.8 \mathrm{~mm}$. diameter of PP-Np-25Kh5FMS self-shielding fluxcored wire was $1.8 \mathrm{~mm}, I_{\mathrm{s}}=200-220 \mathrm{~A}, U_{\mathrm{s}}=$ $=22-24 \mathrm{~V}$.

On all the specimens the total thickness of the sublayer was $3-4 \mathrm{~mm}$, and that of the working layer was 5-6 mm. Hardness and also data of spectral analysis by chemical composition of the deposited metal are given in the Table. Symbols $\mathrm{A}$ and $\mathrm{S}$ in the Table denote automatic and semiautomatic surfacing, respectively.

After deposition, one specimen from each batch was cut perpendicular to surfacing direction for the metallographic examinations. It is seen on the manufactured macrosections of the deposited metal that application of smaller diameter wire in combination with oscillating movements of the electrode in semiautomatic surfacing provided a smaller depth of penetration and more smooth fusion line, as compared with submerged arc surfacing (Figure 4).

Then for comparison, the thermal resistance tests were performed according to the standard procedure up to the appearance of developed network of thermal cracks. The test results showed (Figure 5) that all four types of the deposited metal have almost similar, sufficiently high thermal resistance. At the same time, two regularities were noted:

Chemical composition and hardness of deposited metal depending on method of surfacing

\begin{tabular}{|c|c|c|c|c|c|c|c|c|c|}
\hline \multirow{2}{*}{$\begin{array}{l}\text { Specimen } \\
\text { number }\end{array}$} & \multirow{2}{*}{ Type of deposited metal } & \multirow{2}{*}{$\begin{array}{l}\text { Method } \\
\text { of } \\
\text { surfacing }\end{array}$} & \multicolumn{6}{|c|}{ Composition of alloying elements, wt.\% } & \multirow{2}{*}{$\begin{array}{c}\text { Hardness } \\
H R C\end{array}$} \\
\hline & & & $\mathrm{C}$ & $\mathrm{Si}$ & Mn & $\mathrm{Cr}$ & $\mathrm{V}$ & Mo & \\
\hline 1.1 & \multirow[t]{2}{*}{ PP-Np-25Kh5FMS (without sublayer) } & A & 0.24 & 0.72 & 0.53 & 4.90 & 0.35 & 0.95 & $48-50$ \\
\hline 1.2 & & $\mathrm{~S}$ & 0.26 & 0.79 & 0.64 & 5.50 & 0.40 & 1.01 & $49-51$ \\
\hline 2.1 & \multirow[t]{2}{*}{ Sv-08A sublayer + PP-Np-25Kh5FMS } & A & 0.24 & 0.74 & 0.56 & 5.10 & 0.37 & 0.97 & $48-50$ \\
\hline 2.2 & & $\mathrm{~S}$ & 0.26 & 0.76 & 0.64 & 5.40 & 0.40 & 0.99 & $49-51$ \\
\hline
\end{tabular}




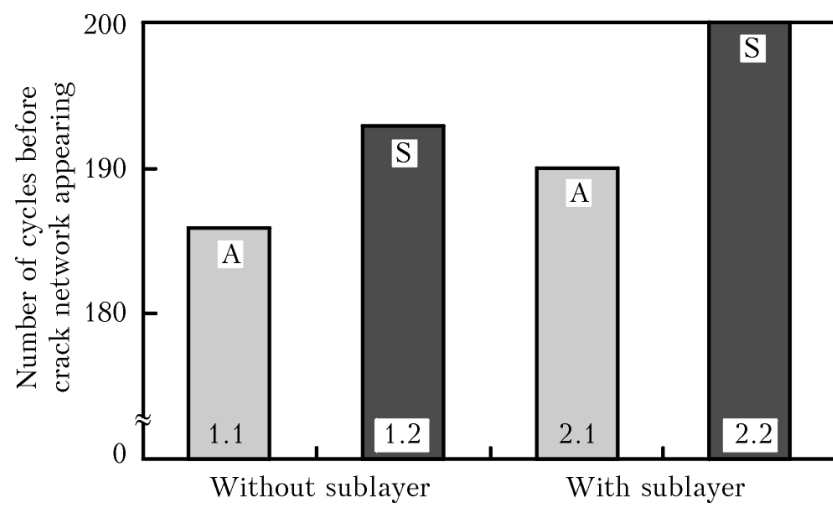

Figure 5. Thermal resistance of specimens 1.1-2.2 deposited by automatic submerged arc (A) and semiautomatic surfacing with self-shielding wire $(\mathrm{S})$

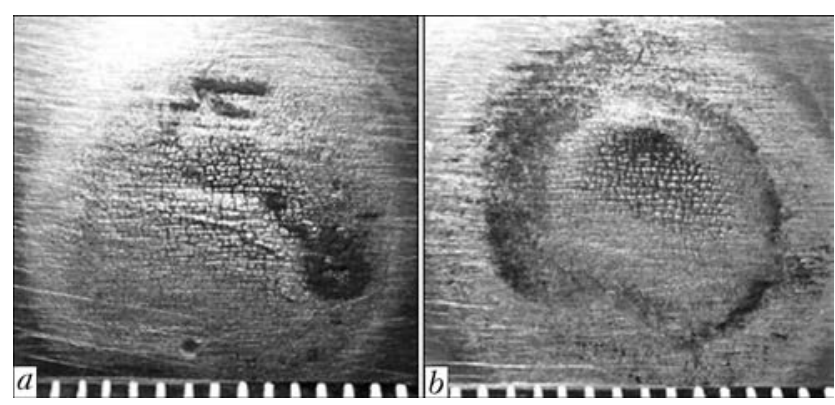

Figure 6. Appearance of surface of specimens, deposited by flux-cored wire PP-Np-25Kh5FMS without sublayer $(a)$ and with sublayer deposited by wire Sv-08A $(b)$, after thermal resistance testing

- thermal resistance of specimens, deposited by semiautomatic method is higher than that in automatic surfacing;

- surfacing of the sublayer contributes to increase in thermal resistance.

The first regularity is, probably, explained by the fact that in specimens, deposited by semiautomatic method, the decrease in depth of penetration and more uniform fusion boundary between separate deposited beads/layers contributes to decrease in levels of chemical and structural heterogeneity, that influences positively on the thermal resistance. To explain the second regularity, the specimens were subjected to tests using the above-mentioned improved procedure.

Analysis of obtained results showed that the specimens, deposited without sublayer, have a greatly developed network of thermal cracks (Figure $6, a$ ). Thickness of the grinded layer after each 200 test cycles was approximately $0.35-0.40 \mathrm{~mm}$. The minimum thickness of the deposited wear-resistant layer was attained after 2000 test cycles, then the specimens were cut in heat spot, and macrosections were manufactured from them (Figure 7, a). As is seen, in this case the thermal cracks are transferred from the deposited metal into the base one.

In specimens with the sublayer, deposited by wire Sv-08A, the less expressed network of ther-
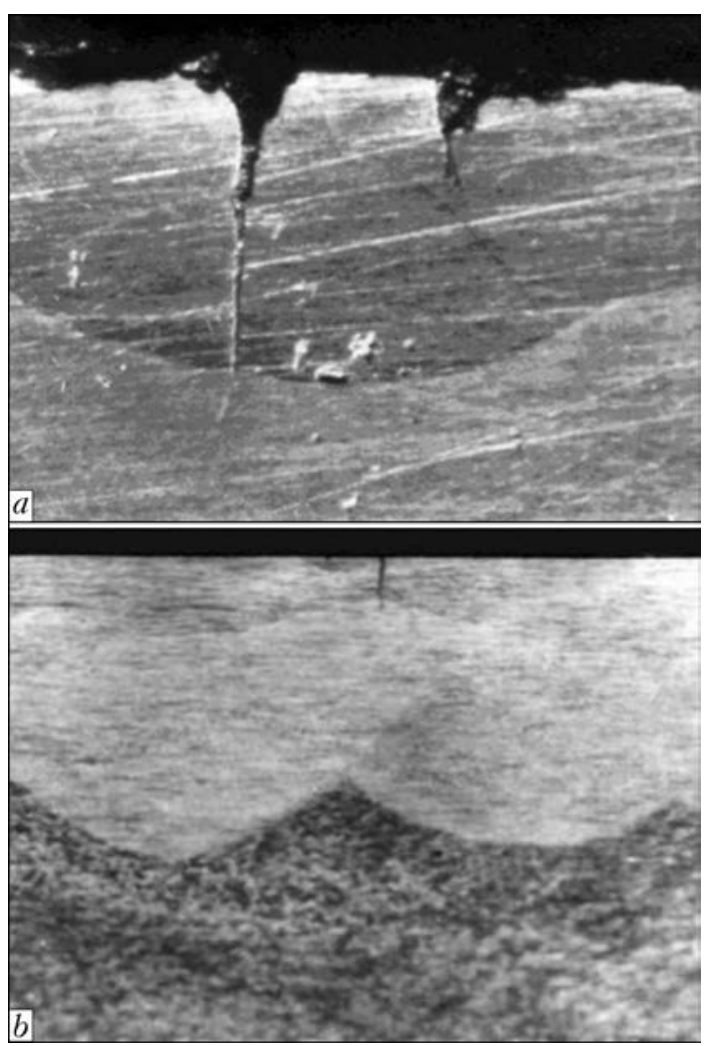

Figure 7. Macrosection of specimens, deposited without sublayer $(a)$ and with Sv-08A sublayer $(b)$, after thermal resistance testing

mal cracks is observed (Figure $6, b$ ). In this case the depth of cracks propagation across the thickness was also smaller. The thickness of the grinded layer after each 200 test cycles was approximately $0.20-0.25 \mathrm{~mm}$. Taking into account a negligible removal of the material, it was possible to carry out 2400 test cycles on these specimens. As-tested specimens were also cut and macrosections were prepared (Figure $7, b$ ). In this case the cracks are passed through the wearresistant layer and arrested in low-carbon sublayer.

Thus, the improvement of procedure of thermal resistance testing by carrying out several stages with regrinding of the specimen surface allowed evaluating the dynamics and nature of development of thermal fatigue cracks across the thickness of deposited layers and revealing the effect of the sublayer on the nature of their propagation.

\section{Conclusions}

1. Existing and sufficiently widely used method of evaluation of thermal resistance, based on determination of number of heating-cooling cycles up to appearance of a network of thermal cracks, does not allow making a precise evaluation of crack resistance at testing of multilayer deposited 
specimens, possessing a rather high thermal resistance.

2. Improvement of procedure of thermal resistance tests by carrying out several stages with a regrinding of the specimen surface made it possible to evaluate the development of thermal fatigue cracks across the thickness of deposited layers and to reveal the effect of sublayer on nature of propagation of the thermal fatigue cracks.

3. It was established that depth of penetration and nature of fusion line of deposited layers has a definite effect on thermal resistance of the deposited specimen as a whole, that it is necessary to take into account in selection of technology and technique of surfacing.

1. Dulnev, R.A., Kotov, P.I. (1980) Thermal fatigue of metals. Moscow: Mashinostroenie.

2. Tylkin, M.A. (1971) Increase in service life of metallurgical equipment parts. Moscow: Metallurgiya.

3. Frumin, I.I. (1961) Automatic electric arc surfacing. Kharkov: Metallurgizdat.

4. Ryabtsev, I.A., Kondratiev, I.A. (1999) Mechanized electric arc surfacing of metallurgical equipment parts: Refer. Book. Kiev: Ekotekhnologiya.
5. Tolstov, I.A., Pryakhin, A.V., Nikolaev, V.A. (1990) Increase in serviceability of hot working tool. Moscow: Metallurgiya.

6. GOST 25.505-85: Methods of mechanical testing of metals. Method of test on low-cycle fatigue in thermomechanical loading.

7. Shkolnik, L.M. (1978) Procedure of fatigue tests: Refer. Book. Moscow: Metallurgiya.

8. Marek, A., Junak, G., Okrajni, J. (2009) Fatigue life of creep resisting steels under conditions of cyclic mechanical and thermal interactions. Archives of Materials Sci. and Eng., Vol. 40, Issue 1, 37-40.

9. Lanin, A.G. (1998) Methods of determination of thermal resistance (Review). Zavod. Laboratoriya. Diagnostika Materialov, 3, 31-47.

10. Ryabtsev, I.I., Chernyak, Ya.P., Osin, V.V. (2004) Block-module unit for tests of deposited metal. Svarshchik, 1, 18-20.

11. Ryabtsev, I.A., Babinets, A.A., Ryabtsev, I.I. (2011) Effect of ductile sub-layer on heat resistance of multilayer deposited metal. The Paton Welding J., 10, 18-21.

12. Babinets, A.A., Ryabtsev, I.A., Kondratiev, I.A. et al. (2014) Investigation of thermal resistance of deposited metal designed for restoration of mill rolls. Ibid., 5, 16-20.

Received 09.07.2015 


\title{
STATE-OF-THE-ART AND TENDENCIES OF DEVELOPMENT \\ OF WORLD MARKET OF THE MAIN STRUCTURAL MATERIALS AND WELDING EQUIPMENT ${ }^{*}$
}

\author{
O.K. MAKOVETSKAYA \\ E.O. Paton Electric Welding Institute, NASU \\ 11 Bozhenko Str., 03680, Kiev, Ukraine. E-mail: office@paton.kiev.ua
}

\begin{abstract}
The paper provides for statistical and economical indices of state and tendencies of development of world market of the main structural materials and welding equipment in the period of 2011-2014. Presented are the results of researches of world volume, structure of production and consumption steel, aluminum etc., and volume of production and consumption of welding equipment. These researches were carried out by leading world manufacturers such as Lincoln Electric, Colfax (ESAB, Victor Technologies Group), ITW etc. as well as leading analytical companies BCC Research, Transparency Market Research, Frost \& Sullivan. Analysis of main tendencies of world market of welding equipment and its separate segments is given. 19 Ref., 2 Tables, 12 Figures.
\end{abstract}

$\boldsymbol{K} \boldsymbol{e} \boldsymbol{y} \boldsymbol{w} \boldsymbol{O} \boldsymbol{r} \boldsymbol{s}:$ world market, production, consumption, main structural materials, welding equipment, statistics

Market of the main structural materials. Period of stabilizing and economic growth has started in the world in 2013. The USA and EU showed the highest rate of economic activity. Chinese economy shifts from an export model to development on the basis of growth of internal consumption. Recovery of the world economy promoted increase of demand on structural material markets. Among the main structural materials of current commercial production are ferrous and non-ferrous metals, nonmetallic materials (plastics, ceramics, glass etc.) and composite materials.

Volume of consumption of the structural materials is continuously growing. World production of the main structural materials, which are most widely used in welded structure production, has increased within the last five years. Steel, structural plastics and composite materials grew per 22, aluminum rose per 24 and titanium per $27 \%$.

In 2013 the volume of world market of structural plastics made $299 \mathrm{mln} t$ and was estimated in USD $70 \mathrm{bln}$. It is predicted that the volume of market of structural plastics will achieve USD 90 bln [1] by 2020 . Half of the world production and consumption of thermoplastics falls to EU countries and USA. Thermoplastics finds more and more

\footnotetext{
${ }^{*}$ Review of materials from collection of economical-statistical data on welding production «SVESTA-2014».
}

๑ O.K. MAKOVETSKAYA, 2015 application in automobile and building industry, in part structures for airspace industry, machine building, power engineering, including windpower engineering $[2,3]$.

It is rise of consumption of non-ferrous metals in industry. Volume of world production of primary aluminum made $49.7 \mathrm{mln} \mathrm{t}$ in 2013 that is $6 \%$ higher than the indices of 2012, world production of primary aluminum has risen per $4.8 \%$ more up to $53.1 \mathrm{mln} t$ in 2014 . It is predicted that production of primary aluminum will exceed $62 \mathrm{mln}$ t by 2017 . The main aluminum consuming branches are motor car construction and building. Their total portion exceeds $50 \%$ in total volume of the world consumption of primary aluminum. Motor car construction (Japan - 43, USA, Western Europe - 35 \%) and machine building (Western Europe, Japan - 19, USA - $15 \%$ ) [4] dominate as for consumption of aluminum in branch structure of industrially advanced countries, i.e. USA, Japan, and Western Europe.

Figure 1 shows the data on production volumes of the main structural materials in 1970 , 2008 and 2013.

Position of titanium as key material in aircraft and space industry guarantees growth of this metal consumption. Steady growth of demand for industrial grade titanium is observed in the period of 2010-2011 in China. «Airbus» and «Boeing», the world leaders of aircraft construction, recommence postponed programs on construction of A380 and B787 airplanes as well as new A350, that resulted in rise of demand for grade of titanium to be applied in space. The world market 


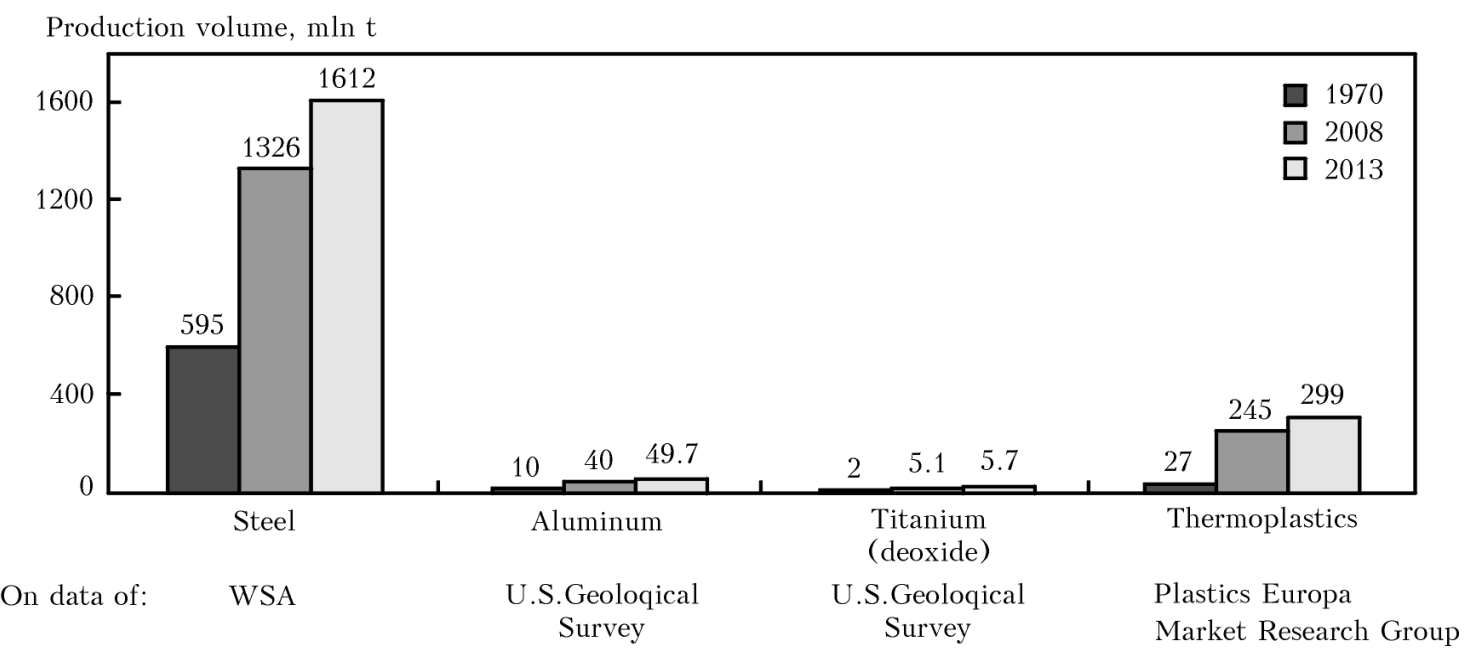

Figure 1. World production of the main structural materials in 1970, 2008 and 2013

of metallic titanium has risen approximately per $60 \%$ in relation to the level of 2009 . World production of titanium sponge in 2013 made around 222 thou t [5].

Regardless significant rise of consumption of non-ferrous, non-metallic and composite materials, steel is indisputable leader in the market of structural materials. Volume of steel production 4 times exceeds total volume of production of other structural materials [6].

According to World Steel Association (WSA) data, the world steel production increased per $1.2 \%$ in 2014 in comparison with 2013, and achieved $1662 \mathrm{mln} \mathrm{t}$. In 2014 the highest rise of steel production was observed in the Middle East. Rate of increase in this case made $7.7 \%$. The similar index for 2014 equaled $1.7 \%$ in EU countries, it was 1.7 in the USA, 0.9 in China and $1.4 \%$ in Asia.

Annual production of steel in Asia for 2014 made $1132.3 \mathrm{mln} t$ and that in China was $822.7 \mathrm{mln}$ t. Portion of the PRC in the world steel production reduced from 49.7 in 2013 to $49.5 \%$ in 2014. Japan produced $110.7 \mathrm{mln} \mathrm{t}$ per year, South Korea 71 and India $83.2 \mathrm{mln} \mathrm{t}$.

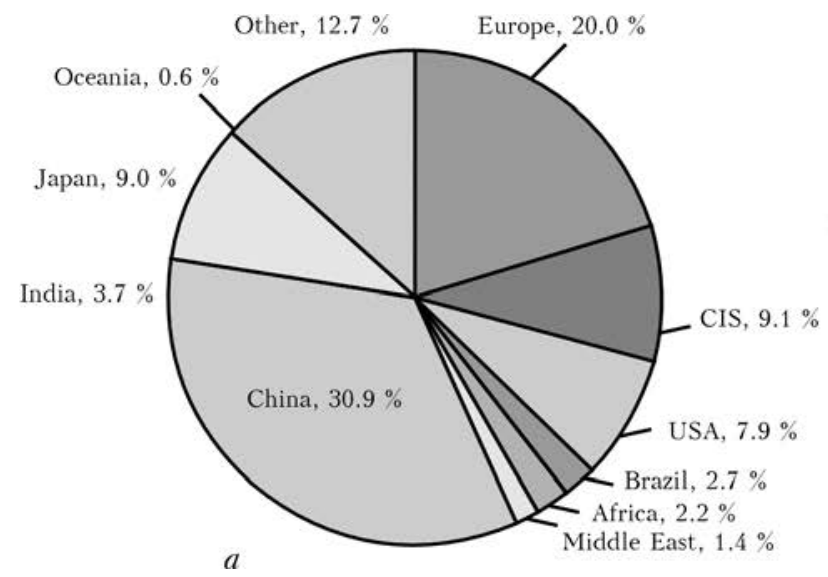

EU countries increased steel production per $1.7 \%$ or up to $169.2 \mathrm{mln} \mathrm{t}$ in 2014 . Steel production in Germany has risen per $0.7 \%$ to $42.9 \mathrm{mln} \mathrm{t}$ in comparison with 2013, and in France made $16.1 \mathrm{mln}$ t that is $2.9 \%$ higher. In 2014 steel production in the USA made $8.3 \mathrm{mln} \mathrm{t}$ that is $1.7 \%$ higher than the level of the last year [7].

Process of reduction of capacities of steel making production continues in the Western Europe, USA, Japan and its rise is observed in Asia (China, India) and the Middle East countries. Figure 2 provides the data characterizing change of regional distribution of the world structure of steel making capacities for 10 years in the period of 2005-2015.

Changes taken place in distribution of the steel making production capacities had an effect on the world regional structure of steel production (Figure 3). Based on OECD data a portion of North America and EU in the structure of steel production reduced from 10 and $16 \%$ in 2007 and to 8 and $10 \%$ in 2013, respectively, at that, portion of Asian countries rose from 56 in 2007 to $67 \%$ in 2013.

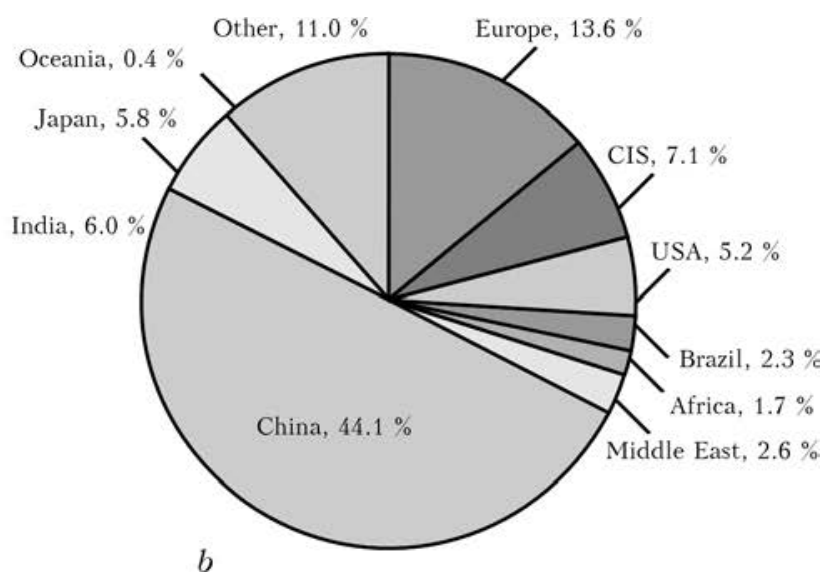

Figure 2. Regional distribution of production capacity of steel in 2005 ( $a$ ) and forecast for 2015 (b) 

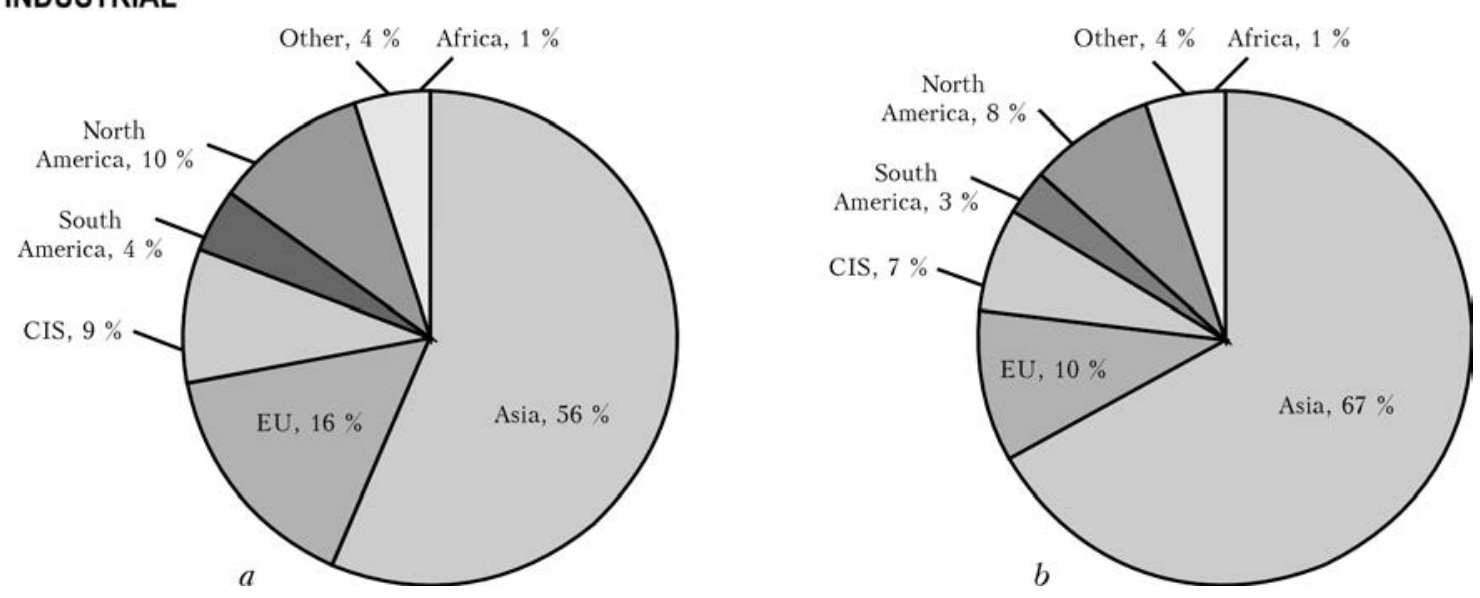

Figure 3. Regional distribution of world production of steel in 2007 ( $a$ ) and 2013 (b)

World consumption of steel in 2013 exceeded $1.5 \mathrm{bln}$ t. Estimation of the WSA specialist showed that the world consumption of steel in 2014 increased per 1.5-2.0\% up to 1.562 bln t, and in 2015 it will increase per $2 \%$ more up to 1.594 bln t [7].

It is a well-known fact that more than $2 / 3$ of steel products are reprocessed using joining technologies, mainly welding. Volume and structure of consumption of steel products on types of products, branches of industry, geographic areas determine the volume and structure of welding equipment market.

Data on the volume of consumption of steel and welding consumables in Japan, one of the world leaders on production and consumption of steel and welding consumables (Figure 4), can visually demonstrate effect of change of steel consumption on the sales volumes of welding consumables [4, 8].

The main consumers of steel in commercial production in 2011 were building (69\% of general consumption), machine-building (17\%), and transport including pipeline construction $(19 \%)$. It is predicted that the main consumers of steel in 2025 will be building ( $68 \%$ of world consumption), machine-building (13\%) and pipeline construction $(9 \%)$. Their total portion are going to exceed $90 \%$ of steel world consump- tion. Figure 5 provides for the data of steel consumption in the main branches of industry in 2011 and prediction for 2025 [6, 7].

Building branch makes significant input in the world and regional economics. Consumption of steel in the world building branch in 2011 made $845 \mathrm{mln}$ t, i.e. $60 \%$ of the total world steel consumption volume. It is expected that the volume of steel consumption in building by 2025 will make $64 \%$ of the whole world volume and reach $1506 \mathrm{mln}$ t. At that, portion of North America countries will make 18.3, EU 10.8, Japan 6.2 and China $24 \%$ in the structure of world surplus value, developed in the branch. Annual growth of the surplus value, developed in building branch of China, will make 5.9 and that for India can be $8.1 \%[6,7]$.

World consumption of steel in power engineering makes around $31 \mathrm{mln} t$. This index will remain the same according to the estimation of Metal Bulletin Research in the period by 2025 , but there are going to be shifts in the structure of steel consumption in separate sectors of the branch. Reduction from 17 to $16 \mathrm{mln}$ t is expected in steel consumption of coal mining sector, at that portion of steel consumption decreases from 56 to $51 \%$. It is also forecasted $3 \%$ decrease in steel consumption in hydropower engineering sector. In the period by 2025 the volume of steel

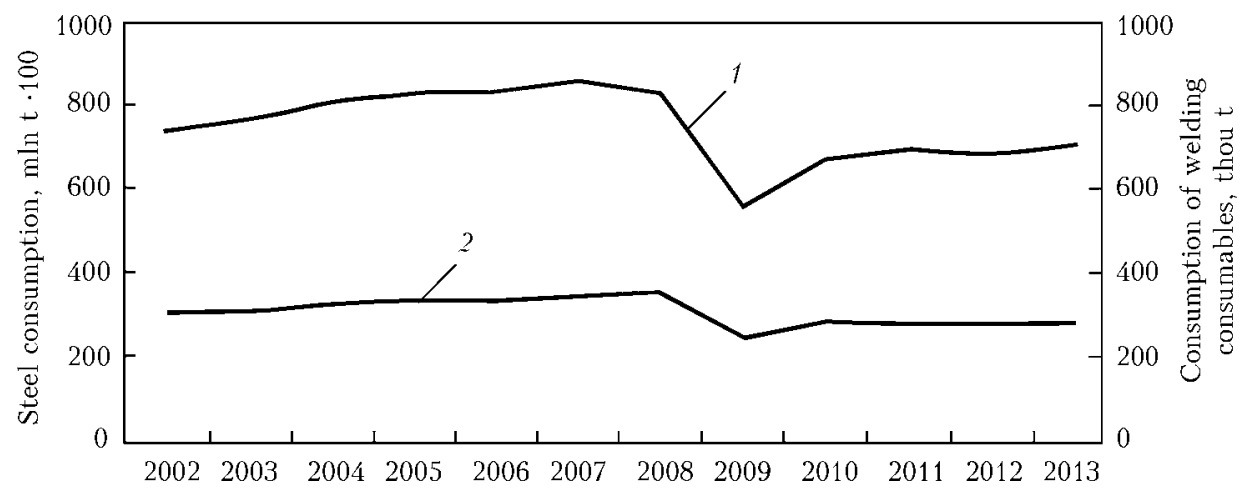

Figure 4. Change of steel consumption (1) and welding consumables (2) in Japan 

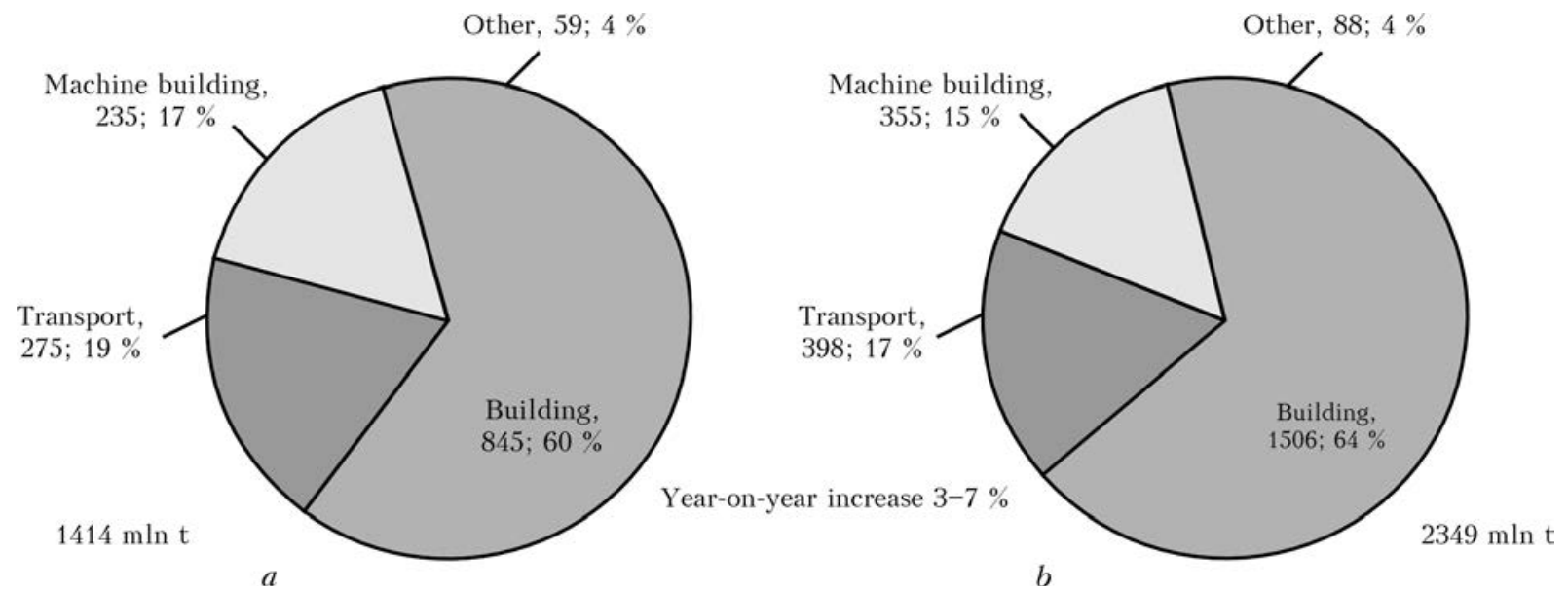

Figure 5. Branch structure of steel consumption in the world in 2011 (a) and forecast for 2025 (b) (here and in Figures 6 and 7 steel consumption in $\mathrm{mln} t$ and \%, respectively)
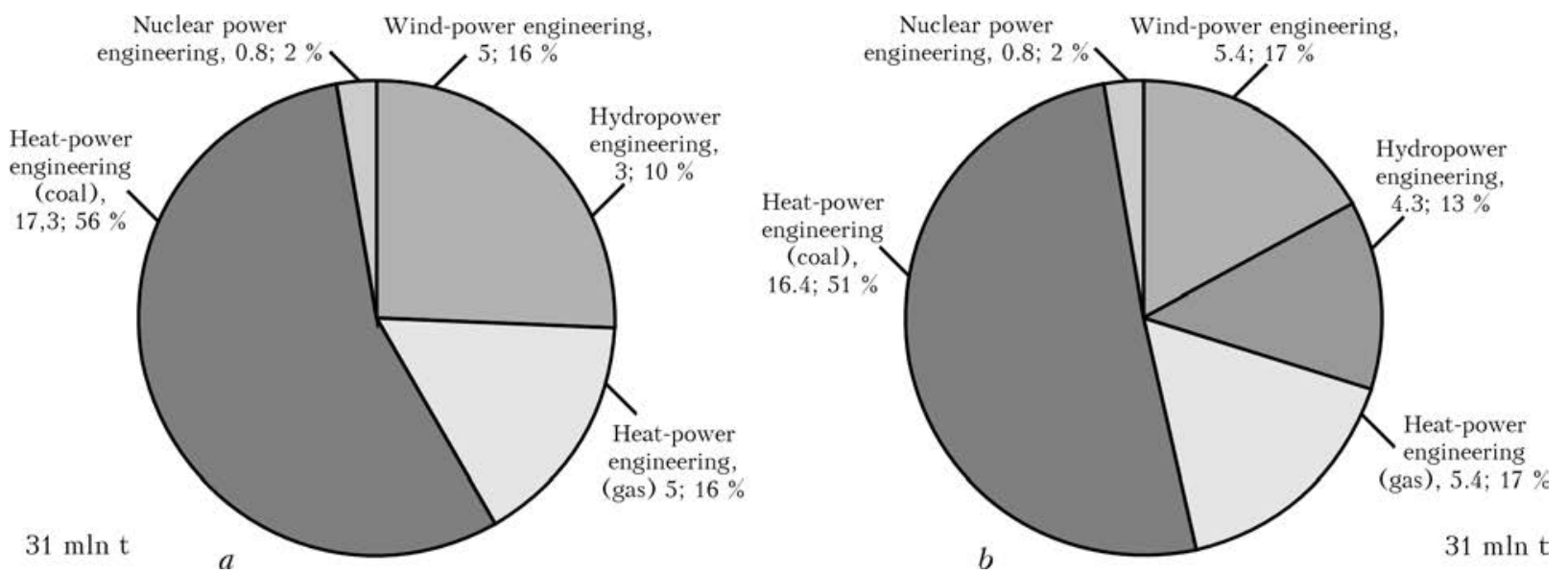

Figure 6. World consumption of steel in power engineering branches in 2011 ( $a$ ) and forecast for 2025 (b)

consumption in this sector reaches $4 \mathrm{mln} \mathrm{t}$. Figure 6 provides for the data of the steel world consumption in power engineering branches in 2011 and prediction for 2025 [6, 7].

Portion of transport machine building branch in 2011 made $19 \%$ of the total world steel consumption, that was $275 \mathrm{mln} \mathrm{t}$. Annual growth of steel in this branch is expected at the level of

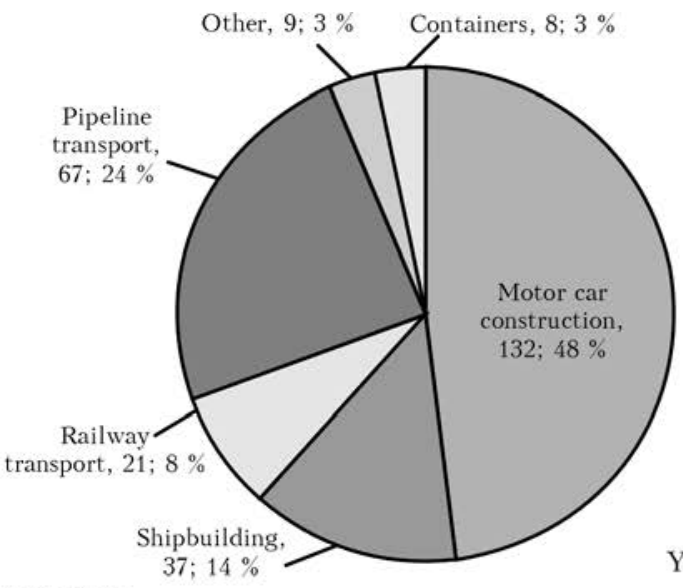

$275 \mathrm{mln} t$

Year-on-year increase $2.7 \%$

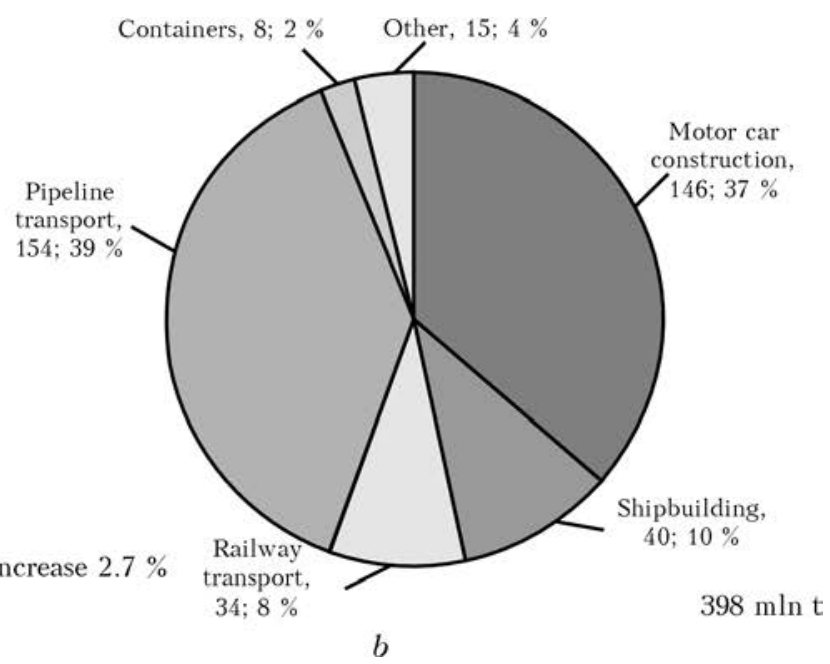

$b$

$2.7 \%$ in the period by 2025 . At that, the portion of steel consumption in transport machine building branch will reduce to $17 \%$ and consumption volume will rise to $398 \mathrm{mln} \mathrm{t}$. The main consumers of steel in the transport machine building are pipeline and motor car construction. Three forth of all steel consumption of the branch falls for their portion. Figure 7 shows the world structure

Figure 7. World consumption of steel in transport machine building branch in $2011(a)$ and forecast for 2025 ( $b$ ) 
of steel consumption in transport machine building branch in 2011 and prediction for 2025 [6, 7].

Steel is a corner stone and drive of the world economy. In long-term prospects the volumes of steel consumption will grow, particularly in the countries with developing economies, where the rate of growth of metal-consuming branches of commercial production and population urbanization are significantly higher than in the advanced economy countries. This provides for substantial input in steel consumption. Growth of consumption of steel as one of the main structural material promotes for also expansion of application of the leading energy-saving and ecologically efficient technologies in commercial production and town development, which can not be fulfilled based on old worn equipment requiring replacement.

World market of welding equipment. World market of equipment for joining and material treatment, traditionally titled welding equipment market, shows continuous growth. This fact is noted in the annual and analytical reports of transnational companies, i.e. the world leaders of welding equipment production (Lincoln Electric, Colfax (ESAB, Victor Technologies Group), ITW etc.) as well as leading analytical companies, namely BCC Research, Transparency Market Research, Frost \& Sullivan.

Welding equipment market is highly multifarious in its content. Its in kind and cost estimation depends on a range of services and goods, which are covered by that or another analysis. Most of the analytical companies incorporate welding consumables, equipment, gases for welding and cutting, means of individual protection and environment protection, welding accessories as a part of welding market goods. Companymanufacturers of welding equipment, making analysis of the volume of world welding market, first of all, evaluate it based on a range of output products. For example, ESAB company at market estimation incorporates means for automation, computerization and robotization in the range of

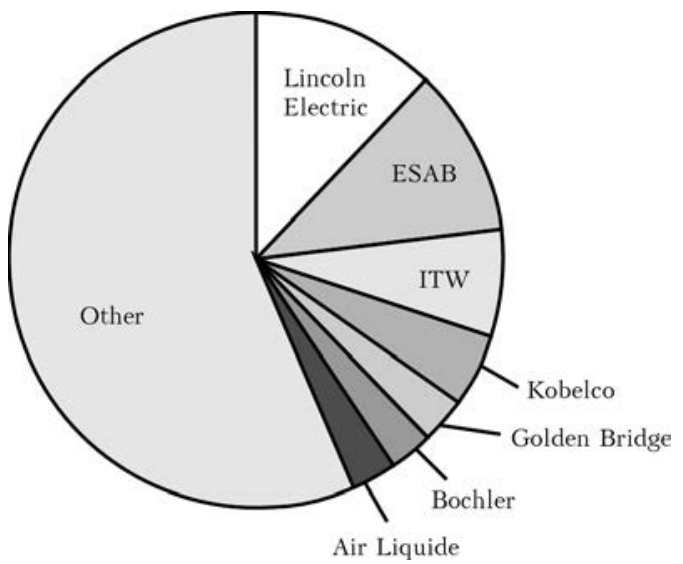

Figure 8. Main manufacturers in the world market of welding equipment in 2014 welding equipment, and special welding consumables, namely for welding of special grades of steels and alloys, aluminum etc., are included as a separate position in the welding consumable range. Estimation of the markets of final consumers of welding equipment and regional markets also plays an important role in evaluation of the world market of welding equipment. Therefore, coverage of economical-statistical indices in estimation of the welding equipment market has significant effect on total estimation that explains indices spread in values during estimation of the volume of world market of welding equipment by different companies.

Below are the data of analysis of current state and prediction of development of the welding equipment world market published in analytical reports of the leading world company-manufacturers of welding equipment and analytical companies specialized in analysis of the welding equipment market.

Process of globalization of the welding equipment market takes place at present moment, namely capital concentration (merging of companies, acquisition of smaller good manufacturers by larger companies), migration of capital and labor at global level, standardization of technological processes etc. Capital and manufacturing capacities tend to migrate in Asia, South America and the Middle East countries. Seven transnational companies, among which undisputable leaders for decades are Lincoln Electric (14\% of market), ESAB (13\%) and ITW (8\%), control almost half of the world market of welding equipment. Total volume of sales in value of terms of these three companies exceeds $30 \%$ of the world market of welding equipment (Figure 8).

Value of the market of welding equipment in 2013 made USD 17-24 bln according to estimation of the leading analytical companies. According to prediction of BCC Research, the volume of market in 2019 will exceed USD 25 bln and based on estimation of Transparency Market Research the welding equipment market will make around USD $24 \mathrm{bln}$ in 2020. Annual growth of market at the level of $4.5-5.3 \%[9,10]$ is predicted in the period of 2014-2019 based on the data of the same companies.

Figure 9 provides for the data of estimation of the volume of world market of welding equipment by expert-analytical company BCC Research.

World market of welding equipment, by estimation of ESAB, made around USD 21 bln in 2012, 24 bln in 2013, and 25 bln in 2014. ESAB company when analyzing the world market of welding equipment proceeds from the estimation of filler materials markets, including for welding of medium alloy steels and alloys as well as welding of aluminum alloys; equipment and accesso- 


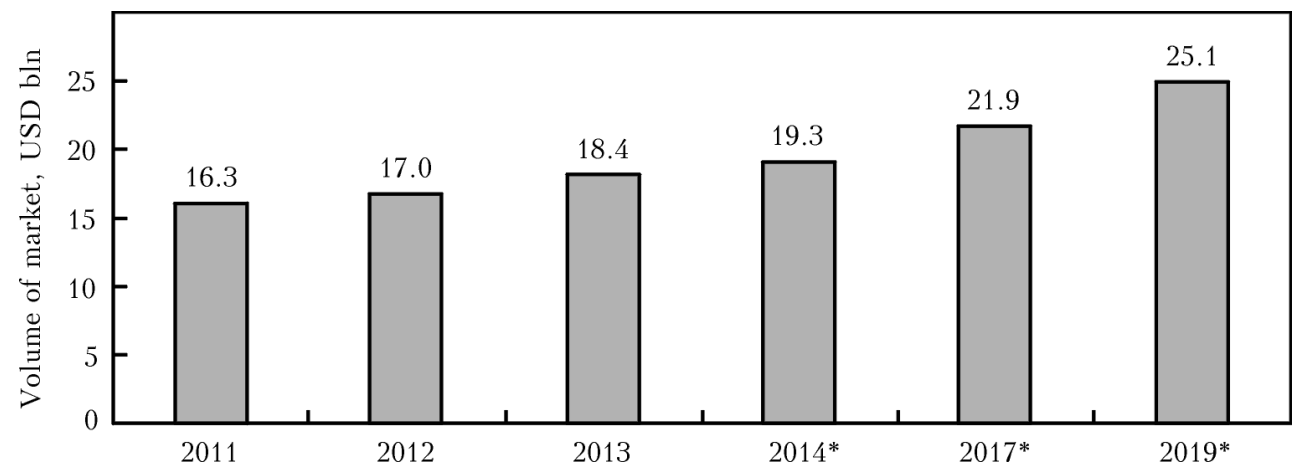

Figure 9. World market of welding equipment and consumables, including gases, means for protection of welder and environment, accessories and robots (* - estimation)

ries, including welding machines, equipment for manual plasma welding and cutting, apparatuses for gas welding and cutting and individual protection means; automated welding systems, robots and robotized complexes, machines for cutting, including automated tables and cutting systems [11].

Experts of Victor Technology Holdings, which is a part of global Colfax corporation as ESAB company, estimated the world market of equipment for welding and cutting approximately in USD 15.9 bln in 2013. At that they studied three main segments of products: goods for cutting including equipment for gas cutting, gas control regulators, plasma cutting and carbon arc gouging systems; equipment and accessories for arc welding; and materials for welding, surfacing and brazing.

According to estimation of the Victor Technology Holdings experts, the market of consumables for welding and surfacing made more than half of the world market in 2013. In the period of 2007-2013 portion of this market segment varied from 50 to $57 \%$. Portion of welding equipment market for the same period virtually did not change and made $24 \%$. In whole structure of the world market of welding equipment was sufficiently stable in 2007-2013, and no significant fluctuations in the structure of consumption of separate types of products were observed $(\mathrm{Fi}-$ gure 10) [11].

Data of the Japan Welding News for the World showed that the volume of world consumption of welding consumables made $6.3 \mathrm{mln} \mathrm{t}$ in 2013. Consumption of coated electrodes (38) and solid wire $(37 \%)$ makes the main portion in the structure of world consumption of welding consumables. Table 1 provides for the data of world volume of consumption of main types of welding consumables in quantitative terms and portion of their consumption in the world in 2011 and 2013 [12, 13].

Tendency to reduction of consumption of coated electrodes and growth of solid and fluxcored wire consumption is observed from the Table in addition to rise of total volume of welding consumable consumption. This indicates increase of the level of mechanization and automation of processes of arc welding.

Analytical company BCC Research carried an analysis of the world market of welding equipment in terms of key technological segments, among which are arc welding, resistance welding, gas-oxygen welding, laser welding etc. Market analysis includes data on the volume of market of welding equipment and consumables, different gases for welding, means of individual protection and environment protection, welding robots and accessories. The volume of world market of welding equipment and consumables made USD 18.4 bln in 2013 according to the BCC Research data. Figure 11 shows the cost structure of the world market of welding equipment and materials in terms of technological segments of the market of welding equipment by BCC Research estimation [9].

Arc welding traditionally dominates in the welding equipment market. Its portion in the

Table 1. Structure of world consumption of main types of welding consumables in 2011 and 2013

\begin{tabular}{|c|c|c|c|c|}
\hline \multirow{3}{*}{ Welding consumables } & \multicolumn{4}{|c|}{ Consumption volume, portion } \\
\hline & \multicolumn{2}{|c|}{2011} & \multicolumn{2}{|c|}{2013} \\
\hline & $\mathrm{t}$ & $\%$ & $\mathrm{t}$ & $\%$ \\
\hline Coated electrodes & $2,442,700$ & 41.1 & $2,389,300$ & 38.0 \\
\hline Wire for submerged arc welding & 669,000 & 11.3 & 706,200 & 11.2 \\
\hline Solid wire & $2,085,200$ & 35.1 & $2,324,400$ & 37.0 \\
\hline Flux-cored wire & 748,700 & 12.6 & 863,700 & 13.8 \\
\hline Total & $5,945,600$ & 100 & $6,283,600$ & 100 \\
\hline
\end{tabular}


INDUSTRIAL

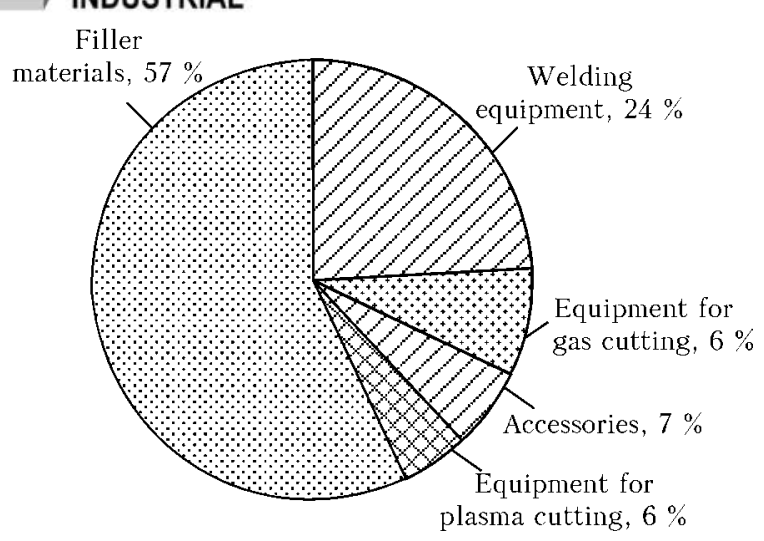

Figure 10. Structure of world market of welding equipment in the volume of main types of products in 2013

world market has reduced only for 3-5\% for the last 20 years, regardless the fact of significant expansion of application in commercial production of beam and other special processes for material joining. Estimation of experts of Lincoln Electric and Frost \& Sullivan showed that the market of equipment for arc welding would make around USD 20 bln in 2014 at its $6 \%$ annual growth [14, 15].

Market of equipment for different types of resistance welding reached USD $570 \mathrm{mln}$ by Frost \& Sullivan estimation. It is predicted that the market volume would make USD $640 \mathrm{mln}$ in 2014 at $5.1 \%$ annual growth, and will reach $820 \mathrm{mln}$ in 2019 during the period of 2014-2019 [16].

World market of welding equipment continues to grow in cost as well as natural indices. The world market of equipment for arc and resistance welding showed annual increase per 14-15\% in the period of 2010-2013 according to The Japan Welding News for the World. Table 2 provides for the data of this market in natural units and their portion for 2011 and 2012 [17, 18].

In 2011 the world market of equipment for arc and resistance welding made 1178.61 and in 2012 it was 1355.55 thou units, from which around $96 \%$ are the machines and apparatuses for arc welding. Growth of the sales in the market of welding equipment in the period of 2011-2012 made approximately $15 \%$. At the same time, it should be noted that the sales in the market of equipment for resistance welding increased per $20 \%$.

Regional structure of the welding equipment market underwent significant changes in the period of 2009-2014. The welding equipment mar-

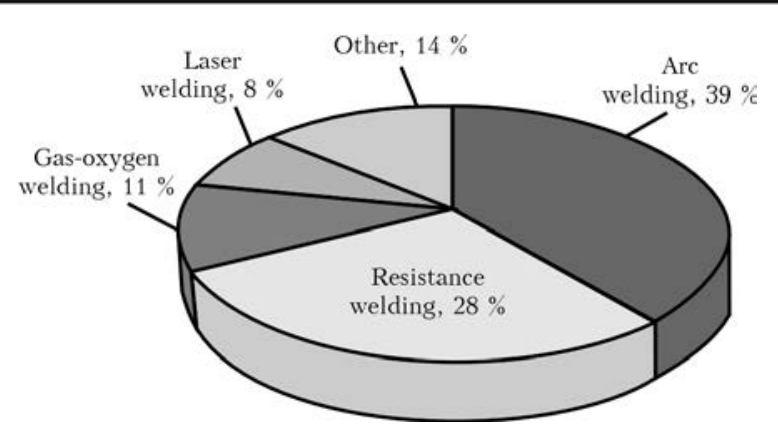

Figure 11. Welding technologies in world market of welding equipment in 2013 (cost structure)

ket along with structural material market (steel, aluminum etc.) continued shift in the Asian region. Positive tendency was noted in the welding market of China, India, Taiwan and ASEAN countries. Portion of the Asian countries in the world market of welding equipment increased to $42 \%$ in 2014, mainly due to China and India markets. $2 \%$ increase of sales was also indicated in the markets of the Middle East (Iran), North America (Mexico) and South America (Brazil). American, European and Japan market of welding equipment somewhat reduced.

At present time, the main regional segments of the welding equipment market are Asia - $42 \%$ of market volume, America - 31, Europe, Russia, the Middle East and Africa - $27 \%$.

The main branch-consumers of welding equipment are building, transport, power engineering (including oil- and gas-production industry, electroenergetics, petrochemical industry, pipe production and pipeline construction etc.). Figure 12 represents industrial structure of the world market of welding equipment according to ESAB data [19].

Frost\&Sullivan and Transparency Market Research estimations show current growth of consumption of welding equipment in a sector of industrial and civil engineering, freight transportation, motor car construction and power engineering, in particular, wind-power engineering. At that, such branches as power engineering, building and motor car construction are characterized as the main driving forces of the world market of welding equipment.

According to Frost \& Sullivan data, the volume of market of welding equipment and consumables in 2011 made USD $445.5 \mathrm{mln}$ for the

Table 2. World market of equipment for arc and resistance welding in 2011 and 2012

\begin{tabular}{|c|c|c|c|c|}
\hline \multirow{3}{*}{ Welding equipment } & \multicolumn{4}{|c|}{ Production volume, portion } \\
\hline & \multicolumn{2}{|c|}{2011} & \multicolumn{2}{|c|}{2012} \\
\hline & thou units & $\%$ & thou units & $\%$ \\
\hline For arc welding & 1133.65 & 96.2 & 1301.70 & 96 \\
\hline For resistance welding & 44.96 & 3.8 & 53.85 & 4 \\
\hline Total & 1178.61 & 100 & 1355.55 & 100 \\
\hline
\end{tabular}


world market of power engineering. It is predicted that in a period by 2017 the volume of welding equipment market in power engineering branch will reach USD $578.7 \mathrm{mln}$, at that its annual growth makes $3.8 \%$.

Insignificant growth of the welding equipment market in such branches as shipbuilding, airspace and military industries is the limiting factor for development of the world market of welding equipment.

Wind-power engineering is the most perspective segment of the welding equipment market by experts' estimation (ESAB, Frost \& Sullivan). There is a continuous increase of investments in welding equipment on this segment of the market. According to estimation of ESAB specialists, each new megawatt of power requires $700 \mathrm{~kg}$ of welding consumables and $600 \mathrm{~kg}$ of welding flux. This segment of the market has good perspectives for further growth [19].

At present time, portion of the world production of energy using wind-driven power plants does not exceed $2 \%$. However, rates of power growth continuously increase, particularly in the countries with expanding economies from the $\mathrm{Pa}$ cific region of Asia.

Frost\&Sullivan experts also indicate in their researches an increase of the volume of sales of welding equipment in repair and reconstruction sector. Sales volume in this segment of the market of welding equipment and consumables exceeded USD 2.2 bln in 2010, and its annual growth is predicted to be on the level of $4 \%$ in a period by 2017 .

Analysis of the latter tendencies in the welding equipment market shows that future development of the welding equipment will be determine by necessity in:

- reduction of production costs and increase of productivity due to tendency to salary growth, increase of cost of materials for production of welding consumables and welding equipment as well as rise of expenses for power and fuel recourses will continue in future;

- improvement of welding structures and reduction of weight of deposited weld metal;

- increase of application in welded structures of the materials, particularly steels and alloys, with higher strength indices as well as light materials;

- increase of requirement to safety and quality of welded structures;

- increase of level of mechanization and automation of arc welding process;

- increase of application, where it is possible, of automated and robotized welding processes;

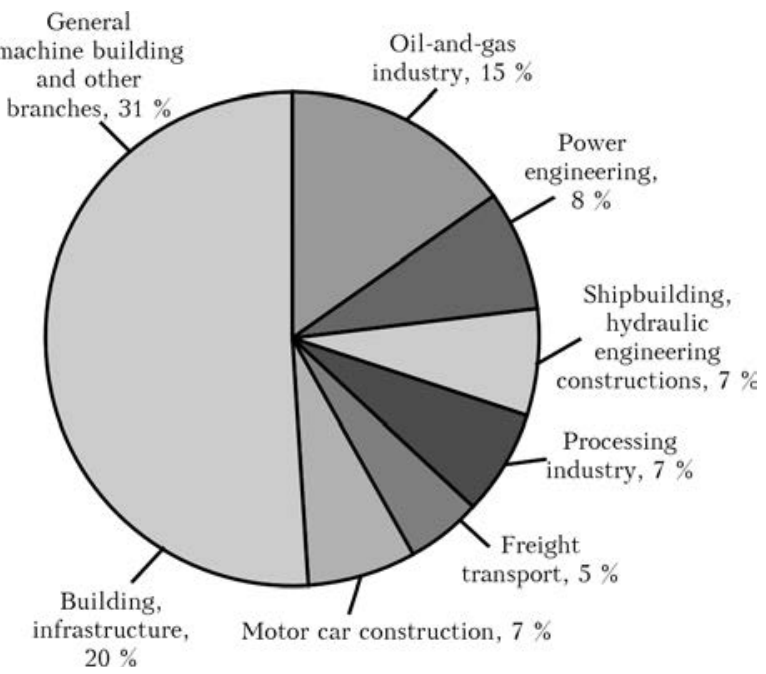

Figure 12. Welding equipment distribution by main branches of industry in 2014 in world market

- expansion of application of new welding methods using energy with high level of concentration (laser, electron beam), friction welding and other processes.

1. Market of engineering plastics will reach $\$ 90$ billion. http: / / plastics.ru /index.php

2. Market of composite materials can increase 10 times to 2020. http: //www.rg.ru/2012/09/18/ materiali.html

3. Eatsevman, M. (2013) Polymer composites and localization. Chemical J., 1, 66-69.

4. World aluminium. http://www.world-aluminium. org / statistics /

5. Brief analysis of titanium world market of 2013/2014. http:/www.metalresearch.ru/world_ titanium_analysis_2014.html

6. (2014) Outlook for the steel market. In: Sherpa group meeting (Bruxelles, 13 March 2014).

7. World Steel Association. http://www.worldsteel. org

8. What does 2012 hold for the Japan's welding industry? The Japan Welding News for the World, 58, 1.

9. Global market for welding products to reach $\$ 25.1$ billion by 2019. http: //www.bccresearch.com

10. Welding products market is set to reach USD 23.78 billion by 2010 . http: / / www.transparencymarketresearch.com

11. Victor Technology Group, Inc. Annual report 2013. http: / www.victortechnologies.com /

12. (2014) General description for welding consumables. The Japan Welding News for the World, 67, 4-5.

13. (2012) General description for welding consumables market. Ibid., 59, 5-6.

14. Study sees arc equipment, consumables rising to $\$ 20$ billion. http://Welding design.com

15. Stopki, J.M., Petrella, V.K. (2013) Lincoln Electric Holdings, Inc. update. In: Proc. of KeyBanc Industrial, Automotive and Transportation Conf. (May 29, 2013).

16. Welding equipment and supplies: The global market - focus on resistance welding. http:// marketwatch.com

17. (2013) Worldwide demand for welding machines. The Japan Welding News for the World, 64, 4

18. (2011) General description for welding machine's market. Ibid., 55, 5-6.

19. (2013) COLFAX. Journey toward excellence investor day December 17, 2013. http://www/colfaxcorp.com 


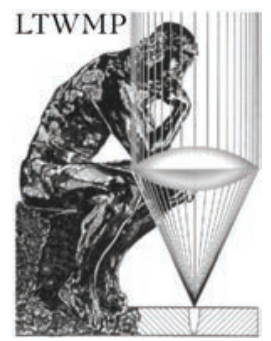

7th International Conference «Laser Technologies in Welding and Material Processing» (LTWMP-2015) was held on September 14-18, 2015 at «Kurortny» boarding house in Odessa (Ukraine). It was organized by the E.O. Paton Electric Welding Institute of the NASU, Laser Technology Research Institute of NTUU «Kiev Polytechnic Institute», Laser Center of Zheijiang University of Technology, and International Association «Welding». Prof. B.E. Paton and Prof. V.S. Kovalenko are the co-chairmen of the Program Committee.

This Conference starting from May 2003 has become a tradition and gathers laser experts from the different countries of the world every two years. 40 scientists and specialists from Ukraine and China as well as specialist with remote participation from Germany, Poland and Spain took part in the Conference work. The Conference was organized in a form of plenary and poster sessions. Working languages of the Conference are Russian, Ukrainian and English with simultaneous translation of the papers. 33 presentations were discussed in a course of plenary and poster sessions.

The Conference was opened by presentation of Prof. V.S. Kovalenko «Development of 3D additive processing for product manufacturing in modern industry» (Laser Technology Research Institute of NTUU «KPI»). The presentation noted that the largest amount of products in present time is manufactured by such classical technologies as casting, welding, forging, stamping, machining etc. At the same time novel and quite original technology of 3D printing and fast prototyping was proposed in the recent decades. Such technologies combine three main factors, namely material (metallic plate or powder, solid and liquid polymer, paper, wood etc.), energy (laser, electron beam, electric discharge, plasma flow etc.) and mathematical model of future part.

Series of presentations of Prof. V.I. Krivtsun with colleagues from Ukraine, Germany and China were dedicated to theoretical analysis of physical processes taking place in laser and hybrid welding.
Presentations on application of lasers in medicine were also made.

There are some presentations which give an idea of topics opened at the Conference:

- «Research progress of supersonic laser deposition technology» by Jianhua Yao (Laser Center of Zhejiang University of Technology, China) and V. Kovalenko ( «KPI»);

- «Interaction of $\mathrm{CO}_{2}$-laser beam with electric arc plasma in hybrid (TIG + laser) welding» by I. Krivtsun, I. Krikent, V. Demchenko (PWI), U. Reisgen, A. Zabirov, O. Mokrov (Welding and Joining Institute, Aachen, Germany);

- «Increase of efficiency of hybrid welding of aluminum alloys» by I. Krivtsun, V. Sidorets, V. Khaskin, V. Korzhik, A. Bushma (PWI), Luo Ziyi (Guangdong General Research Institute for Industrial Technology (Guangzhou Research Institute of Nonferrous Metals), China);

- «Microstructure and wear-resistant properties of WC/SS316L composite coatings prepared with supersonic laser deposition» by Bo Li, Zhihong Li, Lijing Yang, Jianhua Yao (Research Center of Laser Processing Technology and Engineering, Zhejiang University of Technology, China);

- «Laser manual machine for welding of railway transport products» by V. Shelyagin, V. Kurilo, I. Shuba, A. Bernatsky (PWI), WangChunsheng (Changchun Railway Car Building Plant, China), Wan Dinda, Zhen Shukhuey (China-Russian Technological Park, Changchun, China);

- «Effect of electric-magnetic field on WC particulate-reinforced metal matrix composite layers by laser melt injection» by Wang Liang, Yong $\mathrm{Hu}$, Shiying Song, Sanpin Lai, Jianhua Yao (Research Center of Laser Processing Technology and Engineering, Zhejiang University of Technology);

- «Metal penetration in TIG, laser and hybrid (TIG + laser) spot welding. Experimental study» by I. Krivtsun, V. Abdulakh (PWI), M. Svirzhevskaya («KPI»), U. Reisgen, B. Gerhards (Welding and Joining Institute, Aachen); 
- «Metal penetration in TIG, laser and hybrid (TIG + laser) spot welding. Mathematical modelling» by I. Krivtsun, K. Hubaiev, I. Krikent, A. Semenov (PWI), U. Reisgen, A. Zabirov (Welding and Joining Institute, Aachen);

- «Peculiarities of synergic activation of laser welding of steels with the help of argon arc with tungsten electrode (TIGAL process)» by D. Kovalenko, I. Krivtsun, I. Kovalenko (PWI), U. Reisgen, B. Gerhards, A. Zabirov (Welding and Joining Institute, Aachen);

- «Advancements in joint research of laser cladding at components manufacturing» by J. Yao, Q. Zang, H. Hu (Laser Center of Zhejiang University of Technology), V. Kovalenko, M. Anyakin, R. Zhuk («KPI»);

- «Development of technologies for laser welding of body elements of freight railway cars» by V. Shelyagin, V. Khaskin, A. Bernatsky, A. Siora, A. Palagesha, A. Tunik, E. Goncharenko (PWI), A. Chepurnoy (Scientific-Engineering Centre «RTKh», Mariupol, Ukraine);

- «Plasma + laser - new capabilities of plasma-powder surfacing» by A. Som (PlasmaMaster Ltd., Kyiv, Ukraine), I. Krivtsun (PWI);

- «Experimental research of hybrid welding process in combination of GTA with $\mathrm{CO}_{2}$ or Yb:YAG-laser beam» by I. Krivtsun (PWI), U. Reisgen, B. Gerhards, A. Zabirov (Welding and Joining Institute, Aachen);

- «Laser-arc hybrid welding of aluminum alloys» by V. Shelyagin, V. Khaskin, A. Bernatsky, A. Siora, A. Palagesha (PWI).
A Round Table «Perspective directions of development in area of laser technologies» took place at the end of the Conference. Relevant problems of development of laser technologies and peculiarities of physical phenomena, taking place in interaction of laser irradiation and plasma in realizing of hybrid technologies based on energy of laser irradiation, were discussed.

Program and abstracts of papers was published before the Conference opening. Proceedings of LTWMP-2015 will be published till the end of 2015. Proceedings of the previous LTWMP conferences can be ordered in the Editorial Board of «Avtomaticheskaya Svarka» Journal or get in open access from the site of the Paton Welding Institute Publishing House by reference http: / / patonpublishinghouse/eng / proceedings / lt wmp.

Friendly, hospitable and creative atmosphere promoted development of useful discussions and arrangement of business contacts. The Conference participants unanimously agreed on proposal of performance of the next 8th LTWMP Conference in the middle of September 2017 in Odessa, Ukraine.

The organizing committee expresses thanks and gratitude to Company «High-Energy Technologies» (Kiev, Ukraine) for beneficent help provided for performance of the 7th LTWMP2015.

A.T. Zelnichenko, PWI 


\title{
PATON PUBLISHING HOUSE
}

\author{
www.patonpublishinghouse.com
}

SUBSCRIPTION

The Patgobormat

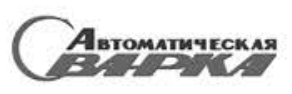

«The Paton Welding Journal» is Published Monthly Since 2000 in English, ISSN 0957-798X.

«Avtomaticheskaya Svarka» Journal (Automatic Welding) is Published

Monthly Since 1948 in Russian, ISSN 005-111X.

«The Paton Welding Journal» is Cover-to-Cover Translation of

Avtomaticheskaya Svarka» Journal into English.

If You are interested in making subscription directly via Editorial Board, fill, please, the coupon and send application by Fax or E-mail.

The cost of annual subscription via Editorial Board is $\$ 348$ for «The Paton Welding Journal» and $\$ 180$ for «Avtomaticheskaya Svarka» Journal.

«The Paton Welding Journal» can be also subscribed worldwide from catalogues subscription agency EBSO.

\author{
SUBSCRIPTION COUPON \\ Address for journal delivery \\ Term of subscription since \\ Name, initials \\ Affiliation \\ Position \\ Tel., Fax, E-mail
}

20

till

20

We offer the subscription all issues of the Journal in pdf format, starting from 2009.

The archives for 2009-2012 are free of charge on wrow.patonpublishinghouse.com site.
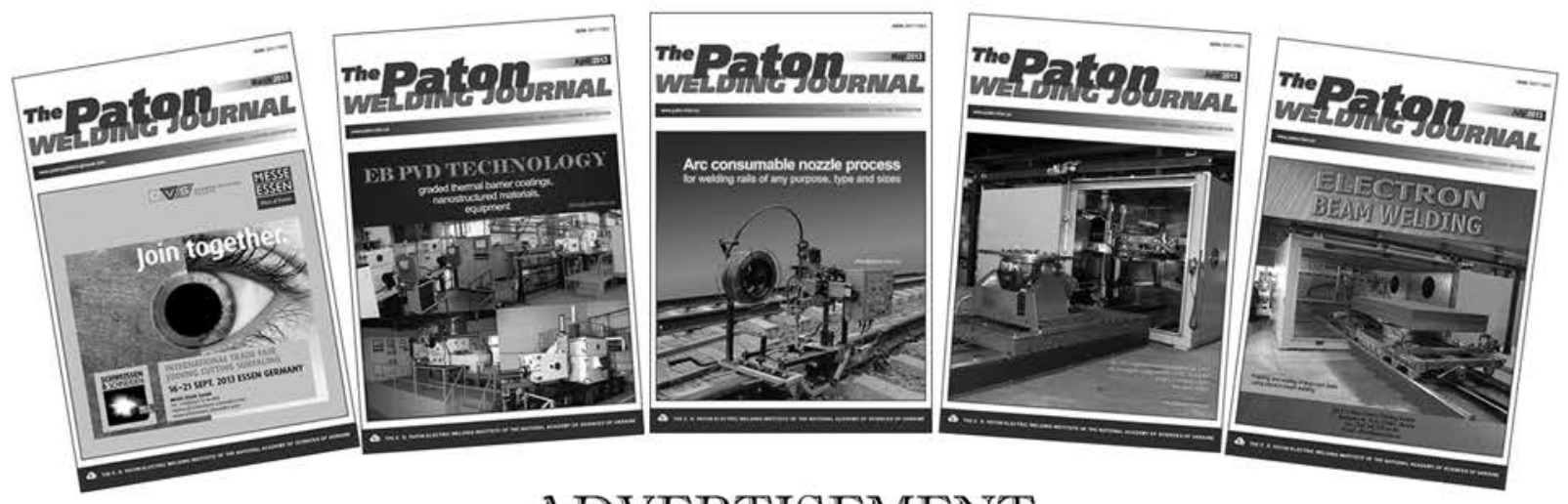

\section{ADVERTISEMENT}

in "Avtomaticheskaya Svarka" and "The Paton Welding Journal"

External cover, fully-colored:

First page of cover

$(190 \times 190 \mathrm{~mm})-\$ 700$

Second page of cover

$(200 \times 290 \mathrm{~mm})-\$ 550$

Third page of cover

$(200 \times 290 \mathrm{~mm})-\$ 500$

Fourth page of cover

$(200 \times 290 \mathrm{~mm})-\$ 600$

\author{
Internal cover, fully-colored: \\ First/second/third/fourth page \\ of cover $(200 \times 290 \mathrm{~mm})-\$ 400$ \\ Internal insert: \\ Fully-colored $(200 \times 290 \mathrm{~mm})-$ \\ $\$ 340$ \\ Fully-colored (double page A3) \\ $(400 \times 290 \mathrm{~mm})-\$ 500$
}

- Article in the form of advertising is $50 \%$ of the cost of advertising area

- When the sum of advertising contracts exceeds $\$ 1001$, a flexible system of discounts is envisaged

Size of journal after cutting is $200 \times 290 \mathrm{~mm}$

Editorial Board of Journal «Avtomaticheskaya Svarka» and «The Paton Welding Journal»

E.O. Paton Electric Welding Institute of the NAS of Ukraine

International Association «Welding

11, Bozhenko Str., 03680, Kyiv, Ukraine

Tel.: (38044) 20060 16, 20082 77; Fax: (38044) 20082 77, 2008145

E-mail: journal@paton.kiev.ua; www.patonpublishinghouse.com 